\title{
A Tritium Systems Test Facility
}

F. A. Cafasso, V. A. Maroni, W. H. Smith,

W. R. Wilkes and L. J. Wittenberg

February 22, 1978

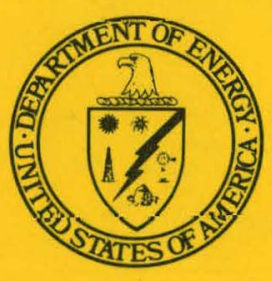

$$
95^{\circ} 67^{30}
$$

\section{MOUND FACILITY}

Miamisburg, Ohio

operated by

MONSANTO RESEARCH CORPORATION

a subsidiany of Monsanto Company

for the

U. S. DEPARTMENT OF ENERGY

Contract No. EY-76-C-04-0053 


\section{DISCLAIMER}

This report was prepared as an account of work sponsored by an agency of the United States Government. Neither the United States Government nor any agency Thereof, nor any of their employees, makes any warranty, express or implied, or assumes any legal liability or responsibility for the accuracy, completeness, or usefulness of any information, apparatus, product, or process disclosed, or represents that its use would not infringe privately owned rights. Reference herein to any specific commercial product, process, or service by trade name, trademark, manufacturer, or otherwise does not necessarily constitute or imply its endorsement, recommendation, or favoring by the United States Government or any agency thereof. The views and opinions of authors expressed herein do not necessarily state or reflect those of the United States Government or any agency thereof. 


\section{DISCLAIMER}

Portions of this document may be illegible in electronic image products. Images are produced from the best available original document. 
This report was prepared as an account of work sponsored by the United States Government. Neither the United States nor the United States Department of Energy, nor any of their employees, nor any of their contractors, subcontractors, or their employees, makes any warranty, express or implied, or assumes any legal liability or responsibility for the accuracy, completeness or usefulness of any information, apparatus, product or process disclosed, or represents that its use would not infringe privately owned rights.

PRINTED IN THE UNITED STATES OF AMERICA

Available from

National Technical Information Service

U. S. Department of Commerce

5285 Port Royal Road

Springfield, Virginia 22161

Price: Printed Copy $\$ 6.00$; Microfiche $\$ 3.00$

50 
MLM-2500

UC-20f

\section{A Tritium Systems Test Facility}

F. A. Cafasso, V. A. Maroni, W. H. Smith,

W. R. Wilkes and L. J. Wittenberg

Issued: February 22, 1978

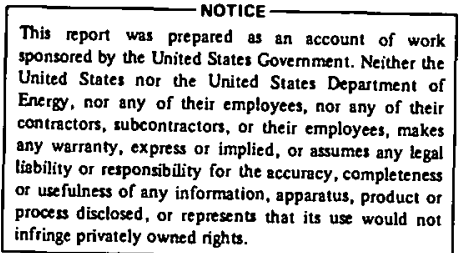

MOUND FACILITY

Miamisburg, Onio 45342

operated by

MONSANTO RESEARCH CORPORATION

a subsidiary of Monsanto Company

for the

U. S. DEPARTMENT OF ENERGY

Contract No. EY-7E-C-04-0053 
THIS PAGE

\section{WAS INTENTIONALLY LEFT BLANK}




\section{Preface}

This report is a reproduction of a proposal, submitted in August 1976 by Argonne National Laboratory and Mound Laboratory to design, construct, and operate a facility for the demonstration of tritium handling and containment in a fusion power reactor environment.

The proposal is reproduced in full except for the deletion of some financial and administrative details which are no longer relevant. The authors gratefully acknowledge the enthusiastic and dedicated support of the many people who assisted in preparing the proposal. These include R. P. Bowser, J. D. Braun, T. M. Flanagan, S. S. Freeman, J. F. Griffin, M. F. Hauenstein, C. S. Sebastian, W. A. Slusher, C. B. Voth and R. A. Watkins. 
THIS PAGE

\section{WAS INTENTIONALLY LEFT BLANK}




\section{Table of Contents}

EXECUTIVE SUMMARY ........................... 7

1. INTRODUCTION . . . . . . . . . . . . . . . . . . . . . . 9

1.1 Background and Need ..................... 9

1.2 Scope . . . . . . . . . . . . . . . . . . . . . 11

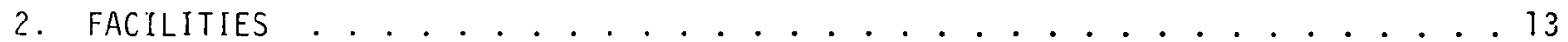

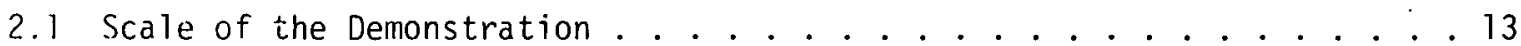

2.2 Existing Facilities.................. . . 19

2.3 Proposed Facility . . . . . . . . . . . . . . . . . . . . . . 24

2.4 Design and Construction Milestones................ . 38

2.5 Facility Costs..................... . . . . . . . . . . .

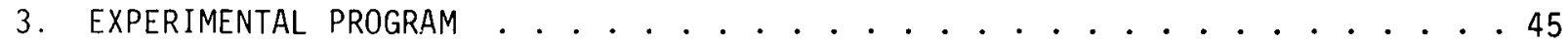

3.1. Fuel Cycling and Conditioning Technology............... . 48

3.2 Vacuum Systems and Neutral Beam Injector. . . . . . . . . . . . . 50

3.3 Coolant Systems . . . . . . . . . . . . . . . . . 51

3.4 Secondary Containment and Atmospheric Systems . . . . . . . . . . . 51

3.5 Materials and Hardware Verification . . . . . . . . . . . . . . . 53

3.6 Bulk Fuel Technology. . . . . . . . . . . . . . . . . . . . . . 55

3.7 Environment and Safety . . . . . . . . . . . . . . . . 55

3.8 Instrumentation and Control Systems . . . . . . . . . . . . . . 56

3.9 Program Planning. . . . . . . . . . . . . . . . . 58

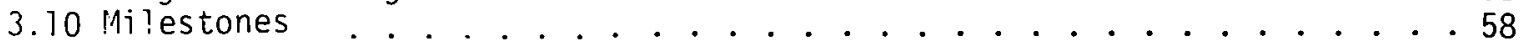

1. PROGRMM MANAGCMCNT AND RESOURCES . . . . . . . . . . . . . . 73

1.1 Organization . . . . . . . . . . . . . . . . . . . . 73

4.2 Technical Resources and Experience . . . . . . . . . . . . 76

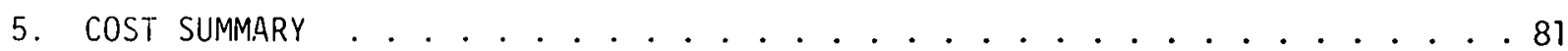

APPENDIX. . . . . . . . . . . . . . . . . . . . . . . . . . 83

Hazard Evaluation . . . . . . . . . . . . . . . . . 85

DISTRIBUTION. . . . . . . . . . . . . . . . . . . . . . 93 
THIS PAGE

\section{WAS INTENTIONALLY \\ LEFT BLANK}




\section{Executive Summary}

Mound Laboratory and Argonne National Laboratory propose the design, construction and operation of a Tritium Systems Test Facility (TSTF) at Mound Laboratory. This proposal is submitted in response to the invitation to design, build and operate a facility to. demonstrate the tritium fuel cycle and environmental control systems for an Experimental Fower Reactor (EPR), as outlined in the memorandum of May 25, 1976, and subsequent TWX of June 16, 1976, by James M. Williams, Assistant Director Development and Technology, Division of Magnetic Fusion Energy, USERDA.

This TSTF proposal has two principal objectives. The first objective is to provide by mid-FY1981 a demonstration of the fuel cycle and tritium containment systems which could be used in a Tokamak Experimental Power Reactor for operation in the mid-1980's. The second objective is to provide a capability for further optimization of tritium fuel cycle and environmental control systems beyond that which is required for the EPR.

The scale and flow rates in TSTF are close to those which have been projected for a prototype experimental power reactor (PEPR/ITR) and will permit reliable extrapolation to the conditions found in an EPR. The fuel concentrations will be the same as in an EPR. Demonstrations of individual components of the deuterium-tritium fuel cycle and of monitoring, accountability and containment systems and of a maintenance methodology will be achieved at various times in the FY1979-80 time span. Subsequent to the individual component demonstrations - which will proceed from tests with hydrogen (and/or deuterium) through tracer levels of tritium to full operational concentrations - a complete test and demonstration of the integrated fuel processing and tritium containment facility will be performed. This will occur near the middle of FY1981.

Two options were considered for the TSTF: 1) The modification of an existing building and 2) the construction of a new facility. The first option requires the modification of a high-integrity, underground building and the utilization of selected existing tritium environmental control facilities at Mound Laboratory. The cost summary for this proposed facility which will occupy $22,000 \mathrm{ft}^{2}$ of usable floor space is as follows:

$\begin{array}{lrrrr} & \text { FY1977 } & & \text { FY1978879 } & \text { Tot. Engr. Cost } \\ \text { Engineering Design } & \$ 800,000 & & \$ 223,000 & \$ 1,023,000 \\ \text { Equipment \& Installation } & & 6,657,000 & 6,657,000 \\ \text { Construction } & & 899,000 & 899,000 \\ \text { Contingency } & & & 2,991,000 & \frac{2,991,000}{10,000} \\ \text { Total } & \$ 800,000 & & \$ 10,770,000 & \$ 11,570,000\end{array}$


The design and construction schedules for this facility will be as follows:

Design (12 months)

Procurement and Construction (18 months)

Start up
FY1977

FY1978-79

FY1979

Assuming an October, 1976, starting date, the TSTF facility will be completed in the third quarter of FYi979.

The second option, the construction of a new facility at Mound Laboratory dedicated exclusively to the TSTF. with the same equipment as in the previously described facility, was estimated to cost $\$ 24,655,000$. The design, construction and equipment installation for this facility are estimated to require nearly three years; consequentiy, the start up of this facility is estimated to begin by FY1981 based upon very optimistic construction schedules. Based on cost and schedule considerations, as presented in this proposal, the first option is recommended.

A comprehensive research and development plan is presented for the period FY1977-82 which will accomplish the objectives of the TSTF program. This program will require approximately 15 scientifi.c and other personnel for development activities in support of the design phase during FY1977. The number of scientific personnel will gradually' increase each year to approximately 43.

The operation of the TSTF at Mound Laboratory will have a negligible environmental impact even under postulated accident conditions. There will be no release of tritium to the aquifer from TSTF operations. 


\section{Introduction}

1.1 Background and Need

The development of controlled thermonuclear power systems as a major national energy resource in the 21 st century is of vital importance. Encouraging experimental and theoretical progress has been accomplished during the past five years in the magnetically confined fusion research program. During the past year ion temperatures, density and confinement times were increased significantly in experimental studies of both the Tokamak and Mirror concepts. Such advances encourage the formulation of plans for the demonstration of a fusion power reactor by the end of this century. In order to achieve such a demonstration, fusion test reactors and experimental power reactors which utilize deuterium-tritium fuel must be designed, built, and operated during the next decade. The introduction of the radioactive constituent, tritium, into the experimental controlled thermonuclear program will produce new constraints and these must be recognized. In particular, public acceptance of the entire fusion reactor program may depend upon the successful demonstration of tritium management.

The initial utilization of tritium in fusion research studies will occur approximately in 1981 at the TFTR facility where a maximum of about $100 \mathrm{Ci}$ of tritium will be utilized in a single "shot". The entire TFTR experimental program calls for perhaps 4,000 such shots and many more which will not use tritium; consequently, only stateof-the-art tritium technology will be applied to TFTR. A fusion power reactor will require large extrapolations from present technology in many areas. Therefore, TFTR must be followed by one or more experimental power reactors (EPR), which will provide a bridge to the technology required in a large power reactor. Various magnetic fusion development plans have been suggested for the next two decades, but nearly all contemplate reactors which, by mid-1980's, will require large quantities $\left(>10^{7} \mathrm{C} i\right)$ of tritium. Although references in lihe remainder of this proposal will be made only to an EPR, it should be understood that the technology to be developed will be applicable to intermediate-sized EPR's, e.g., (PEPR/ITR) as well as other DT fueled machines (FERF, TETR). Proven technologies of tritium management must be in hand in order to direct the design of fuel cycle and containment systems for experimental reactors which will be built in the mid-1980's. The TSTF and associated program described herein are focused on making certain that this technology is available when needed.

The basic scientific information appears to be available to form the foundation of the tritium technology required for the early experimental power reactors which do not incorporate tritium breeders. This scientific information must be developed rapidly for the following reasons: 1) the quantities, flow rates and impurity control requirements for tritium in an EPR may be expected to be typical of those of succeeding fusion power systems; 2) the tritium instrumentation and control for the EPR may need to be more stringent that for a full-scale power reactor because the EPR is also a plasma physics experiment; 3 ) a policy of discharge of tritium to the environment at the "lowest practicable" level must be in effect from the outset of the trilium fueled reactor experimental program; it must not be postponed to later reactors. 
A tritium technology development program over the next five years should be initiated, therefore, with the following objectives: 1) select the most effective and reliable methods that are available for handling, processing, storing and containing tritium; and 2) verify the integrated operation of these methods in a reasonably scaled facility. This point of view is not intended to exclude the need or desire for new technology; but in the face of current programmatic funding levels and scheduling commitments for a late-1980's operating date, the tritium handling systems will in all likelihood be based on existing or near-existing technology, except for the blanket processing area where effective tritium recovery methods do not exist.

Table 1-1 contains a listing of major tritium handling systems for prototypical power reactors that have been identified thus far. Of the systems listed, the blanket-processing systems will be excluded from consideration in this proposal because they probably will not be needed in early operating reactors. Instead, attention will be focused on design criteria and development requirements for the mainstream circulation, processing, and containment systems.

Table 1-1

TRITIUM HANDLING AND CONTROL SYSTEMS FOR AN EPR

System

Fuel-Delivery System

Fuel-Processing System

Fuel-Storage System

Fuel-Circulation System

In-Plant-Containment System

Purge-Processing System

Blanket-Processing System

\section{Functions}

Condition Fuel for Injection into Torus Provide Controlled Injection of DT Blend

Remove Helium, Gaseous Impurities, and Particulate Debris

Provide Isotopic Adjustment

Provide Fail-Safe Fuel Storage

Provide Interface with Fuel-Storage System Evacuate Plasma Chamber and Collect Exhaust Transport Exhaust Gas to Fuel-Processing System

Transport Processed Fuel to Fuel-Delivery System

Primary - Low Permeation Construction Secondary - Double Wall Purge Jackets Tertiary - Reactor Hall Purge

Remove Tritium from Purge Streams Concentrate for Disposal or Recycle

Remove Tritium from Blanket Material Control Impurities that Limit Processing and Recycle Efficiencies 
1.2 Scope

Mound Laboratory and Argonne National Laboratory jointly propose the design, construction and operation of a Tritium Systems Test Facility (TSTF) at Mound Laboratory and the conduct of an experimental program directed to the development of the tritium technology required for the design and operation of an EPR. The initial emphasis in the TSTF and its associated experimental program will be directed toward the following:

- Demonstrate the Fuel Cycle with Tritium-Deuterium Mixtures

- Demonstrate Tritium Containment

- Demonstrate Tritium Monitoring and Accountability

- Demonstrate Tritium Cleanup in Both Routine and Off-Normal Situations

- Demonstrate Maintenance and Modification in a Tritium Environment

As the program develops, emphasis will be placed on the tritium control needs of the demonstration reactors and on research and development suggested during the demonstration phase. Hence, TSTF will be contained in a Tritium Systems Development Laboratory (TSDL) which is designed to provide the flexib ility and capacity to support a continuing program to improve tritium management technoiogy. The demonstration phase will be briefly described below. A more complete description is in the Experimental Program plan, Section 3.

1:2.1 Demonstrate the Fuel Cycle with Tritium-Deuterium Mixtures

The quantity of fuel supplied and exhausted from the plasma of an EPR is expected to be very large because the fuel burnup per confinement time is small. The unburned fuel must be recovered from the plasma exhaust, purified and rapidly recycled to the plasma feed system. All necessary processing steps and major components of the mainstream fuel cycle system must be identified at an early stage of the program. As part of this program, the various process steps will be tested and major components will be designed, fabricated, and tested individually. A semi-scale demonstration system will be designed and assembled which will duplicate a typical EPR fuel cycle. The completed system will be operated for an extended period with significant quantities of deuterium-tritium fuel mixtures. Provisions for analytical determinations will be made at numerous points in the fuel cycle stream. The possible effects of tritium contamination combined with results from materials testing facilities (e.g., INS) will be evaluated in regard to the usefulness of all materials and hardware utilized in the fuel cycle system.

\subsubsection{Demonstrate Tritium Containment}

Tritium containment will be demonstrated by the use of a triple enclosure design philosophy. The primary containment, consisting of all the fluid flow equipment. enclosing the tritium, will be fabricated according to carefully prescribed procedures with certified, high-integrity components, inspected and tested before being. contaminated with tritium. Secondary enclosures will surround primary components which have a high potential for leakage or which contain large quantities of tritium. Tertiary containment will be provided by low-leakage building construction and an emergency air detritiation system which will clean the building atmosphere before it is exhausted. 


\subsubsection{Demonstrate Tritium Monitoring Accountability}

Existing monitoring equipment will be used to detect the radioactivity of tritium in the primary, secondary, and tertiary enclosures and in the nearby environs. A program to improve monitor sensitivity and to develop and test monitors that will function in radiation environments is included in the proposed experimental plan. Tritium accountability will be provided by analytical determinations, PVT measurements and calorimetry. Development of an on-line accountability system is an objective of the program plan for this facility. Personnel monitoring will be closely followed and related to work functions.

\subsubsection{Demonstrate Tritium Cleanup in Both Routine and Off-Normal Situations}

Tritium cleanup on a routine basis will begin with detritiation of the circulating atmosphere in the secondary containment system by directing all contaminated waste gas streams to an Effluent Removal System (ERS). All contaminated liquid streams will be directed to a waste collection system. For off-normal operations, an Emergency Containment System (ECS) will be activated to detritiate the air in the tertiary. enclosure. In addition, residual contamination on laboratory equipment following. a release of airborne tritium will be determined. Components of both the ERS and ECS systems. will be tested.

1.2.5 Demonstrate Maintenance and Modification in a Tritium Environment Provisions will be made in the facility to permit maintenance and modification of contaminated equipment based upon experiences at Mound Laboratory. Various techniques will be developed to accomplish these tasks utilizing remote maintenance methods. Preplanned operational job assignments will precede all maintenance work. A record of all maintenance functions, subsequent tritium releases, and personnel exposures, if any, will be kept. 


\section{Facilities}

\subsection{Scale of the Demonstration}

The major aspect of the TSTF in its initial years of operation will be the demonstration of the operation of a semi-scale model of the fuel cycle for a deuterium-tritium fueled Tokamak fusion power reactor and the demonstration of the containment and safe handling of tritium in a large integrated processing facility. This requires the creation of a reference design of the fuel cycle model and of the containment system and tritium control methodology that will be employed in the TSTF.

Studies at Argonne National Laboratory, General Atomics Corporation, and Oak Ridge National Laboratory have resulted in three designs for a Tokamak Experimental Power Reactor*. A common feature of these designs is a toroidal vacuum chamber with a major radiusto minor radius ratio of 22.5 (plasma aspect ratio $\sim 3$ ) and a volume of $2600 \mathrm{~m}^{3}$. This vacuum chamber is evacuated by a large number (40-64) of liquid-helium-cooled cryosorption pumps.

In order to simulate this chamber and provide a firm basis for extrapolation to the EPR, a quarter section of a torus with a $1.2 \mathrm{~m}$ radius and a $3.1 \mathrm{~m}$ radius will be constructed. The torus will be evacuated by sixteen $6,0001 \mathrm{iter} / \mathrm{sec}$ (hydrogen speed) cryosorption pumps, phased so that only eight pumps are pumping at a given time. A design basis shot will be 80 torr liters of DT mixture with a 1 -min cycle . length including $12 \mathrm{sec}$ for pump down. The toroidal quadrant design has several advantages: 1) it simulates the geometry seen by the plasma (neglecting end effects) and by external equipment which must interact with the vacuum chamber; 2) it preserves the surface-to-volume and pump-speed-to-volume ratios of the EPR design; 3 ) the number of cryopumps is sufficient to simulate and test pump phasing and cycling phenomena; and 4) the size of the equipment is sufficient to permit scaling with confidence to an EPR as the linear dimensions are approximately half those of an EPR. Figure 2-1 shows the proposed toroidal section vacuum chamber installed in a high bay work area. A fuel cycle block diagram and flow sheet are shown in figures 2-2 and $2-3$.

*W. M. Stacey, et al., Tokamak Experimental Power Reactor Studies, ANL/CTR-75-2, June, 1975.

Experimental Power Reactor Conceptual Design Study, 12 Month Progress Report for the Period July 1, 1974, through June 30, 1975, GA-A13534, JuTy, 1975.

M. Roberts, et al., Oak Ridge Tokamak Experimental Power Reactor Study - Reference Design, ORNL-TM-5042, August, 1975. 
The cryosorption pumps will be operated on a 6-hr cycle with approximately equal times for pumping and regeneration plus cool down. Four liquid-nitrogencooled sorption pumps (also phased) will collect the helium cryopump exhaust and boost the pressure of the fuel mixture to approximately $2 \mathrm{~atm}$ for further processing. Debris which flows from the helium cryosorption pumps will be separated by a precipitator ahead of the nitrogen-cooled pumps.

The fuel will then pass through a methane cracker and a series of palladiumsilver diffusers. The scale of these and later components will be set by the size of the toroidal segment. As the fuel flow will be only of the order of one-half STP liter per minute, these components will not be large.

Nonhydrogenic materials will not diffuse and will be pumped off for further processing. The remaining DT mixture will enter a series of cryogenic distillation columns to separate all three hydrogen isotopes. Isotopomeric equilibrators will be provided to convert heteronuclear molecules into homonuclear ones. The separated isotopes may be either stored or remixed for reentry to the toroidal segment. Tritium and deuterium will be stored on uranium beds. Emergency storage will be provided for liquified gases contained in the stills or sorption pumps by means of evacuated tanks.

The toroidal section will be provided with an access port for a neutral beam injector, although an injector will not be included in the facility. Heated panels in the vacuum chamber will permit the simulation of a $500{ }^{\circ} \mathrm{C}$ first wall exposed to the plasma. Cooling coils on the exterior surface of the vacuum vessel will maintain a cool - hence impermeable - enclosure.

All components of the test facility with the exception of the vacuum chamber will be doubly contained. The helium cryosorption pumps are by their nature doubly contained. Piping which connects nonadjacent components will be double-walled. The nitrogen sorption pumps, methane cracker, diffusers, stills, pumps, and storage containers all will be enclosed in gloveboxes. Large components on the vacuum chamber such as valves and flanges will be surrounded by evacuated jackets. A dedicated liquid nitrogen sorption pumping system (also enclosed) will maintain the vacuum in these jackets.

The atmosphere in the gloveboxes will be argon which will be continuously circulated, dried, and purified of oxygen. The glovebox pressure will be slightly below that of the room: Tritium purification of the circulating argon will be provided only under off-normal conditions as is described below.

Two tritium processing systems (part of existing factlities) will be provided. The first is an Effluent Removal System (ERS) which processes gaseous waste material to remove tritium. The glovebox purifiers and the diffusers are two of the many sources. of material for the ERS. In addition, if a tritium leak in a primary system contaminates a glovebox, the entire glovebox atmosphere will be dumped to an evacuated surge tank to be processed by the ERS. The ERS converts tritium to tritiated water which is then fixed, encapsulated, and buried. 


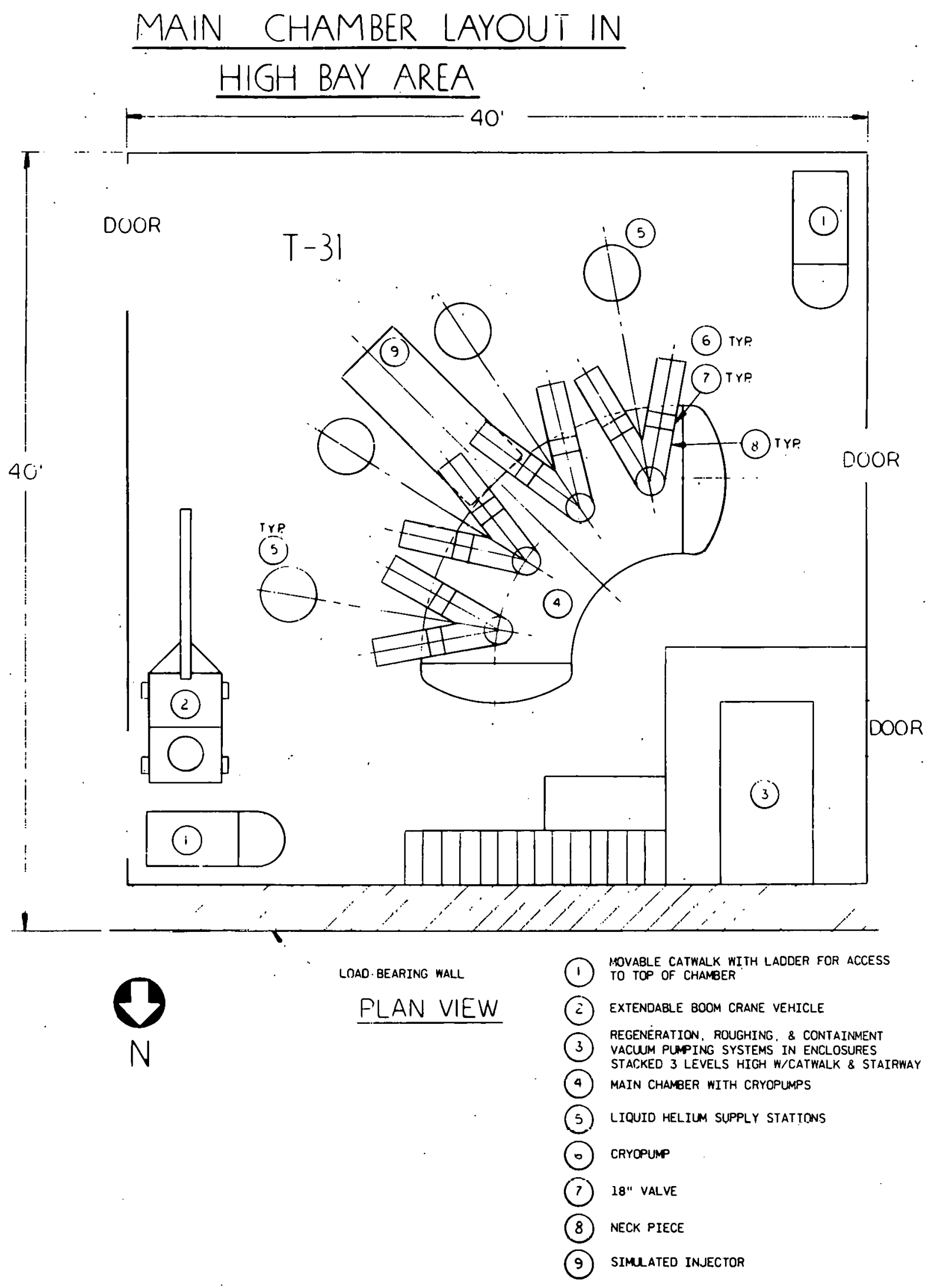

Figure 2-1. 
FUEL CYCLE

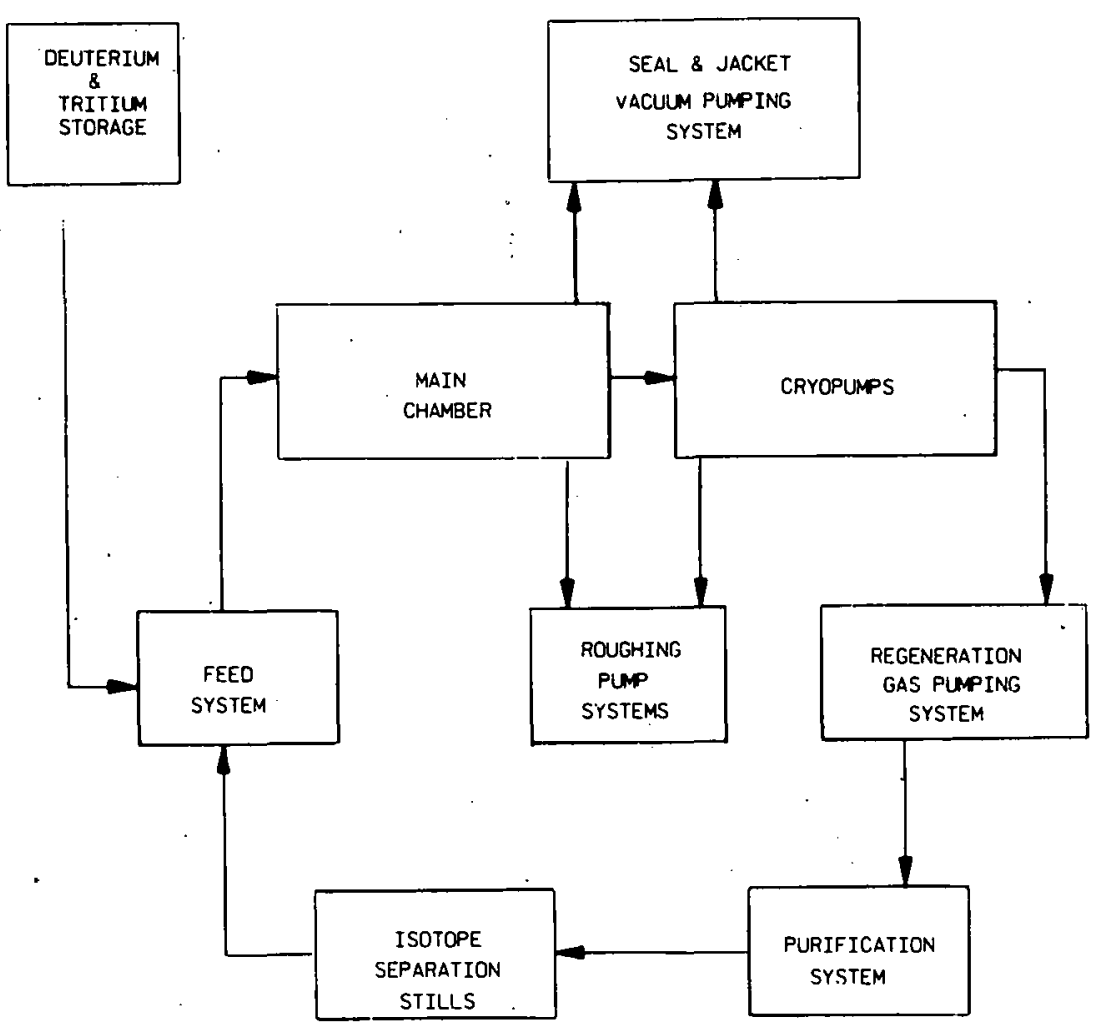

Figure 2-2 


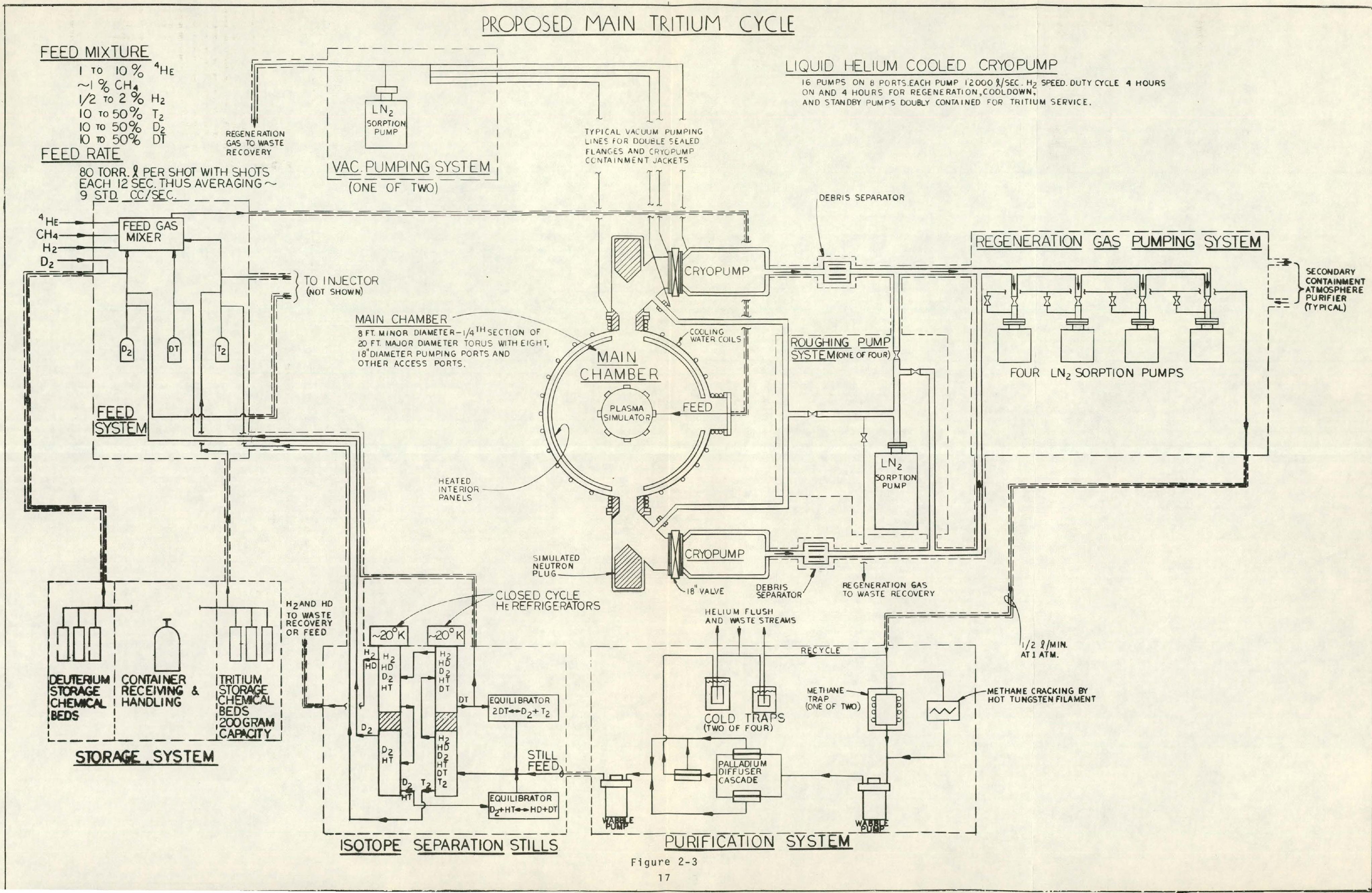


THIS PAGE

\section{WAS INTENTIONALLY \\ LEFT BLANK}


The second processing system is the Emergency Containment System (ECS). It is a $1000 \mathrm{ft} 3 / \mathrm{min}$ air processing system which removes tritium from room air in the event both primary and secondary containment systems fail. If such a release occurs, the affected room will be isolated from the remainder of the building and the ECS will recirculate the air to remove the tritium. Purification occurs by catalysed oxidation at $170{ }^{\circ} \mathrm{C}$ followed by HTO adsorption on a pair of $1000 \mathrm{~kg}$ alumina beds. Room pressures will be adjusted during ECS operation so that the affected room will be at the lowest pressure in the building. The building, in turn, will be below atmospheric pressure. Only clean air from the outlet of the ECS will be vented during ECS operation.

A maintenance area equipped with a glovebox large enough to accommodate a helium cryopump will be near the test facility room, connected to it by a corridor which will permit moving hot equipment without using general access corridors. A central control and computer room on the upper floor will overlook the test facility. These and the other TSDL systems are indicated in the simplified block diagram (Figure 2-4).

\subsection{Existing Facilities}

The "Technical Building" (T Bldg.) at Mound Laboratory where Mound and Argonne propose to install the Tritium Systems Test Facility is an underground, two story, heavily reinforced concrete structure which was originally built to process polonium-210. As it was designed to withstand a direct hit by a conventional bomb, it is capable of withstanding the design basis tornado and the design basis earthquake. There is a vehicle tunnel along one side for delivery and removal of material and equipment. $200-\mathrm{ft}$ high brick stack is located at each end of the building for dispersal of exhausted air. The location of T Bldg. (and that of the alternate new building) is shown in the Mound Laboratory Site Plan, Figure 2-5.

At the time the polonium-210 operation was discontinued and the facilities were decontaminated, contaminated exhaust ducts within the building were removed, so it will be necessary to install new exhaust ducts for the TSTF. The supply air for the building is equipped to provide the proper temperature and humidity control for a tritium processing facility.

A double-ended 2000 kVA capacity substation, a machine shop, and a maintenance shop are located on the first floor of the building. The building is properly equipped with fire doors and is fully equipped with sprinklers. The T Bldg. has a total net usable space of about $60,000 \mathrm{ft}^{2}$ excluding change rooms, corridors, elevators, and equipment rooms. About $8000 \mathrm{ft}^{2}$ are now vacant and the additional space required by the TSTF can be readily made available by relocating several operations to other buildings. Even more space beyond the 22,000 ft 2 proposed for the current facility can be made available in the event of an expansion or extension of the TSTF.

In the west end of the first floor, a developmental laboratory is presently under construction for the purpose of removing low concentrations of tritium from water and subsequent isotopic separation. Included in this area is a $1000 \mathrm{ft} 3 / \mathrm{min}$ [mergency Containment System (ECS) designed to remove tritium from the room air in the event of a tritium release. This $\$ 225,000$ system will, with some modifications for regeneration, provide the same protection for the TSTF and the development laboratory. Figure 2-6 shows an ECS block diagram.

A $60 \mathrm{ft}^{3} / \mathrm{min}$ Effluent Removal System (ERS), see Figure 2-7, is located in the SW B1dg. approximately $500 \mathrm{ft}$ northwest of the T Bldg. This system has been in use for over 12 years to support existing tritium processing facilities. The system is used to remove tritium, as water, from the effluents of various support equipment such as vacuum pumps and glovebox atmosphere purifiers before the gases are exhausted to the atmosphere. 


\section{SIMPLIFIED BLOCK DIAGRAM}

\section{TSTF}

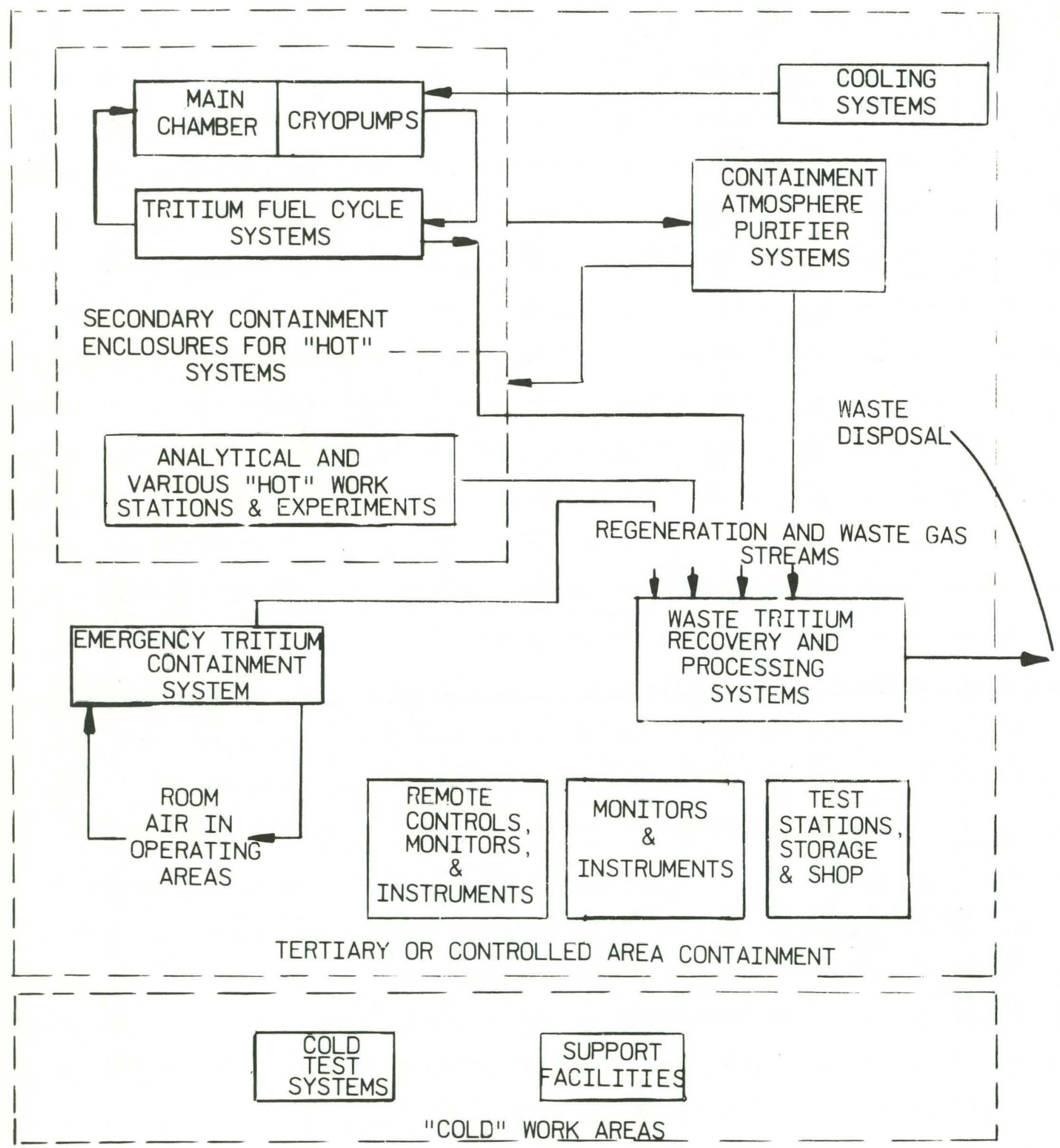

Figure 2-4 


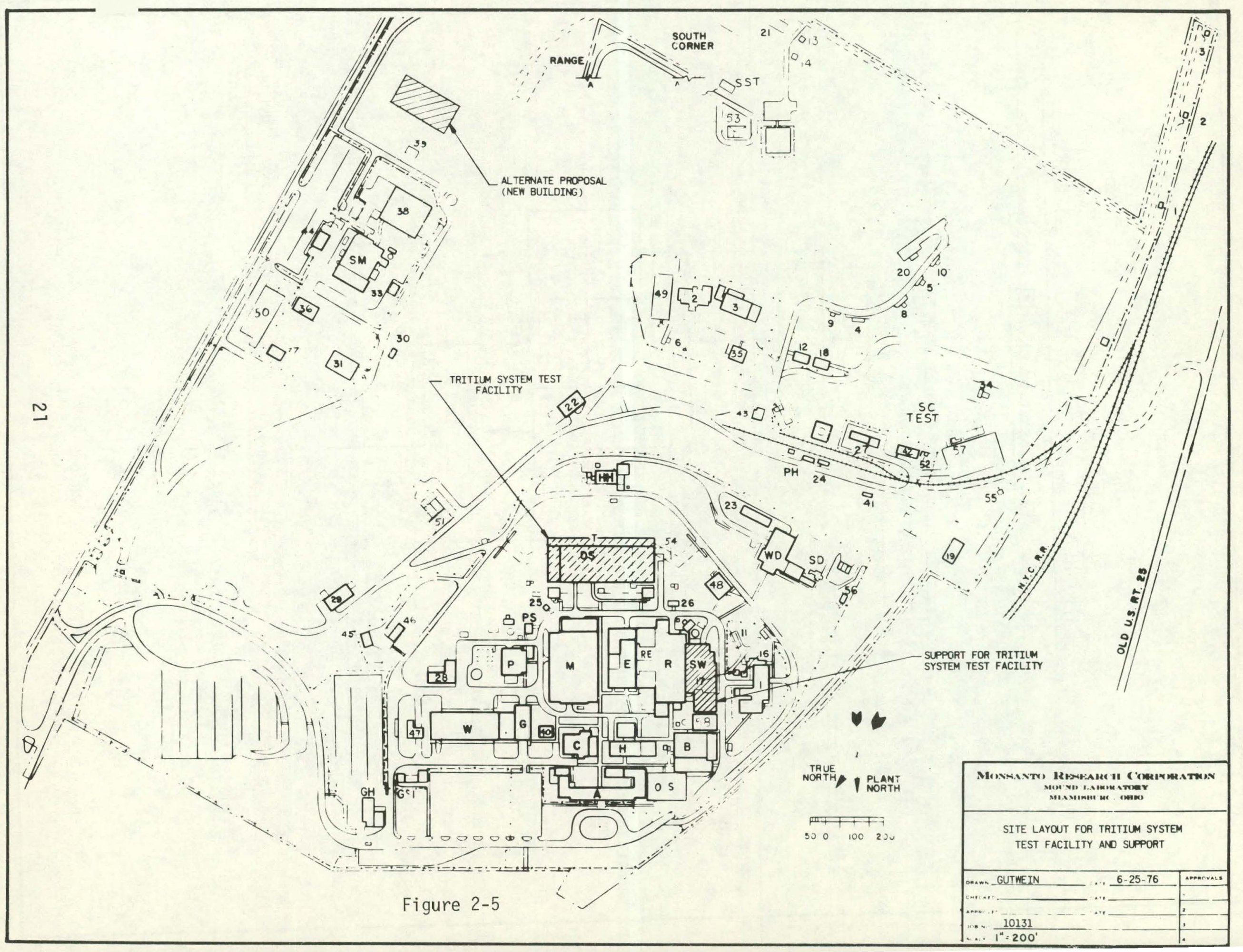




\section{EMERGENCY CONTAINMENT SYSTEM (ECS) BLOCK DIAGRAM}

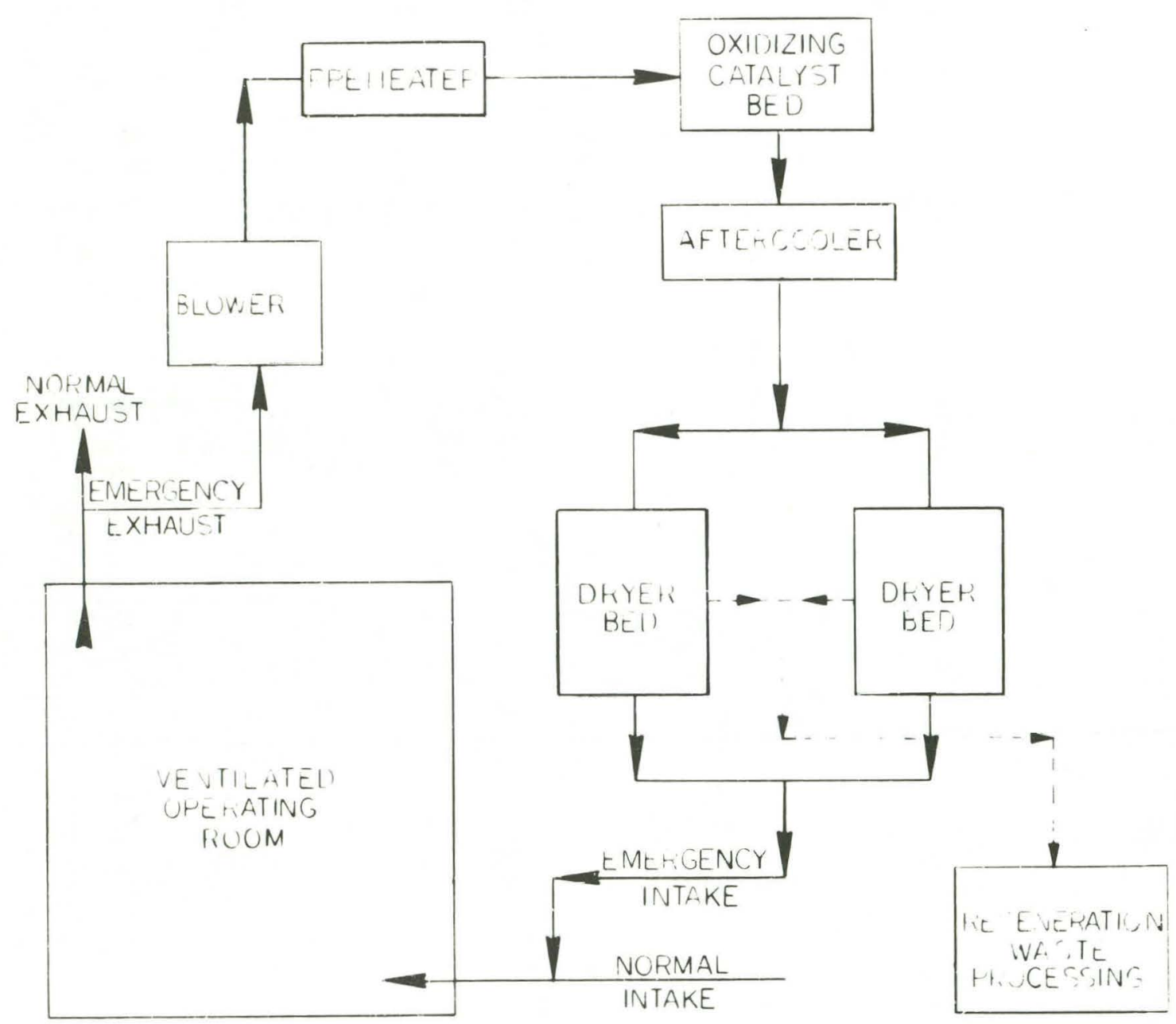

Figure 2-6 


\section{EFFLUENT REMOVAL SYSTEM}
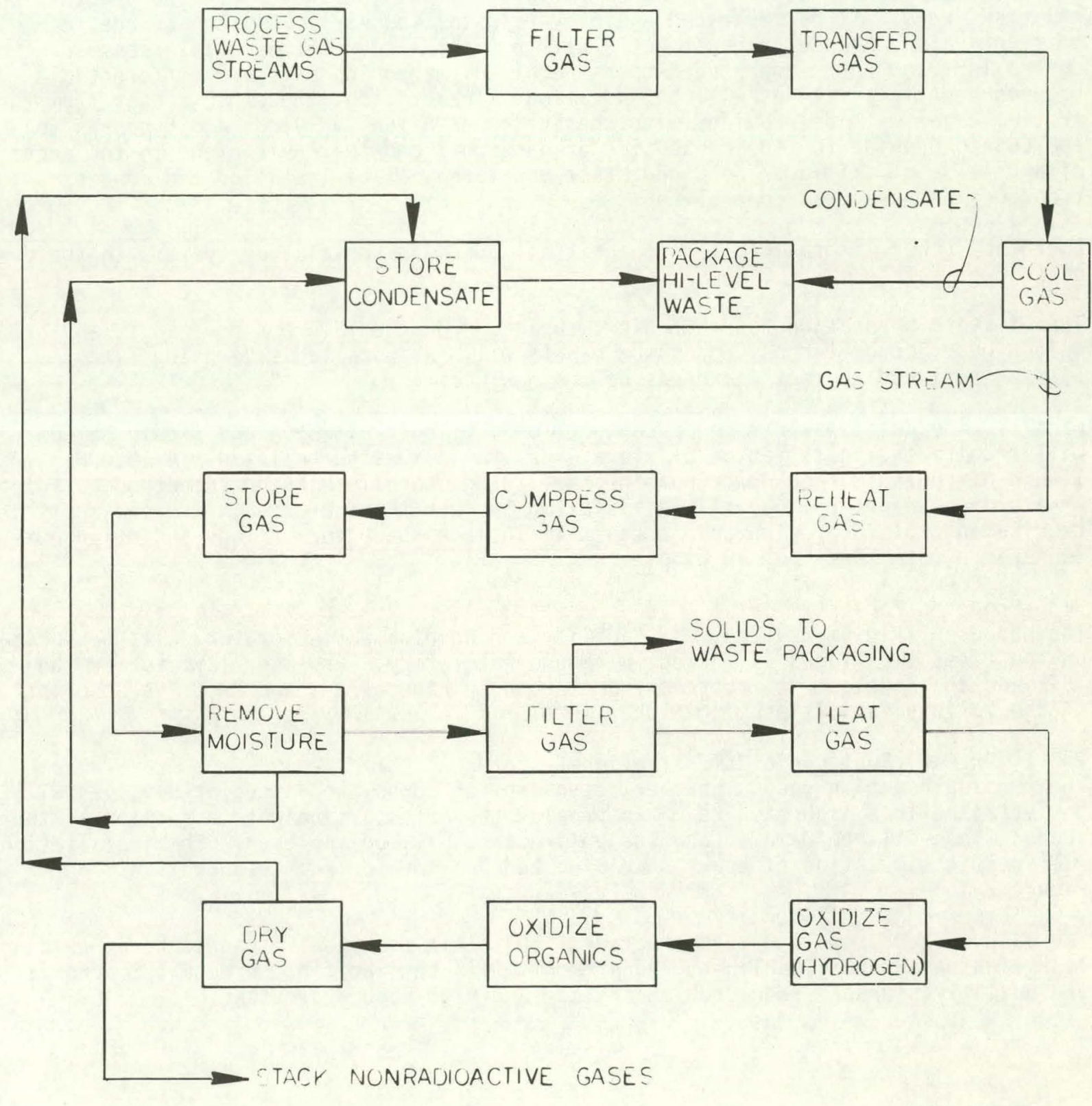

Figure 2-7 
The ERS occupies approximately $2000 \mathrm{ft}^{2}$ of floor space; it has been upuratied in capahility several times and its estinated capital value is $\$ 1,250,000$. With the addition of a double-walled pipeline connecting $T$ Bldg. and SW Bldg., a surge tank, and appropriate controls; this system can be used to support the TSTF.

Also located in the SW Bldg. is a facility (Figure 2-8) for evaluation of the tritium content of and packaging for disposal of liquid wastes such as vacuum pump $0 i 1$ and water which contain high levels of tritium. The equipment occupies $300 \mathrm{ft}^{2}$ of floor space at a capital value of about $\$ 100,000$ and will be used to support the TSTF at no additional cost. A11 packaged radioactive waste is trarsferred to a waste staging and storage building for off-site shipment and burial.

Building modifications are planned to prepare T BIdg. for the TSTF. The original cold and risk areas will be separated again by reinstalling air locks, the change room will be reactivated, and new exhaust ducts will be installed. Differential pressure controllers and motor-operated dampers required to provide pressure differentials between ventilation zones will be installed. In addition, the exhaust duct from the tritium areas will be provided with the instrumentation, valving, and bypasses to the ECS to provide for the protection of personnel and the environment in the event of a release of tritium. Room and stack monitors will be installed and connected to recorders in a central control room.

Emergency power is provided for the critical building ventilation systems in the event of a power outage.

The existing substation has sufficient capacity for the TSTF but some additional switch gear, conduit runs, and power panels will be installed. Lighting fixtures will be replaced to meet the needs of the new facility.

Finally, the anticipated rate of consumption of liquid nitrogen and liquid helium will require the installation of storage dewars inside the building. A 10,000-gal liquid-nitrogen storage dewar outside the T Bldg. supplies it and one other building. An improved transfer line will be installed to meet the increased nitrogen supply requirements of TSTF. The cold areas will include space for offices and a large conference room for about 40 people.

2.3 Proposed Facility

The proposed Tritium Systems Test Facility and Development Laboratory will be located on the first two floors of T Bldg. at Mound Laboratory. Proposed layouts for the TSTF and the Development Laboratory are shown in Figures 2-9 and 2-10. A description of the various facilities within the TSDL is as follows:

\subsubsection{Primary Fuel Cycle Demonstration System}

The toroidal section vacuum chamber, cryosorption pumps, and associated valves will be installed in a high bay area. To provide the necessary height, a section of the second floor will be removed and the entire area will be enclosed. The installation will permit simulation of heavy shielding and provide for remote operation. See Figure 2-1.

The vacuum chamber will be constructed of 304 stainless steel. Fabrication, welding, leak tightness, and cleanliness requirements will be specified in detail to provide the quality assurance required for tritium and high vacuum service. 


\section{$\frac{\text { HIGH LEVEL LIQUID }}{\text { WASTE DISPOSAL LAB. }}$}

(1) CONTAINER UNLOADING

(2) CALORIMETRY \& METERING

(3) DRUM LOADING BOX

(4) LIDDING FUME HOOD

(5) ENVIRONMENTAL BATH

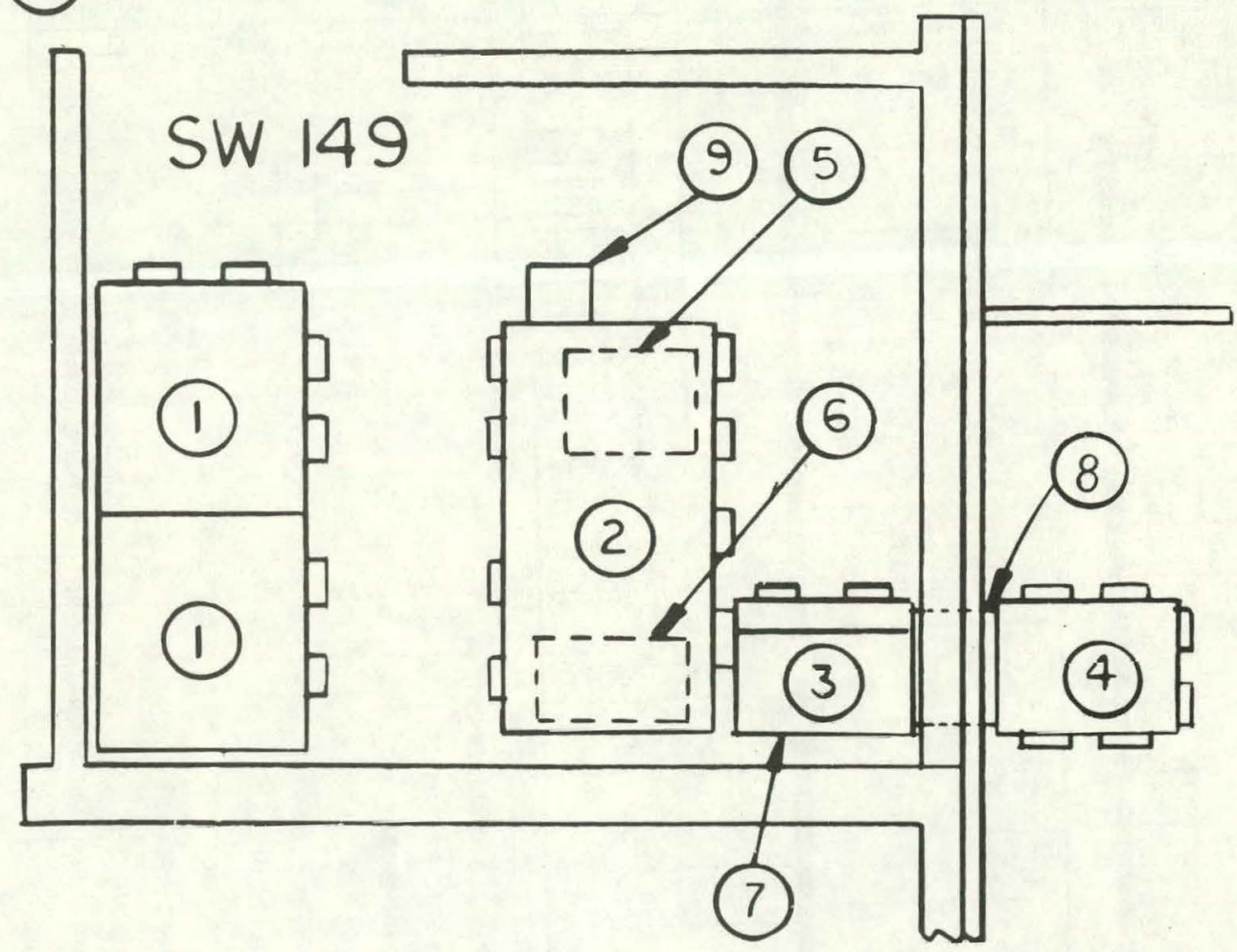

PLAN VIEW
(6) VAC PUMP

(7) ELEVATOR DRUM PRESS ( IN FLOOR)

(8) FIRE DAMPER

(9) PASS BOX 


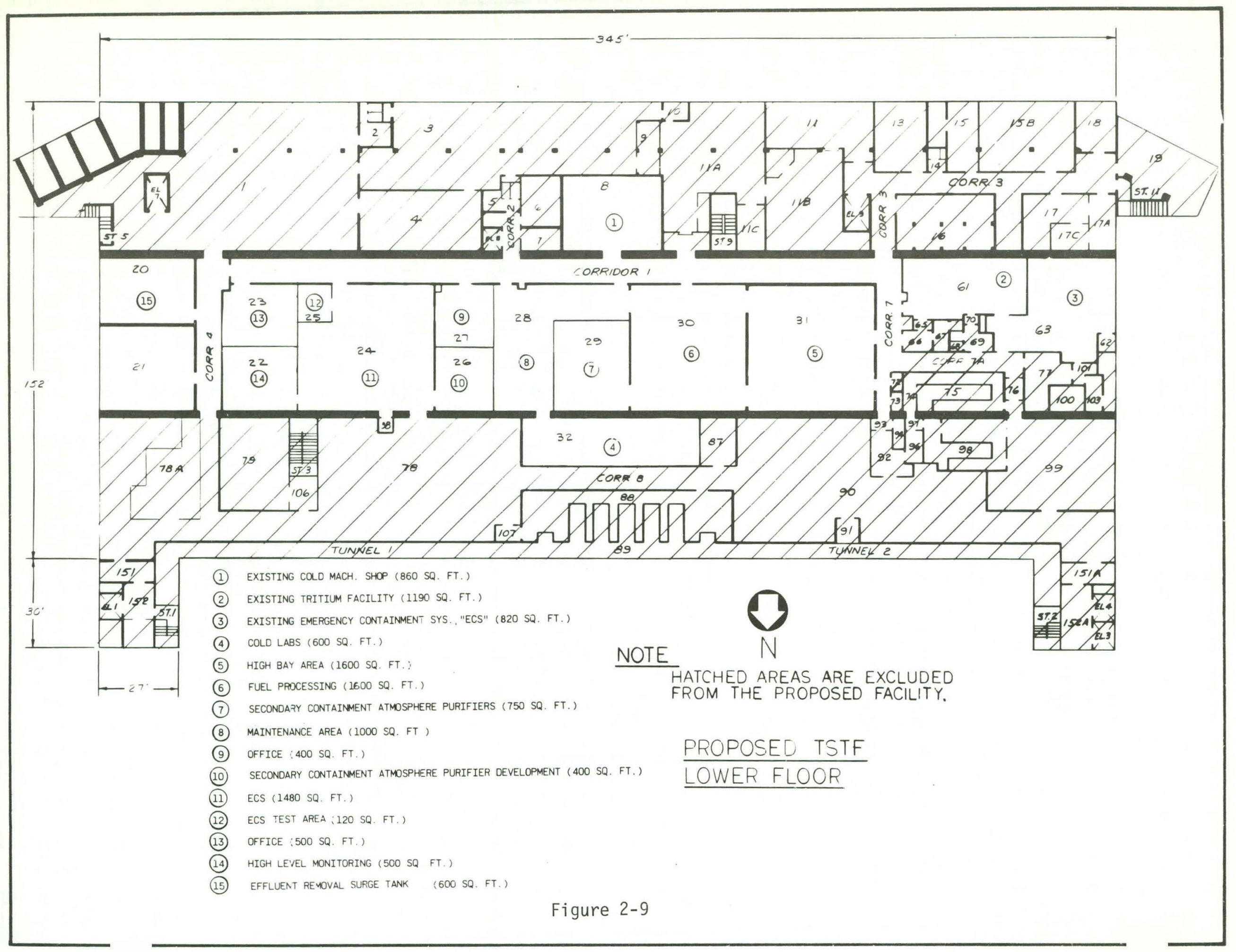




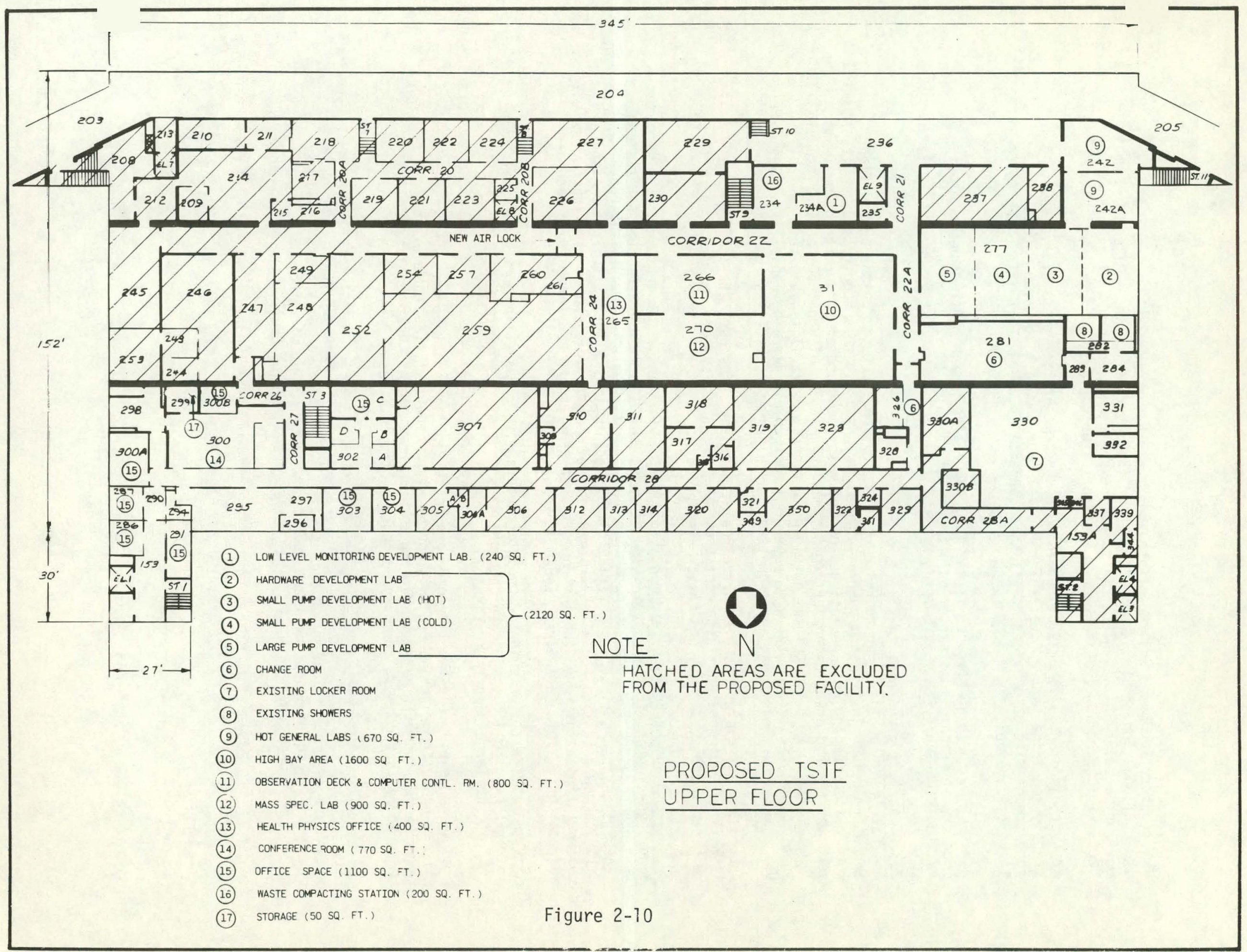


The cryosorption pumps will be off-the-shelf purchases modified as required to meet the configuration of the vacuum chamber and the laboratory. The vacuum ducts will be fabricated of 304 stainless steel and the entire assembly of vacuum chamber and ducts will be helium leak tested at the fabricator's plant.

An overhead crane will be provided to move the cryosorption pumps and valves to a transfer container set on tracks for removal from the high bay area. Double containment will be provided for flanged connections where there is a potential for leaks to develop.

Adjacent to the high bay area is the fuel processing system which occupies about $1600 \mathrm{ft}^{2}$ of space. This system will be housed in about $60 \mathrm{ft}$ of glovebox with a recirculated inert atmosphere (Figure 2-11).

\subsubsection{Analytical Support Facility}

An analytical facility (Figure 2-12) will occupy about $800 \mathrm{ft}^{2}$ on the second floor and will include instruments such as chromatographs and a mass spectrometer. Titanium sublimation pumping will be included on the mass spectrometer to permit the maximum accuracy for hydrogen isotope determinations. A network of about 60 capillary sample lines, running from the tritium development laboratory facilities to this centrally located analytical facility, will provide direct, rapid sampling capability. Residual gas analyzers, laser Raman spectrometers, and hygrometers will also be provided.

About $33 \mathrm{ft}$ of gloveboxes with a recirculating inert atmosphere will be required. Associated equipment and instrumentation such as vacuum systems, gauges, controllers, recorders, ovens, piping, and valves are included.

\subsubsection{Pump and Hardware Development Facilities}

A pump development facility consisting of about $2100 \mathrm{ft}^{2}$ will provide for the testing of large cryosorption pumps to determine pump speeds, liquid helium and nitrogen consumption, capacities, regeneration times, and impurity effects. The test stands will include a test valve, a test volume, roughing pumps, gloveboxes with inert recirculating atmosphere, and instruments such as pressure and temperature recorders and monitors. This facility is shown in Figure 2-13.

Similar tests will be conducted on intermediate size cryosorption and mechanical pumps and will require a hot and a cold bench-sized test stand with equipment similar to that of the large pump test stands.

A hardware development facility of approximately $500 \mathrm{ft}^{2}$ will be provided to test valves and instruments under conditions of high magnetic fields and elevated temperatures and will be equipped with a large bore magnet, heaters, pressure and temperature transducers, timers, and other instrumentation.

\subsubsection{Contaminated Equipment Maintenance Facility}

This facility of approximately $1000 \mathrm{ft}^{2}$ will provide the means to repair and replace components on contaminated pumps and valves. It will include gloveboxes sized to take the largest cryosorption pump. Machine shop equipment will include a lathe, drill press, precision grinders, and other assorted machine tools. The maintenance area is shown in Figure 2-14. 


\section{FUEL PROCESSING}
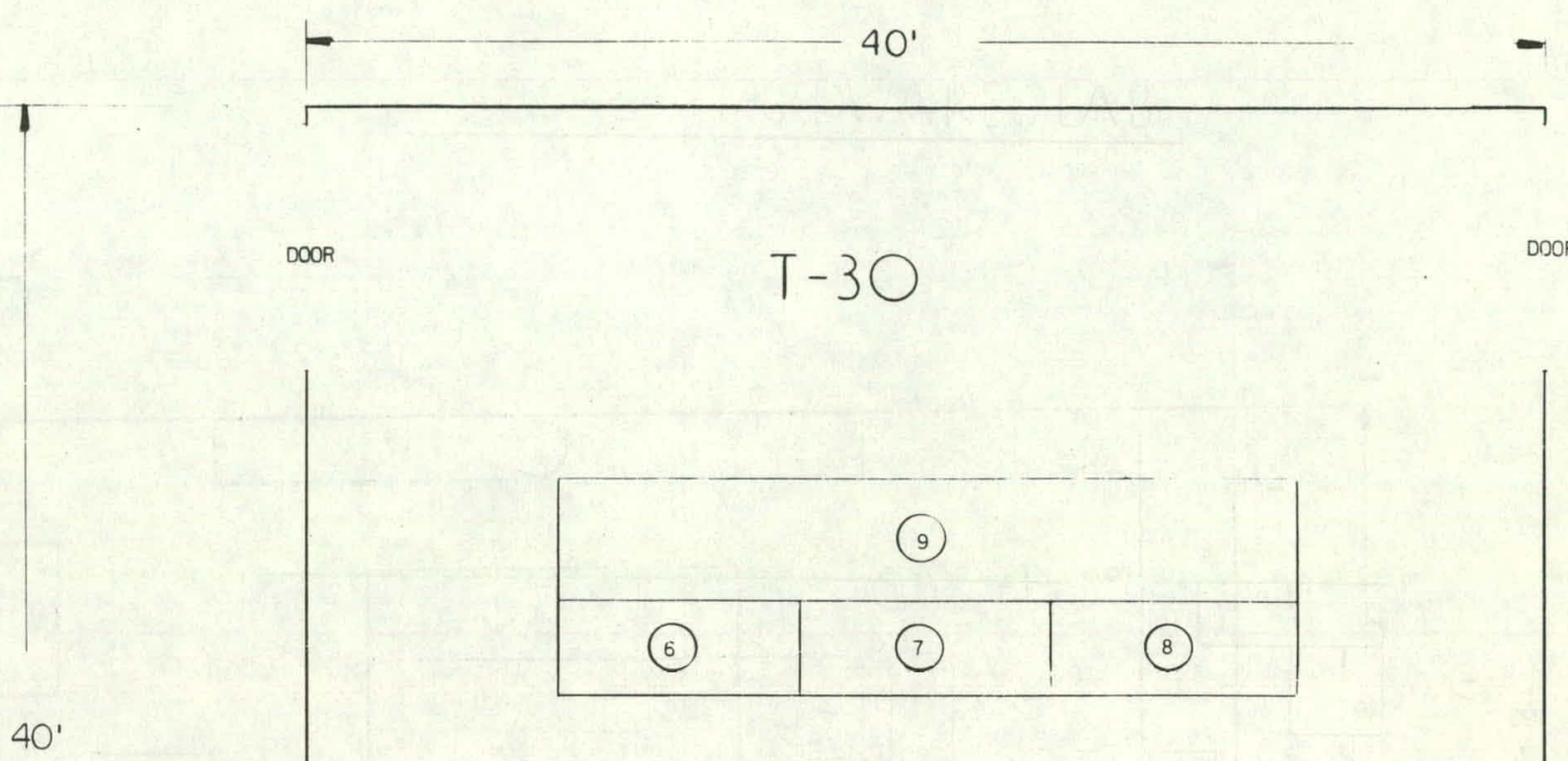

DOOR

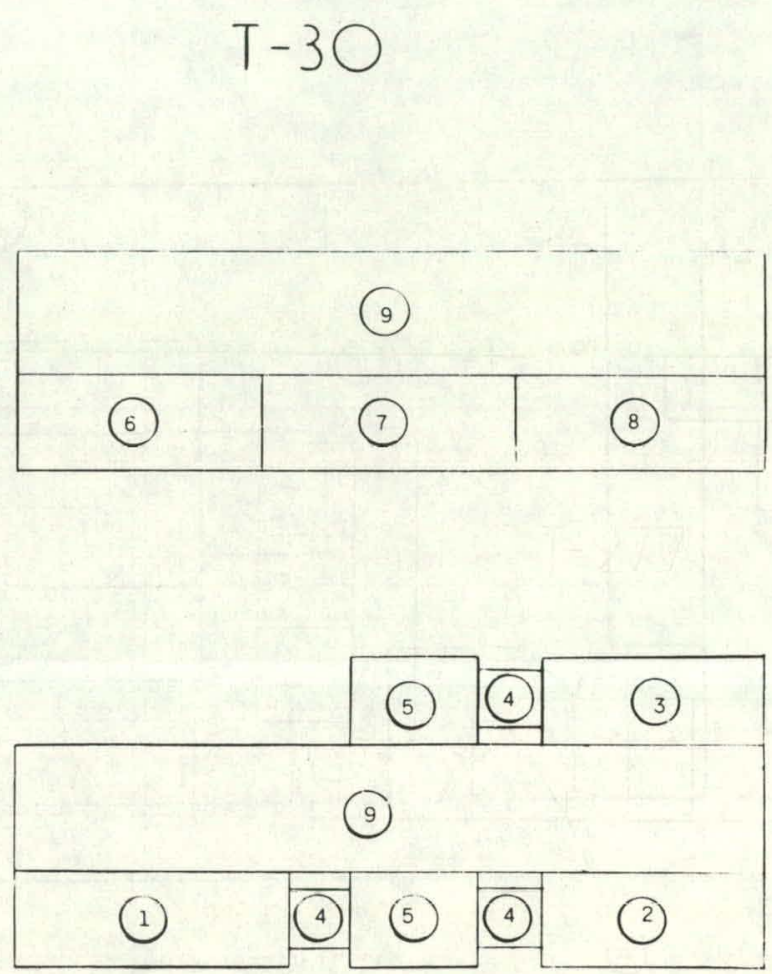

40

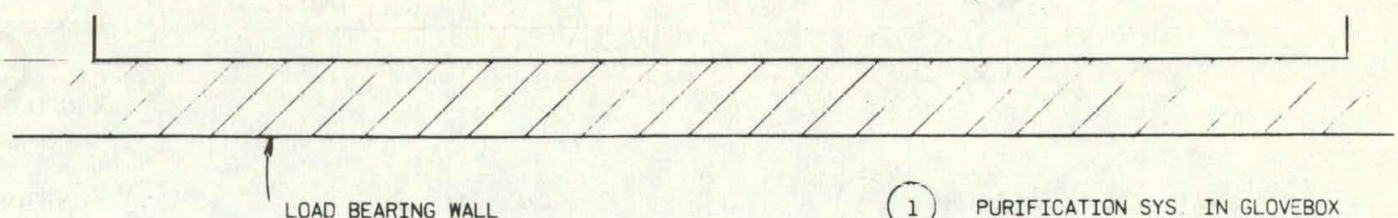

LOAD BEARING WALL

(1) PURIFICATION SYS IN GLOVEBOX

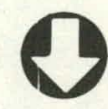

N
PLAN VIEW
(2) isotope separation Stills in Glovebox

(3) FEED MIXING SYS IN ENCLOSURE

(4) Vacuum Passbox

(5) FUME HOOO

6) deuterium storage sys in enclosure

(7) CONTAINER RECEIVING AND HANDLING SYSTEM IN ENCLOSURE

(8) tritium storage system in enclosure

(9) maintenanice cnclosure

Figure 2-11 
MASS SPEC.- GAS CHROMATOGRAPHY LAB.

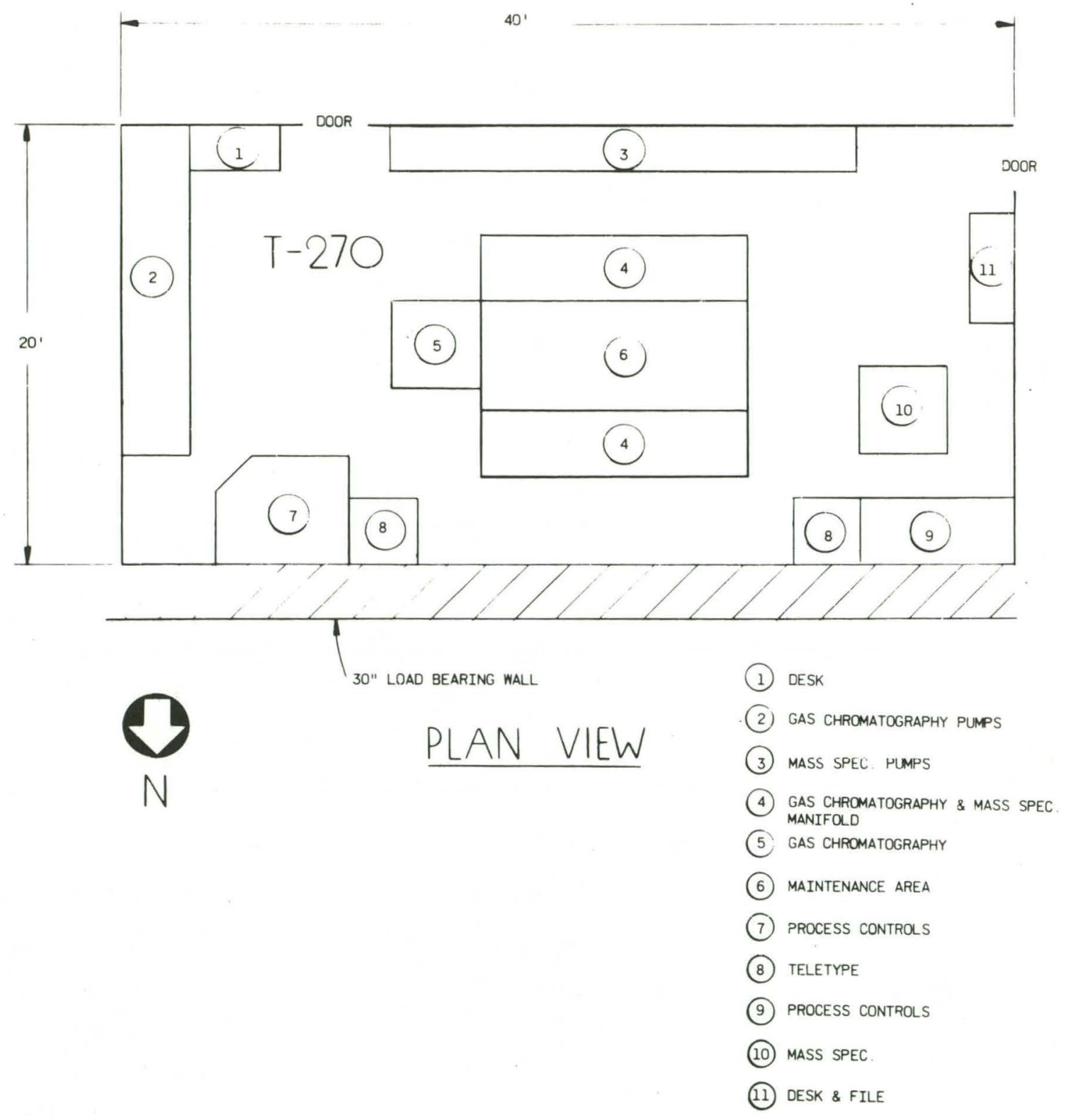

Figure 2-12 
PUMP \& HARDWARE LAB
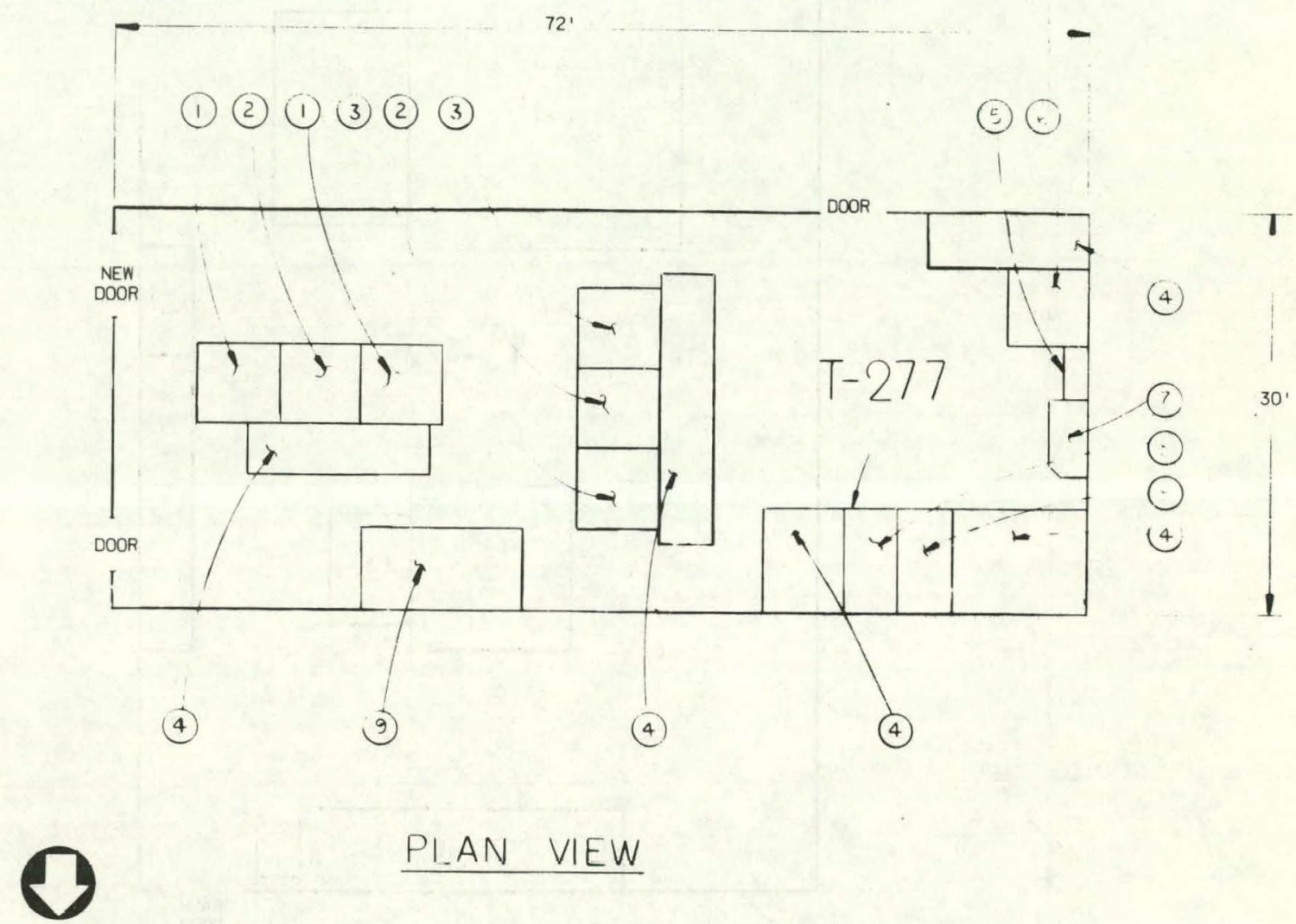

PIAN VIEW

(1) Large Pump stand

(2) PASSBOX

(3) intFrmantate PIMp Stand

6 electro magnet test Stand

(4) Test stand support equip.

(7) $B E N C H$

(5) Control

(8) INTERMEDIATE PUMP (FORE PUMP)

(9) Control system \& data COllector

Figure 2-13 
MAINTENANCE AREA

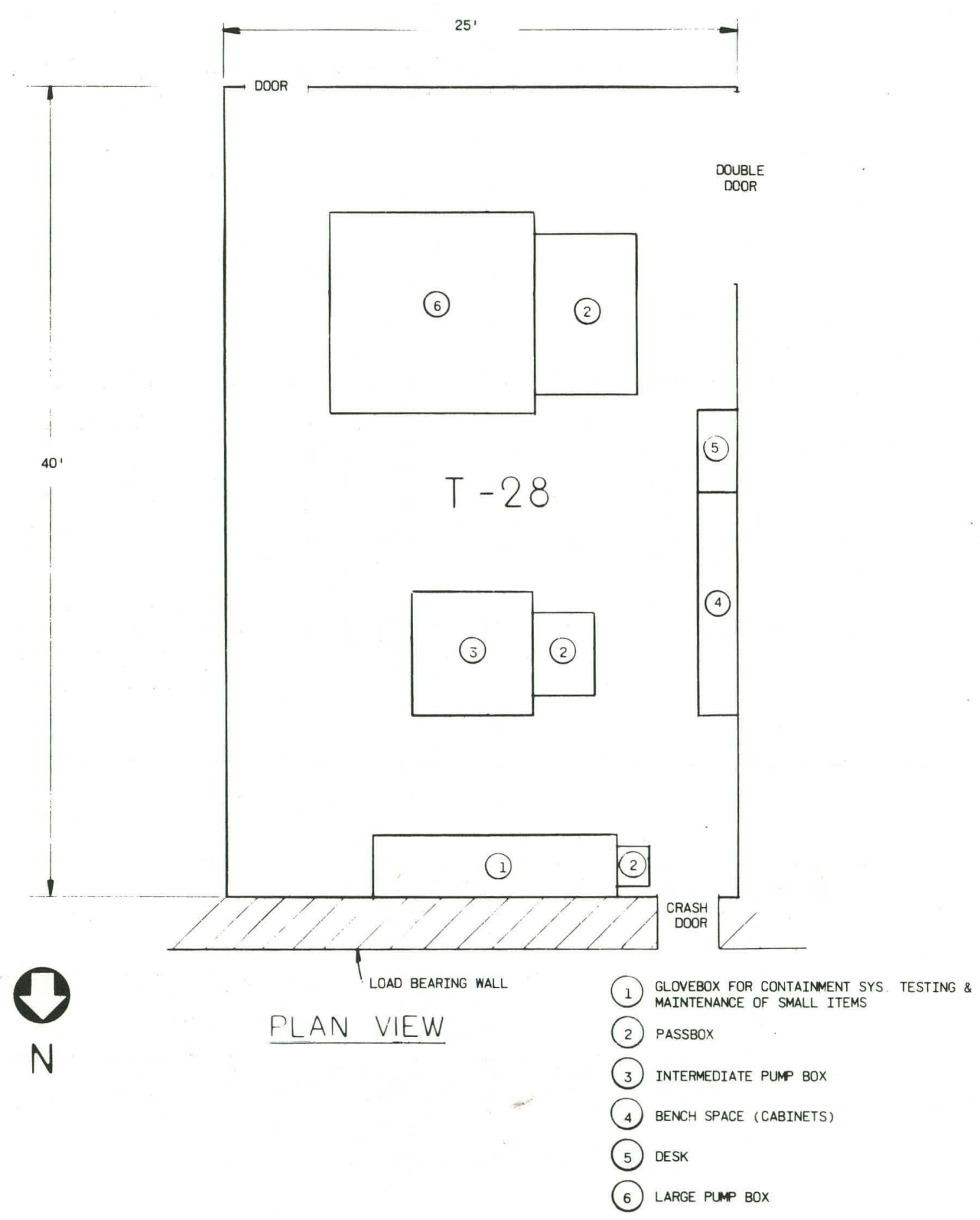

Figure 2-14 


\subsubsection{Computer and Control Facility}

A dedicated minicomputer will provide a major portion of the control of the TSTF. This machine will provide a multiprogramming environment with full provision for realtime, batch, and interactive subsystems. Real-time functions will include concurrent process monitoring and control of TSTF, analytical instrument control, and data acquisition. The batch input subsystem will be available for data reduction and FORTRAN computational jobs. The interactive subsystems will be used for graphics manipulations, source editing, etc. Multiprocessor hardware and software will be available for process control expansion.

A terminal will be provided for possible tie-in to the MFE computer facility at LLL or to other high speed data processing facilities.

\subsubsection{Monitor and Instrument Development Facilities}

Approximately $500 \mathrm{ft} 2$ of space will provide for the development of instruments for strategic material accountability. Another $700 \mathrm{ft}^{2}$ will be provided for developing new and improved tritium monitors for room ventilation and stack effluent measurements with and without the influence of high neutron and gamma radiation.

This facility will include timing devices for recording response to the detection of low levels of tritium in air, precise sample preparation equipment, and gloveboxes. It will also include neutron and gamma sources installed within gloveboxes (Figures 2-15 and 2-16).

\subsubsection{General Purpose Radioactive Facilities}

Two rooms of approximately $300 \mathrm{ft}^{2}$ each will be provided for hot analytical work of a general nature including metallographic analyses. Gloveboxes, fume hoods, and laboratory benches with services such as power and compressed and liquified gases will be included in these facilities. The metallographic equipment will include sample preparation equipment, metallograph, and microscope (Figure 2-17).

\subsubsection{Contaminated Room Development Facility}

A room of about $120 \mathrm{ft}^{2}$ is included for the purpose of conducting experiments to determine techniques for hermetically sealing large volume rooms and testing surface finishes to minimize the adsorption of tritium.

This room may also serve to test sensing instrumentation and large valves for response time and sealing efficiency. Controlled tritium releases will be conducted in this test room. The contaminated air will be recycled by the ECS. A stainless steel liner on the inside wall surfaces will prevent tritium permeation from the room.

\subsubsection{Emergency Containment System (ECS) Development. Facility}

An area of $1600 \mathrm{ft}^{2}$ (Figure 2-18) is being provided to allow for installation of an ECS of $5000 \mathrm{ft} 3 / \mathrm{min}$ capacity. As the cost of this system is approximately $\$ 3,000,000$ the decision to include this system will be based on the results of the experimental program utilizing the existing $1000 \mathrm{ft} / \mathrm{min}$ system. The existing ECS will provide the means to recirculate the tritium-contaminated air from the "Contaminated Room" facility. 


\section{HIGH LEVEL MONITORING}

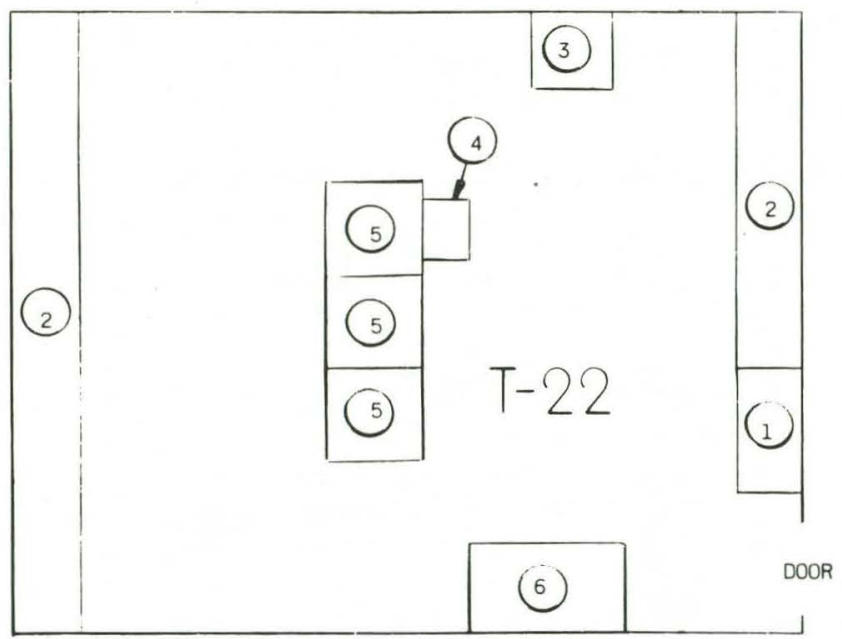

PLAN VIEW

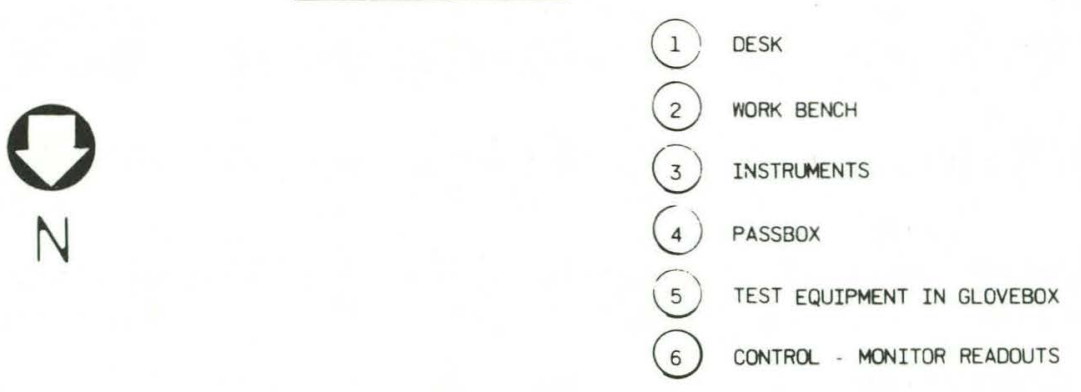

Figure 2-15 


\section{LOW LEVEL MONITORING DEVELOPMENT LAB. \& WASTE COMPACTING STATION}
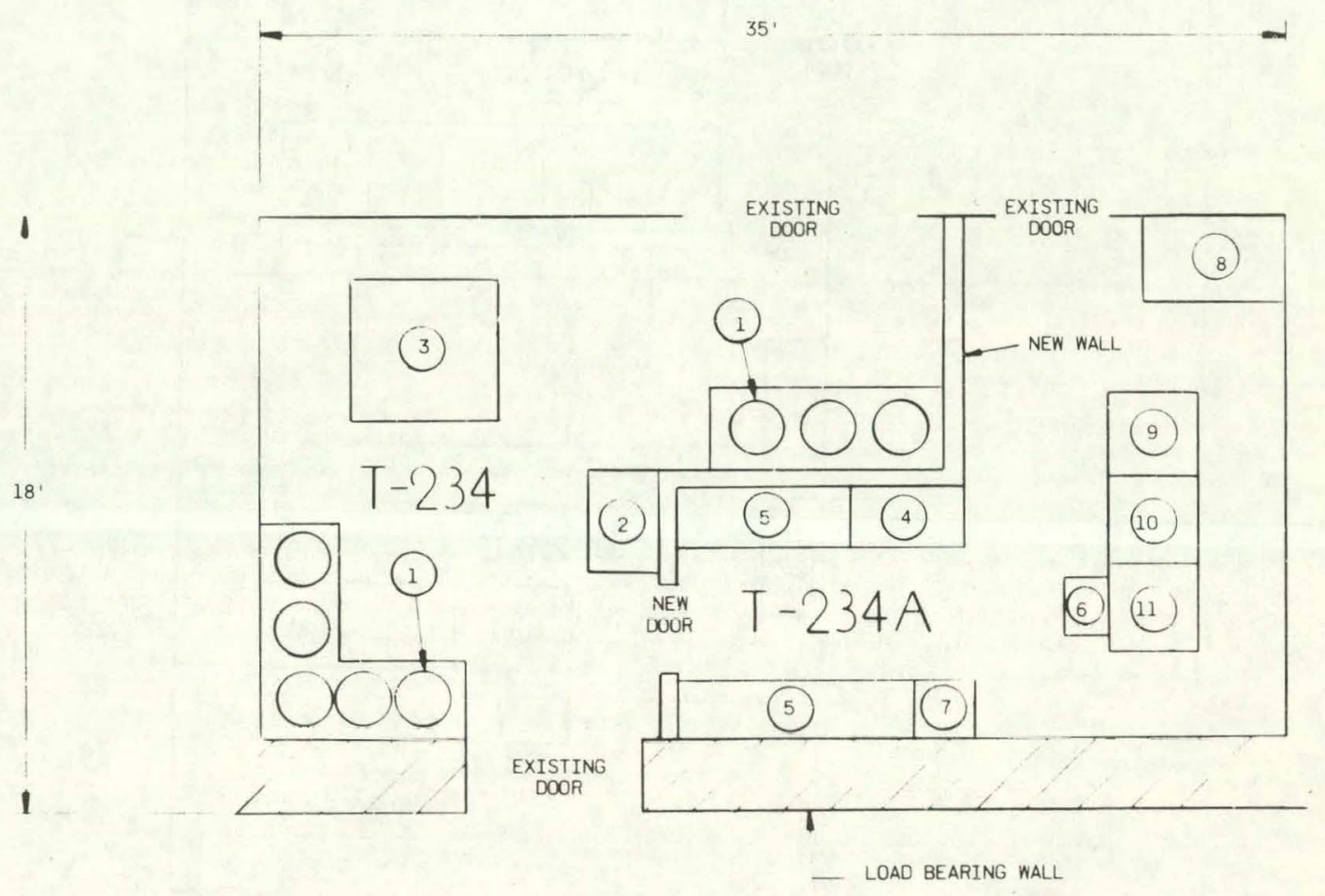

PLAN VIEW

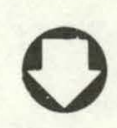

N

(1) DRUM StORAGE

(2) CONTROL-MONItOR READOUTS

(3) COMPACtOR

(4) DESK

(5) WORK BENCH

(6) PASSBUX
(7) INSTRUMENT RACK

(8) File : spare parts

(9) GLovebox (U-1300)

(10) BLUNER

(11) TEst volume

Figure 2-16 
HOT LABS.

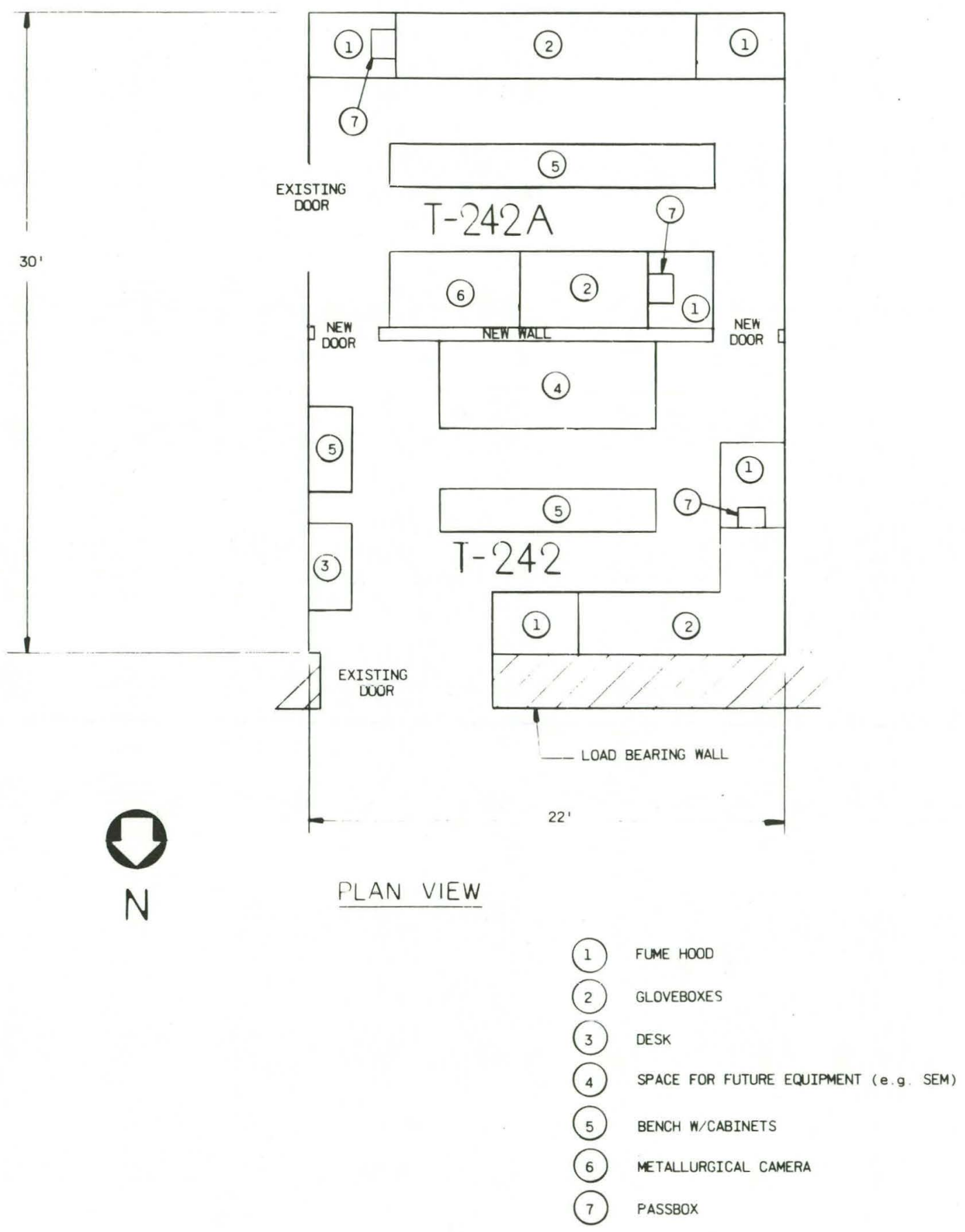

Figure 2-17 


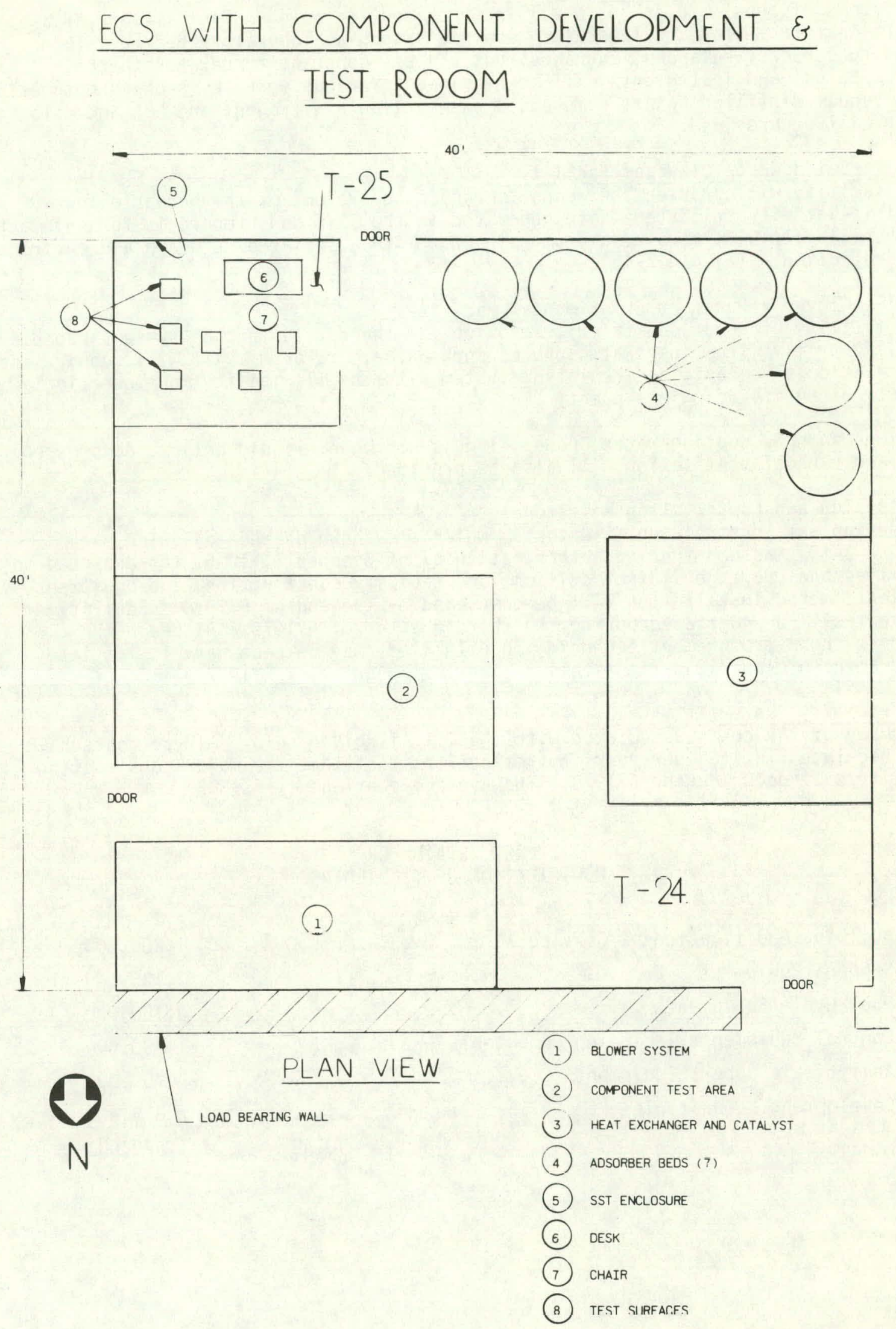

Figure 2-18 


\subsubsection{General Purpose Cold Facilities}

Four rooms of about $200 \mathrm{ft} 2$ each will be provided for cold analytical work of a general nature. Standard laboratory equipment such as laboratory benches, fume hoods, gas racks, balances, furnaces, hot plates, constant temperature baths, vacuum pumps, and instruments will be required. Various services such as compressed air, vacuum, distilled water, compressed gases, liquid nitrogen, and hot and cold water will be provided.

\subsubsection{Solid Waste Disposal Facility}

This facility will provide the means to reduce the volume of the burnable lowspecific-activity tritiated waste generated in the TSTF and prepare it for shipment and burial. It will require a drum compactor with associated hardware and environmental protection (Figure 2-16).

\subsubsection{Glovebox Purifier Experimental Facility}

This facility of about $400 \mathrm{ft}^{2}$ will provide for the development of systems capable of removing tritium from inert atmospheres such as $\mathrm{He}$, $\mathrm{Ar}$, or $\mathrm{N}_{2}$. It will require the installation of a basic recirculating system with the flexibility for inserting a variety of purification equipment.

Services such as cooling water, power, liquid nitrogen, liquid helium, compressed air, and exhaust ventilation will also be provided.

\subsection{Design and Construction Milestones}

The design and construction milestones, which are shown on the following page (Figure 2-19), assume funding authorization as of 0ctober 1, 1976. As depicted on the milestone chart, building modification, facility construction, and equipment fabrication and installation will be completed by the end of FYl978. Facility checkout will be completed during the third quarter of FY1979. Although the schedule shows procurement beginning in FY1978, it may be necessary to initiate procurement of long lead-time items in the last quarter of FY1977.

\subsection{Facility Costs}

A summary of the costs associated with the TSTF is given below. These costs have been escalated $12 \%$ ( $8 \%$ per year) to reflect the fact that the major construction activity will occur during FY1978. The average contingency is $35 \%$.

\section{COST DETAIL FOR \\ MODIFICATION OF T BUILDING}

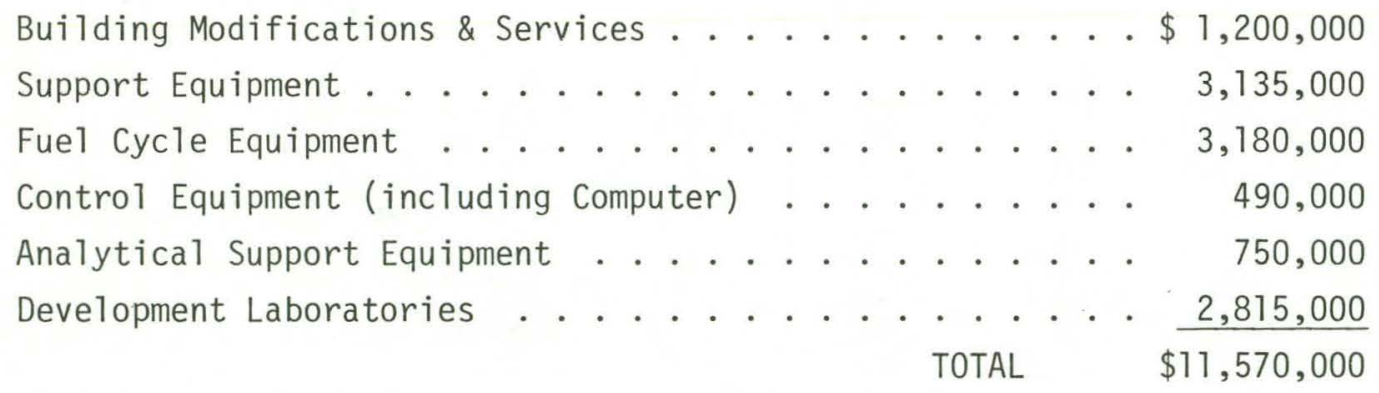




\section{FISCAL YEAR PLANNING}

THE FACILITY

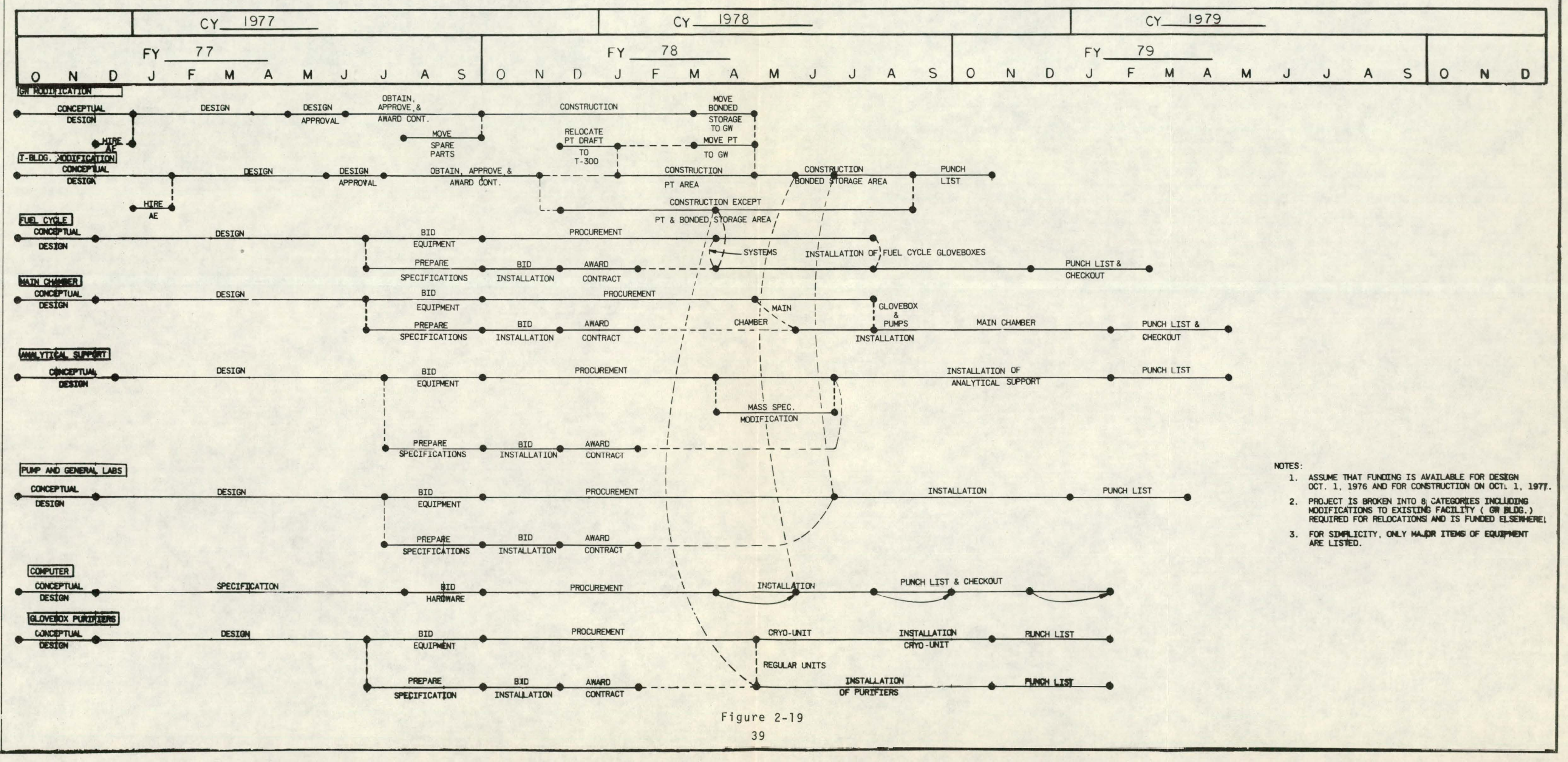


THIS PAGE

\section{WAS INTENTIONALLY \\ LEFT BLANK}


FY1977

Engineering Design

Equipment \& Installation

Construction

Contingency
$\$ 800,000$

$\$ 800,000$
FY1978-79

$\$ 223,000$

$6,657,000$

899,000

$2,991,000$

$\$ 10,770,000$

Four options which were considered for the TSTF have not been included. These options are desirable, but substantially increase the cost of the facility. They are described here for the sake of completeness, as it may be necessary at some time to include one or more of them in TSTF.

2.5.1 New Effluent Removal System (ERS)

An ERS dedicated to TSTF would be desirable, but the estimated cost of a new ERS with a $60 \mathrm{ft} 3 / \mathrm{min}$ capacity is $\$ 3,000,000$. By installing a dedicated, evacuated surge tank and connecting piping to the existing ERS in SW BIdg., the required protection is provided at a cost of $\$ 360,000$.

2.5.2 New Emergency Containment System (ECS)

A new $5000 \mathrm{ft}^{3} / \mathrm{min}$ ECS would be desirable to provide a five-fold increase over the size of existing air detritiation systems and hence a firmer base for extrapolation to an EPR system. The cost of this new system, including sufficient additional equipment to provide both building protection and experimental flexibility, is estimated to be $\$ 4,000,000$. The existing ECS can provide one air change in $3 \mathrm{hr}$ for the entire TSTF and the Development Laboratory. This is roughly the same as an EPR air cleanup system. The proposed mode of ECS operation for TSTF is to clean only the affected room(s) in the event of a spill, hence the recirculation rate will be higher than one change per $3 \mathrm{hr}$. The cost of modifying the existing ECS to provide experimental flexibility and building protection is $\$ 470,000$.

\subsubsection{Neutral Beam Injector}

As will be discussed in the section on the Experimental Program Plan, neutral beam injector simulation experiments are proposed for the TSTF. It is expected that a semi-scale injector will be designed in accordance with previously developed tritium containment criteria and will be constructed by or in conjunction with the ORNL or LLL neutral beam injection programs. Such a semi-scale injector is estimated to cost about $\$ 500,000$. The cost of the injector has not been included in this proposal because we have assumed the injector would be supplied by ORNL or LLL.

\subsubsection{New Building}

A new building would provide the opportunity to optimize the entire facility to the needs of the TSTF. The cost of a new building with $20,000 \mathrm{ft}^{2}$ of usable floor space $\left(40,000 \mathrm{ft}^{2}\right.$ gross space) is estimated to be $\$ 10,000,000$. TSTF equipment (including a new ERS and ECS) would increase the cost to a total $\$ 24,000,000$. A preliminary layout of such a new building is shown in Figure 2-20. A cost summary for the new building is given below. 
COST ESTIMATE SUMMARY FOR A NEW BUILDING AND PROCESS EQUIPMENT

Construction of Building \& Services.......... $\$ 10,000,000$ Support Equipment . . . . . . . . . . . . 7,955,000

Fuel Cycle Equipment . . . . . . . . . . . . 3,670,000

Analytical Support Laboratories . . . . . . . . . . 750,000

Development Laboratories . . . . . . . . . . . 2, 2,280,000

TOTAL $\$ 24,655,000$ 


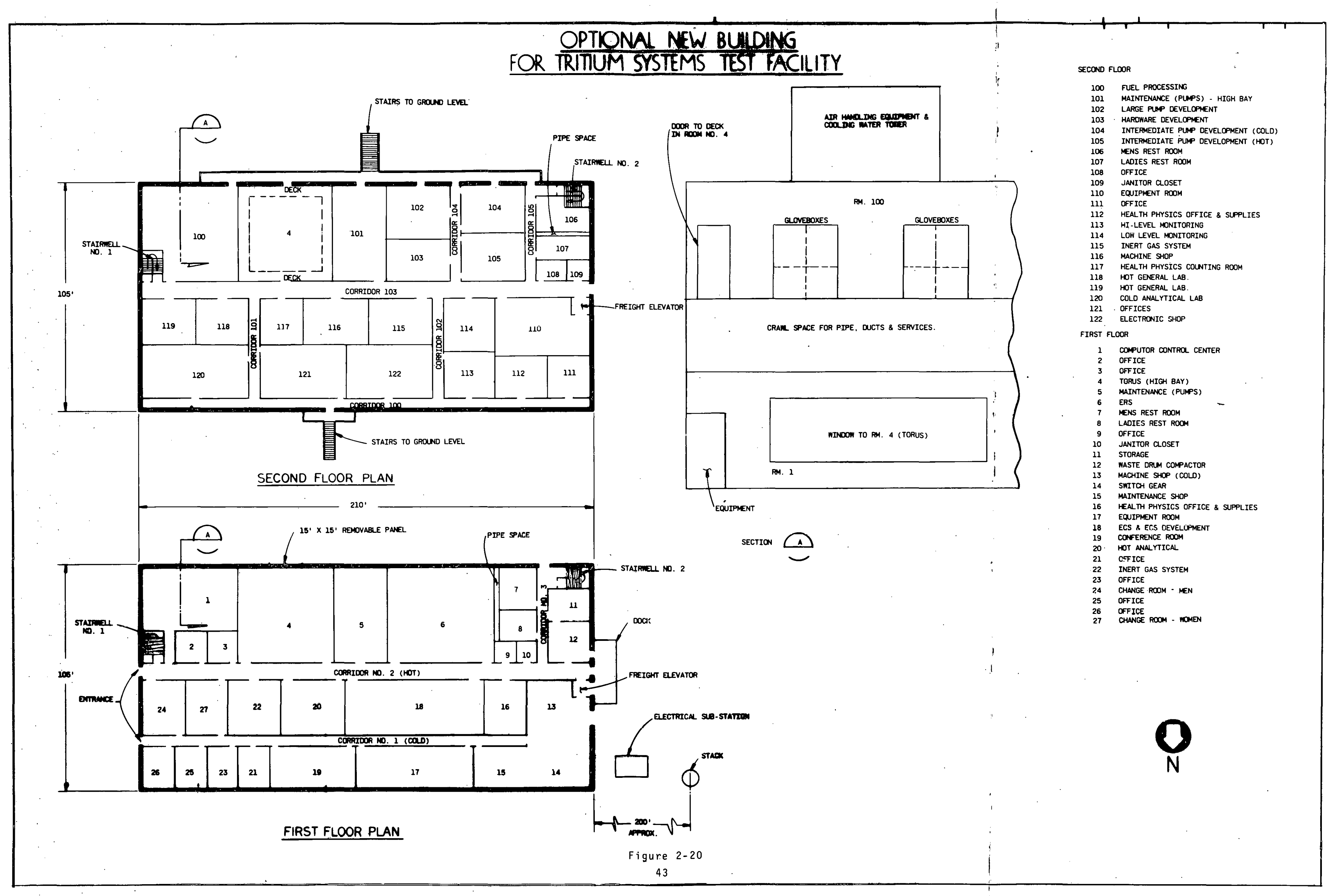


THIS PAGE

\section{WAS INTENTIONALLY \\ LEFT BLANK}




\section{Experimental Program}

The TSTF proposal by Mound Laboratory and Argonne National Laboratory has two principal objectives. The first objective is to provide a demonstration of the fuel cycle and tritium containment components which will be used to design a Tokamak experimental power reactor. The second objective is to provide a capability for further development of tritium processing and containment technology beyond that which is required for the EPR.

The scale and flow rates in TSTF are chosen to permit reliable extrapolation to the conditions found in an EPR, and the fuel concentrations will be the same as in an EPR. Demonstrations of individual components of the deuterium-tritium fuel cycle. and of the storage, transportation, and containment systems will be achieved at various times in the FY1979-80 time span. Subsequent to the individual component demonstrations - which will proceed from tests with hydrogen (and/or deuterium) through tracer levels of tritium to full operational concentations - a complete test and demonstration of the integrated fuel processing and tritium containment facility will be performed. This will occur near the middle of FY1981.

The second objective of this proposal - to develop advanced tritium control technology will be addressed at the outset of the program plan with the initiation of hardware development in cold work areas at Mound and Argonne. During the construction period and the preparation for the integrated system demonstration, some tests of hot systems will be possible as well, and both hot and cold programs will emphasize the identification of major problem areas which will require further research and development. beginning during FY1981.

The experimental program is divided into eight major areas. A description of each of the areas and its subelements and their relationship to the overall program objectives is presented following the outline given below. When funds for the TSTF are received, a detailed program plan will be developed. 
3.1 FUEL CYCLING AND CONDITIONING TECHNOLOGY

3.1.1 Debris Separation and Handling

3.1.2 Nonmetall ic El ement Separations

3.1.3 Isotopic Enrichment

3.1.4 Integrated Systems Tests with Fuel Cycle Simulator

\subsection{VACUUM SYSTEMS AND NEUTRAL BEAM INJECTORS}

\subsubsection{Neutral Beam Injection System Interfacing}

3.2.2 Vacuum System Interfacing

\subsection{COOLANT SYSTEMS}

3.3.1 Water Coolant

3.3.2 Helium Coolant

\subsection{SECONDARY CONTAINMENT AND ATMOSPHERIC SYSTEMS}

3.4.1 Secondary Containment Systems

3.4.2 Atmospheric (Tertiary) Containment Systems

3.4.3 Scrubber (Detritiation) Systems.

3.4.4 Integrated Systems Tests

\subsection{MATERIALS AND HARDWARE VERIFICATION}

\subsubsection{Materials Development and Testing*}

3.5.2 Hardware Development

*Coordination with DMFE Materials and Radiation Effects Branch. 


\subsection{BULK FUEL TECHNOLOGY}

3.6.1 Fuel Storage

3.6.2 Shipping

3.6.3 Safeguards

\subsection{FNVIRONMENT AND SAFETY}

3.7.1 Plant Monitoring

3.7.2 Environment Monitoring

3.7.3 Safety Analysis of Entire Fuel Cycle

3.7.4 Waste Disposal and Retrieval

\subsection{INSTRUMENTATION AND CONTROL SYSTEMS}

3.8.1 Fuel Cycle Diagnostic Systems Development

3.8.2 Integrated Tritium Facility Maintenance, Control and Response Systems

3.8.3 Verification of Monitoring in Anticipated Power Reactor Radiation Environments 
A principal objective of the TSTF program will be the development and verification of fuel recycle and conditioning technology for DT burning fusion reactors. Early efforts will identify and test processing methods and hardware technology. Later, a total simulation of the design basis fuel cycle for the first DT fueled experimental reactor will be conducted at the site of the TSTF. The major program elements for this facet of TSTF operations are summarized below.

\subsubsection{Debris Separation and Handling}

The harsh radiation environment anticipated for the first wall of an experimental fusion device is likely to cause sizable quantities of fine particulate metal and metal compounds to be dislodged. Although most of this debris is expected to either settle out or reattach itself to the first wall, plans must be made to accommodate the migration of some particulate material into and beyond the vacuum pumps. Because the first wall will become highly radioactive after only a few days of operation at modest wall loadings $\left(0.2\right.$ to $\left.1.0 \mathrm{MW} / \mathrm{m}^{2}\right)$, the debris will be highly radioactive and maintenance of the vacuum pumps and the equipment immediately downstream of them will become quite complex. Although debris in the torus exhaust gases will undoubtedly adversely effect pump lifetime and performance, attempts to filter the debris in advance of the vacuum pumps (between the plasma chamber and the pumps) could lead to unacceptably large conductance losses. During cryopump regeneration, the release characteristics of the adsorbed gases on the cryopanels will determine whether the debris deposited on the panels is fluidized and carried beyond the pumps themselves.

The selection of a debris separation scheme will depend on characteristics of the particle dispersoids that are not yet understood. In the event that large quantities of debris greater than $5 \mu \mathrm{m}$ in size are present in the pump intake gases, it may be necessary to remove them in advance of the pumps with a low pressure drop separator, such as a cyclone separator or an electrostatic precipitator. However, selection of the final separation equipment will depend on the results of studies of particle dynamics in the spent fuel. In the near term, debris transport simulation studies will be conducted in a cold laboratory to identify the type of equipment needed and its proper location in the purification system. Ultimately debris separation will be proof tested on the TSTF.

\subsubsection{Nonmetallic Element Separations}

The presence of helium, oxygen, carbon, nitrogen, and other nonmetallic impurities in the exhaust of a DT burning reactor will for all practical purposes be unavoidable. In order to reduce impurity levels in the preburn fuel mixture as low as possible, it will be necessary to continuously remove nonmetallic elements in the plasma exhuast.

Early studies of impurity removal will focus on selection of catalysts and/or getters designed to 1) crack hydrocarbons and other hydrogeneous materials, and 2) adsorb carbon monoxide, oxygen, water vapor, nitrogen, etc., in a fixed form suitable for disposal. The selection of impurity trapping methods will be based on optimum specific efficiencies, heats of adsorption, adsorption and desorption kinetics, and impact on vacuum systems performance. Anticipated impurity levels in reactor fuel recycle streams will be simulated and their effect on system performance will be analyzed. Efforts will also be directed towards selection or development (as appropriate) of getter-bed or adsorber-bed technology which minimizes energy consumption and size and maximizes regeneration efficiency, ease of replacement, and maintenance. As the presence of helium in the cryogenic distillation cascade is expected to degrade fractionating efficiency, appropriate methods will be determined. for removing helium in advance of the distillation cascade, e.g., using palladium diffusers, countercurrent stripping columns, and/or selective adsorption. All the processing methods and conditioning systems will be subjected to rigorous testing programs on the TSTF. 


\subsubsection{Isotopic Enrichment}

The methods employed for isotopic enrichment of the spent fuel in a DT burning reactor will depend to a large extent on the relative isotopic concentrations. quantity and nature of the fluids involved will determine whether batch or continuous procedures should be used. Although there are several methods, such as cryogenic distillation, chromatography, electrolysis, laser stimulated separation, and thermal diffusion that can be used for separation and enrichment of the hydrogen isotopes, economy and reliability will undoubtedly dictate which method is adapted for each enrichment application. In this connection, cost/benefit and reliability studies will be conducted.

Considering the large spent fuel flow for even an experimental scale reactor, cryogenic distillation appears to be the most practical, reliable, and economic method for mainstream enrichment. Early studies in the TSDL will seek to confirm that the requirements for isotopic purity and isotope ratio adjustment can be met using appropriately designed cascades of cryogenic columns and isotopomeric equilibrators. In the prototype fuel cycle simulation studies, all aspects of the enrichment for DT fueled reactors will be verified. This will include tests of on-line adjustment capabilities for variations in fuel stream compositions.

Another feed requiring isotopic enrichment will come from the tritium recovered from waste streams, such as the glovebox purification system. Recovery and recycle of this tritium will be a long-range objective of the TSDL. Hydrogen isotopes recovered from these waste streams must be chemically purified before they are used as feed for the isotopic enrichment process. Feasibility studies and experimental tests will be needed to demonstrate the lowest tritium concentration in the feed for which it is economically or environmentally practical to recover the tritium.

\subsubsection{Integrated Systems Tests with Fuel Cycle Simulator} Identifying processing steps and selecting equipment for fuel cycle processing operations are only the first steps in designing a complete system. Although individual components or equipment items may function satisfactorily as single units, it is essential to determine how they will function in an integrated system. During the development stages while many parallel efforts are being pursued for individual processing steps, it will be necessary to begin determination of the interfacing requirements in preparation for the integrated systems tests.

Once the above steps have been completed, an integrated fuel cycle demonstration will be performed incorporating simulated plasma chamber operating conditions. As the precise nature of reactor burn cycle conditions is not known, it will be necessary to study the system response to operating variables, such as base pressures, temperature, impurity concentrations, flow rates, and dispositions of the hydrogen isotopic species. Both normal and off-normal conditions will be investigated to ensure the successful operation of an integrated unit. In conjunction with fuel cycle verification, the proposed startup and shutdown sequence, the instrumentation and control systems, and the range of safe operating limits for all processing equipment will be investigated. 


\subsection{Vacuum Systems and Neutral Beam Injectors}

In addition to the fuel circulation and process hardware and the various containment devices, there are other special systems, essential to the operation of a DT fueled experimental reactor, that will interface directly with the tritium systems. Two such systems are neutral beam injectors and the plasma chamber evacuation pumps. Some programmatic considerations related to the study of these special systems within the TSTF framework are summarized below. As other essential reactor systems that have a direct interaction with, or that have access to, the tritium systems are identified, they too will come under study in the TSTF.

\subsubsection{Neutral Beam Injection System Interfacing}

Recent conceptual design studies have shown that experimental tokamak and mirror reactors may require energetic particle insertion to reach ignition. As currently conceived, the neutral injector systems that would be used to provide these energetic particles represent a direct access to the plasma chamber, and hence to the tritium contained in it during a burn cycle. The beam line, the neutralizer, and the accelerator itself are all subject to tritium backglow from the plasma chamber. Thus tritium can enter the neutral beam pumping systems and the neutralizer vapor circulation system, and pass through the electrostatic grid structure into the grid coolant.

The objective of neutral injection experiments performed in the TSTF will be to identify significant tritium interactions and to evolve and test designs that will permit the making of a workable injector/reactor interface. This effort will include the determination of tritium containment criteria for neutral injectors and the development of a maintenance methodology for tritium contaminated injector systems. Early neutral injector studies in the TSTF will be devoted to detailed analyses of the neutral injector concepts presently being developed at ORNL and LLL, e.g., for the TFTR. This phase will be followed by injector/reactor simulation tests using an operational semi-scale neutral injector in conjunction with the toroidal section test chamber. To conduct these simulation tests, it is expected that the semi-scale injector would be designed in accord with previously developed tritium containment criteria and would be constructed by or in conjunction with the ORNL or LLL neutral injection programs.

\subsubsection{Vacuum System Interfacing}

The large, high-speed primary and roughing vacuum systems required on the plasma chambers currently envisioned for magnetically and inertially confined fusion devices will be subjected to massive continuous and/or pulsed tritium flows. Major problem areas that warrant study with respect to these pumping operations relate to large instantaneous inventories (in the case of sorption and getter pumps), leakage through shaft seals (in the case of mechanical pumps), and contamination (in the case of oil or mercury diffusion pumps). On the TSTF, experiments will be done to evaluate the relative merits of mercury diffusion, turbomolecular, cryosorption and getter pumps for the toroidal and neutral beam vacuum systems, assess the magnitude of the problem of regenerating pumps in the tritium processing and recovery circuit, develop a methodology for maintaining vacuum systems employing tritium, and develop advanced vacuum pumping techniques as required. Based on the technology that is developed through these activities, prototype pump units will be designed, constructed and tested on TSTF for performance verification. 


\subsection{Coolant Systems}

Although the major detritiation challenges associated with tritium breeding power reactors will not be encountered on DT fueled reactors during the 1980's, coolant systems for these early reactors can be expected to become tritiated as a result of permeation through coolant system walls. Both helium and water are still possible coolants for experimental power reactors.

\subsubsection{Water Coolant}

The initial research effort on water coolant will include a study of CANDU heavywater operating experience, a comparison of closed versus open cycles, and a study of disposal versus detritiation options within the open cycle scheme. The emphasis of this study will be on containment, reliability, and benefit/cost ratio optimization.

A water coolant loop which combines current US and Canadian technology will be tested on TSTF and will permit study of tritium buildup rates and verification of operating strategy performance. Existing Mound Laboratory programs (funded by DMA and DNFC\&P) for water detritiation will continue, and as advances are made they will be incorporated into TSTF. The ultimate goal of these efforts is the recovery of tritium from water at all levels down to RCG and below.

\subsubsection{Helium Coolant}

In the case of helium coolant, the principal early effort will be to select systems capable of effectively and continuously removing tritium from the coolant. This will include study of getters, oxidation-drying, and cryogenic adsorption. Isotopic swarnping may also be advantageous in a helium atmosphere and this method will be investigated. A helium coolant test loop will be available on TSTF. An experimental verification of the performance of promising methods of tritium scavenging will be conducted on the test loop.

\subsection{Secondary Containment and Atmospheric Systems}

\subsubsection{Secondary Containment Systems}

Secondary containment in TSTF will consist of gloveboxes, fume hoods, portable enclosures, and integral jackets. The nature of the device that is to be enclosed will generally determine the nature of the enclosure; e.g., fume hoods will be used to enclose equipment that rarely contains tritium, integral jackets will be used for long pipe runs, and gloveboxes will enclose apparatus that requires frequent manipulation. Current technology appears adequate to meet the secondary enclosure requirements of the EPR, although in some cases, for example, around the neutral beam injectors, considerable ingenuity will be required to ensure both accessibility and tritium containment. Thus in the early stages of TSTF operation, standard Mound Laboratory containment procedures will generally be employed.

Some secondary containment development will occur later as the needs of the EPR systems are identified, but the majur effort on developmient wi 11 occur after 1980. At this time, emphasis will be on improved seal integrity and resistance to radiation damage, reduced permeation through elastomers, and development or cust effective containment methods. Examples of the latter include portable and temporary enclosures which will permit rapid maintenance while preventing tritium release and comparisons of alternate containment atmospheres and cleanup systems. 


\subsubsection{Atmospheric (Tertiary) Containment Systems}

Tertiary containment and air detritiation systems which are adequate to satisfy EPR requirements can be specified today, but the question of whether they will scale predictably has not been answered. Hence, a major aspect of TSTF will be the demonstration of a large (1000 $\left.\mathrm{ft}^{3} / \mathrm{min}\right)$ air detritiation system (ECS). This is of the order of 1/10-1/100 of the flow rate that will be required in the EPR and is large enough to permit adequate design of the EPR air detritiation system.

Although the ECS will be designed to operate on one room at a time, the construction of the ECS will permit tests of detritiation of the entire Tritium Systems Development Laboratory. In this way progress can be made in solving one of the principal longterm problems of large-scale air detritiation systems, i.e., reducing the cost.

Unless one assumes that the reactor hall atmosphere is to be ventilated directly to the outside without tritium processing, the cost associated with the necessary EPR detritiation system is very high, principally because of the cost associated with catalysts and adsorbers capable of handling air flows of $>10^{4} \mathrm{ft}^{3} / \mathrm{min}$. These costs are generally independent of whether the system is used for continuous air processing or only for emergency processing. Long-term tertiary containment development efforts will be directed, therefore, toward optimizing air flow patterns or otherwise preventing remixing of processed and unprocessed air, minimizing room cleanup times, and reducing system costs.

\subsubsection{Scrubber (Detritiation) Systems}

In the long term, there is a need for development of the hardware which performs the detritiation function in secondary and tertiary containment systems. A sensitivity analysis of alternate secondary containment atmospheres and detritiation schemes will be performed. Candidate atmospheres include argon, nitrogen, and helium, and detritiation schemes include cryogenic adsorption, chemical getters, and oxidation-drying. In addition, there is the option, which will be used initially in most TSTF gloveboxes, of maintaining a dry, oxygen-free atmosphere and detritiating only in case of a release. Development work on tertiary systems scrubbers will focus on improving catalyst and adsorber efficiencies; minimizing the dilution of tritium during cleanup operations; developing an adsorber regeneration methodology; and determining the effects of temperature, humidity, and impurity levels on system pertormance.

\subsubsection{Integrated Systems Tests}

A smal1, release test room will be constructed which will be dedicated to the study of atmosphere detritiation campaigns and equipment decontamination. This room which will have a volume of $1200 \mathrm{ft}^{3}$ will have a stainless steel liner and will be sealed to prevent tritium leakage from the room. Thus, deliberate high-level $\left(\sim 1 \mathrm{Ci} / \mathrm{m}^{3}\right)$ tritium release tests can be performed in this room without risk to the remainder of the laboratory.

Although most of the containment systems will be of conventional design, an integrated test of secondary and tertiary containment systems will be performed in conjunction with the fuel cycle integrated system test. This will involve deliberate small tritium releases designed to simulate failure of various primary fuel cycle components. 


\subsection{Materials and Hardware Verification}

\subsubsection{Materials Development and Testing}

The successful development of tritium handling facilities for near-term fusion devices will rest heavily on the applicability and suitability of existing materials and fabrication technology: This aspect of the TSTF program will seek 1) to identify appropriate materials for individual tritium systems applications, 2) to establish specifications for materials procurement, and 3 ) to investigate unique materials requirements in areas where solutions are not readily available. All materialsrelated research and development will be closely coordinated with parallel activities conducted under the auspices of the DMFE Materials and Radiation Effects Branch. In particular, because the TSTF, as conceived in this proposal, will not accommodate radiation effect tests, the consequences of irradiation on the performance of materials selected for tritium facilty applications will have to be determined by other laboratories in conjunction with the TSTF.

The selection and specification of materials for use in the fabrication of tritium handling systems for fusion devices must be made an integral part of the TSTF development. and testing programs. This includes 1) structural materials used in transfer lines, valves, pumps, vessels, secondary containment systems, and related hardware; 2) elastomers, gasket and sealing materials, lubricants, coating substances, paints, and other materials used in nonstructural applications. In the early phases of TSTF activities the materials selection process will be based largely on existing experience. As TSTF operations progress towards the prototype testing stages, formal specifications for all materials to be used in direct tritium service will be drafted. The principal objective of this portion of the materials development and testing program is to establish quality assurance criteria for materials procurement phases of subsequent experimental reactor programs.

During the course of TSTF operations many materials requirements will emerge for which solutions are not readily available. The TSTF and associated programs will be structured with the flexibility required to address these problems as they arise. Two problem areas which have already been identified are described below:

One area of need is for effective barriers to tritium permeation in elevatedtemperature $\left(>300^{\circ} \mathrm{C}\right)$ metallic structures. Examples of reactor systems where such barriers will be required include 1) first wall assemblies, 2) primary and intermediate piping and heat exchangers that interface with the first wall and blanket coolants, 3) portions of neutral injector systems that operate at elevated teiiiperalures, and 4) ilners for high temperature getter traps. In this connection, current DMFE studies in this area will be expanded in scope and incorporated where appropriate into the program for the TSTF. Promising barrier materials and concepts would be tested in conjunction with and as part of the TSTF simulation studies. Concepts currently under study, which include ceramic coatings, vapor-deposited layers, laminates, and related preparations, would be tested in the early stages of the TSTF program.

A second area of materials need relates to the rate of tritium adsorption onto and migration into the exposed exterior surfaces of reactor hardware and the interior surfaces of conldinment bulldings following possible accidental tritium releases within the fusion reactor facility. Although the development and demonstration of rapid clean-up technology is a high priority undertaking of the TSTF, there is little evidence to guarantee that massive uptake of the released tritium by the surfaces within the reactor building will not complicate and/or unduly extend clean-up operations to the point of seriously jeopardizing their usefulness. It is possible that by judicious selection of construction materials; by careful adjustment of temperature, humidity, and related conditions of exposed surfaces; and 
through the development of effective surface preparations and/or coating procedures, the rate of tritium uptake by these surfaces could be greatly reduced. In particular, the development of hydrophobic coatings or paints will be included in the near-term program in the TSTF.

Fabrication techniques must be developed for the assembly of the individual components into a complete fuel cycle system. Based upon existing experience, it is anticipated that connections and joints for the TSTF will be made by welding, whenever possible, because threaded connections cannot be used on the primary system. Metal seals on flanges may be satisfactory but polymer seals must be avoided. Demountable connections will generally use compression fittings employing metal-to-metal seals. Specifications for these joining operations need to be written for the TSTF installation. The entire primary and secondary systems must be helium leak-checked according to established procedures before tritium is admitted to the system. Extra valves will be installed in order to isolate the sections of the system during leak checking and to provide a means of replacing malfunctioning equipment during operation. Because cost limitations will be a major factor determining the commercial feasibility of fusion power, cost/benefit factors and related economic incentives will be considered for selection and qualification of all materials.

\subsubsection{Hardware Development}

Both short-term and long-term development programs for hardware required for tritium service in fusion reactors will be pursued at Mound and Argonne. At this time, it is expected that development will be required for valves, compressors, pumps, and traps for tritium service in an EPR. Some general criteria will be specified as the design objectives of these hardware items. In most cases, items will be designed which are fully welded structures rather than constructed with hermetic seals. Where rotating or sliding seals are required, the use of such techniques as magnetic-coupled drives will be considered. These seals and their lubricants must not add any contaminant to the flowing fluids. The hardware items will be designed to prevent tritium loss upon failure as well as to provide the more usual safety features. Specifications and quality assurance procedures will be developed for each piece of hardware.

Valves for tritium use at both atmospheric pressure and vacuum have generally been of all welded construction with a metal bellows in place of a shaft seal. For the EPR, large, high-conductance valves which are suitable for tritium use will need to be developed. In addition to tritium, these valves may be required to withstand very high $\left(300^{\circ} \mathrm{C}\right)$ or very $10 \mathrm{w}\left(-100^{\circ} \mathrm{C}\right)$ temperatures, high magnetic fields, or the effects of neutron irradiation. As such valves are developed they will be tested in the TSTF fuel cycle.

Metal diaphragm compressors have been successfully used for tritium work but their flow rates need to be increased. Mechanical pumps and metal hydride-sorption pumps al so need to be developed and tested for hydrogen isotopic gas mixtures. Mechanical pumps will require the use of special shaft seals or seal enclosures to reduce the leakage of tritium. Another type of pump will need to be developed to transfer tritiated liquids such as water or pump oils for detritiation processing or disposal. Early TSTF development efforts will focus on identifying promising areas for pump development. Later efforts will focus on pump and hardware development and testing. The TSTF fuel cycle will serve to verify the performance of hardware which is developed.

Trap development will include studies on absorption beds to remove the tritium from a flowing fluid stream or to remove impurities from a flowing tritiated fuel stream. These traps need to be designed for high flow rates and low pressure drop. Also, methods to regenerate the traps and quantitatively recover the tritium will be developed. 


\subsection{Bulk Fuel Technology}

Existing tritium storage and shipping technology is adequate to serve current, nonMFE requirements; but the advent of fusion power reactors and, later, tritium-breeding reactors may impose new restraints on storage and shipping systems, principally from the point of view of safety.

\subsubsection{Fuel Storage}

During the demonstration phase of TSTF, tritium will be stored either on hydride beds or as a low pressure $(<2 \mathrm{~atm})$ gas in cylinders. Both types of storage facilities will be provided as there is no clear basis for choosing either at this date. The safety and reliability of these two systems and of other possible storage systems (e.g., cryogenic or high pressure gas) will be evaluated with rogard to possible accident situations.

\subsubsection{Shipping}

Tritium shipments from production facilities to an EPR may occur frequently because of the lack of breeding in an EPR. While tritium shipping containers do exist which meet DOT and ERDA regulations, a fusion economy may require new standards and new containers. The TSTF staff will assist in establishing new standards for shipping and will perform the necessary tests to verify the compliance of any new containers. with federal regulations.

\subsubsection{Safeguards}

As tritium is a strategic nuclear material, and hence accountable, safeguards accountabilility systems must be developed to verify tritium inventories. The objective of this effort will be to devise a measurement system for the timely control and verification of the SNM process plant inventory that is sensitive to changes for safeguards purposes, meeting current and further ERDA and NRC requirements.

Mound Laboratory is currently funded for devising such systems by ERDA/DSS and NRC/ONRR. The results of these studies are directly related to fusion reactor systems and will serve as the base for fusion systems application.

\subsection{Environment and Safety}

\subsubsection{Plant Monitoring}

Mound Laboratory has an existing program for monitoring work areas, personnel, and the environment surrounding the laboratory. The existing plant program will meet the needs of TSTF with the addition of new air and water monitoring points within the facility and the monitoring of TSTF personnel, beginning when tritium is introduced to TSTF. Because TSTF operations differ from past tritium operations in some respects, it is expected that some modifications to present practice will be required. A review of existing practices and personnel exposures will occur in FY1981 to identify new operating procedure requirements.

\subsubsection{Environment Monitoring}

Off-site monitoring will continue with present practices during TSTF operation. Improved monitor sensitivity will be required to distinguish variations in off-site tritium concentrations at current and expected future release rates. Atmospheric modeling studies, if required, will be performed after completion of the TSTF demonstration, as the quantities of tritium contained in and the release rates from near-term fusion reactors are expected to be well below later values.

\subsubsection{Safety Analysis of Entire Fuel Cycle}

A detailed safety analysis of the entire fuel cycle will begin early in the TSTF program with a completion milestone in FY1980 followed by updates as they may be required by system modifications. 
3.7.4 Waste Disposal and Retrieval

Waste disposal in TSTF involves two categories: 1) low-volume waste from containment systems, vacuum pumps, and the like, and 2) high-volume waste as may be generated in the coolant test modules. In the first case, the existing effluent removal system (ERS) at Mound Laboratory is adequate to service TSTF. Waste gases, liquids, and solids will be transported from TSTF to the existing waste disposal area for processing.

Tritium waste which is generated in the coolant test modules will be the subject of coolant system development efforts. In the event amounts of wastes are generated beyond that which these development programs can safely manage, these wastes will be processed by the ERS.

In addition, the waste disposal program will be correlated with progress in isotopic enrichment of low-level aqueous waste achieved by existing Mound programs and with fuel cycle and containment system enrichment programs in TSDL.

\subsection{Instrumentation and Control Systems}

The development and testing of instrumentation and control systems will be a vital part of the program to establish the tritium handling and control technology required for near-term and longer-range fusion devices. This facet of TSTF operations will include the research and development required to verify 1) on-line diagnostic and assay systems for the fuel cycle, 2) monitoring and surveillance systems for the secondary and tertiary containment systems, 3) response systems and methodology to cope with off-normal events, and 4) the overall sensing and logic circuitry required to operate and control all phases of tritium management at a fusion reactor.

3.8.1 Fuel Cycle Diagnostic Systems Development

Diagnostic requirements of the fuel cycle include measurement capabilities for 1) hydrogen isotope concentrations and isotopomeric distributions; 2) characterization and quantitative assay of nonmetallic elements; 3 ) flow rate, temperature, pressure, and related parameters; and 4) overall tritium assay to accommodate accountability commitments. Although state-of-the-art diagnostic practices will be employed in the early phases of the TSTF fuel cycle studies, it is expected that a need for systems with more rapid response and greater quantitative accuracy requires an advanced instrumentation development program.

Present analyses of hydrogen isotope concentrations, isotopomeric ratios, and nonmetallic impurities are accomplished by the use of cycloid-focusing mass spectrometers. The gases should be well mixed and fully equilibrated, which may require several hours. Gas samples are conveyed from outlying laboratories through metal capillary tubing to a central mass spectrometer sample cell. The presence of helium isotopes complicates the accurate measurement of hydrogen isotopic ratios by mass spectrometry. For accurate measurements, a titanium sublimation pump is used to remove all hydrogen from the sample. This permits quantitative determination of the helium interference and hence of the hydrogen concentrations.

In the TSTF, a very short time will be available for the analysis of the gases flowing in the fuel cycle simulator. Procedures must be developed which will permit rapid sample delivery and analysis. The decrease in precision of the analysis caused by the shorter time requirement must be determined. For certain locations in the fuel cycle, residual gas analyzers and/or laser Raman spectrometers will be located either in the main stream or very close to it. The effects of flow rates, temperature, and pressure of the gas samples must be determined for both residual gas analyzers and mass spectrometers. 
High precision analyses of nonmetallic volatile impurities in hydrogen gas mixtures are presently being accomplished by a gas chromatographic method developed at Mound Laboratory. Hydrogen isotopomeric ratios are also determined by this technique. A sample requires $20 \mathrm{~min}$ for an analysis, however. Techniques must be developed which will shorten the analysis time while retaining the accuracy for analys is of the nonmetallic impurities.

The concentration of hydrogen isotope oxides (water vapor) in gas samples must be accomplished by use of in-line moisture meters or other analyzers. The usefulness of commercially available moisture meters in a tritium atmosphere needs to be determined at various points of the fuel cycle as a function of flow rate, temperature, and pressure of the fuel mixtures.

The tritium content of the materials in discrete packages will be assayed calorimetrically in-line. Calorimeters must be developed and tested which will be able to measure the quantity of tritium at various storage points of the fuel cycle and to measure the tritium content of high level waste packages. Techniques need to be developed using the calorimeter supported by other analytical instruments so that a total assay and the location of all the tritium in the fuel cycie is known at all times to the personnel in the control room.

Accurate PVT measurements of gaseous mixtures involving tritium, such as hydrogen isotopes and helium mixtures, require special techniques and long equilibration times. Techniques need to be developed in the TSDL to reduce the time for these measurements without greatly sacrificing accuracy. The reliability of mass fiow meters to accurately provide required mixture of the hydrogen isotopes in the volumes required will be determined largely by use of the precalibrated PVT apparatus.

\subsubsection{Integrated Tritium Facility Maintenance, Control and Response Systems}

In the longer range, the TSTF efforts on instrumentation technology will focus on the sensing, logic, and response circuits required to control tritium facility operations. A fully automated approach to these operations will be pursued, with the aim of developing a rapid response, fail-safe system-control methodology that minimizes or el iminates human error, provides sufficient redundancy to nullify machine error, and accommodates all plausible failure modes without jeopardizing reactor operations or personnel safety. Integrally connected with this facet of the instrumentation development program will be a series of extensive fault tree analyses and failure mode studies of the entire tritium facility for a DT fueled fusion reactor.

3.8.3 Verification of Monitoring in Anticipated Power Reactor Radiation Environments Real-time ionization tritium monitors for work areas, stack effluents, and the environs are fairly well developed with sensitivity minima to $<1 \mu \mathrm{Ci} / \mathrm{m}^{3}$. Adapting these instruments for use within the intense neutron and gamma radiation fields of a fusion reactor will require considerable development.

Because of the high gamma-ray background expected near an operating fusion reactor, tritium monitors in use today will not be adequate. Also, the neutron flux near the fusion reactor would be so large that it could activate components of the monitor and permanently contaminate the instrument. For these reasons, the tritium monitors will probably be located remotely and be connected to the reactor enclosure by high velocity air sampling systems. A significant, but reduced, gamma and neutron flux may still exist near the monitors. Monitors need to be developed, therefore, which can compensate for moderate to low-level gamma and neutron fluxes. 
Another source of radiation interference for the tritium monitors in a fusion reactor will be the radioactive isotopes formed by neutron irradiation of air. The principal isotopes formed are $13 \mathrm{~N}, 16 \mathrm{~N}$, and $41 \mathrm{Ar}$, which are all beta emitters, as is tritium, with some accompanying gamma-rays. Because these isotopes have half-lives ranging from $7 \mathrm{sec}$ to nearly $2 \mathrm{hr}$, they will be swept through the gas sampling systems and into the remotely located tritium monitors. Some work has been reported on compensating for $41_{A r}$ interference; however, when ${ }^{41} \mathrm{Ar}$ exceeds the tritium concentration by more than 10:1, the tritium analyses become erratic and inaccurate. Considerable development work will be required, therefore, to provide sample cells and monitors which can discriminate between tritium and $13 \mathrm{~N}, 16_{\mathrm{N}}$, or ${ }^{4} \mathrm{Ar}$.

Analytical instruments such as mass spectrometers and gas chromatographs are known to operate satisfactorily in the presence of the beta radiation from tritium. Their usefulness in the presence of the neutron and gamma radiations near a fusion reactor is unknown. In most cases, these instruments will be remotely located or in shielded positions outside the reactor. The possible interferences caused by low flux fields. will be determined while these instruments are operating in the TSTF fuel cycle.

Tritium monitoring in high pressure helium coolants is another area where little information is available. Safety, design, response, and accuracy of ionization chambers for this type of monitoring will be developed.

\subsection{Program Planning}

A detailed program plan will be developed describing the experimental program and specifying when and where experiments will be done. This function will

also be concerned with 1) identifying the milestones that will be met; 2) assuring

that the overall program is complete and is responsive to the recommendations of

the advisory committee; and 3 ) guaranteeing that new and useful information developed in the RDD-, DPR-, NSF-sponsored projects is factored into the TSTF program.

As the research and development program advances, the program plan will be updated; hence the planning function will be conducted in parallel with the experimental R\&D program.

\subsection{Milestones}

Charts of work areas for the TSTF, roughly related to fiscal years, are presented in Figures 3-i through 3-4. These figures are intended as an aid for determining manpower levels, and hence do not contain milestone information. In addition to the manpower noted, one and one-half manyears in FY1977 and three manyears thereafter will be devoted to overall program planning.

Milestone charts for TSTF operations through mid-FY1981, with projections through FY1982, are in Figures 3-5 and 3-6. For the sake of simplicity, feedback interactions among various parts of the program are not shown. Updating of requirements is a continuing function with an additional milestone of an overall program update and identification of future requirements at the end of FY1980. Also included is a table of major milestones. 


\section{MAJOR MILESTONES}

\begin{tabular}{|c|c|}
\hline December, 1976 & Conceptual Design Completed \\
\hline June, 1977 & Engineering Design Completed \\
\hline October, 1977 & Construction Initiated \\
\hline January, 1979 & Construction Completed \\
\hline Apri1, 1979 & Shakedown (Punch List) Completed \\
\hline April, 1980 & Tests of Individual Components of the Fuel Cycle Completed \\
\hline October, 1980 & Demonstration of Containment Systems Components Completed. \\
\hline October, 1980 & $\begin{array}{l}\text { Future R\&D Requirements Identified for Optimization of Fuel } \\
\text { Cycle and Tritiuin Containment Systems }\end{array}$ \\
\hline October, 1980 & Coolant Loop Demonstrations Completed \\
\hline October, 1980 & Materials Development arid Testing - First Phase Completed \\
\hline October, 1980 & $\begin{array}{l}\text { Adequate Monitoring, Maintenance, and Waste Disposal for } \\
\text { EPR Demonstrated }\end{array}$ \\
\hline October, 1980 & Adequate Monitoring and Instrumentation for EPR Demonstrated \\
\hline Apri1, 1981 & $\begin{array}{l}\text { Integrated Systems Tests Completed (Fuel Cycle and Containment } \\
\text { Systems) }\end{array}$ \\
\hline
\end{tabular}


THIS PAGE

\section{WAS INTENTIONALLY \\ LEFT BLANK}




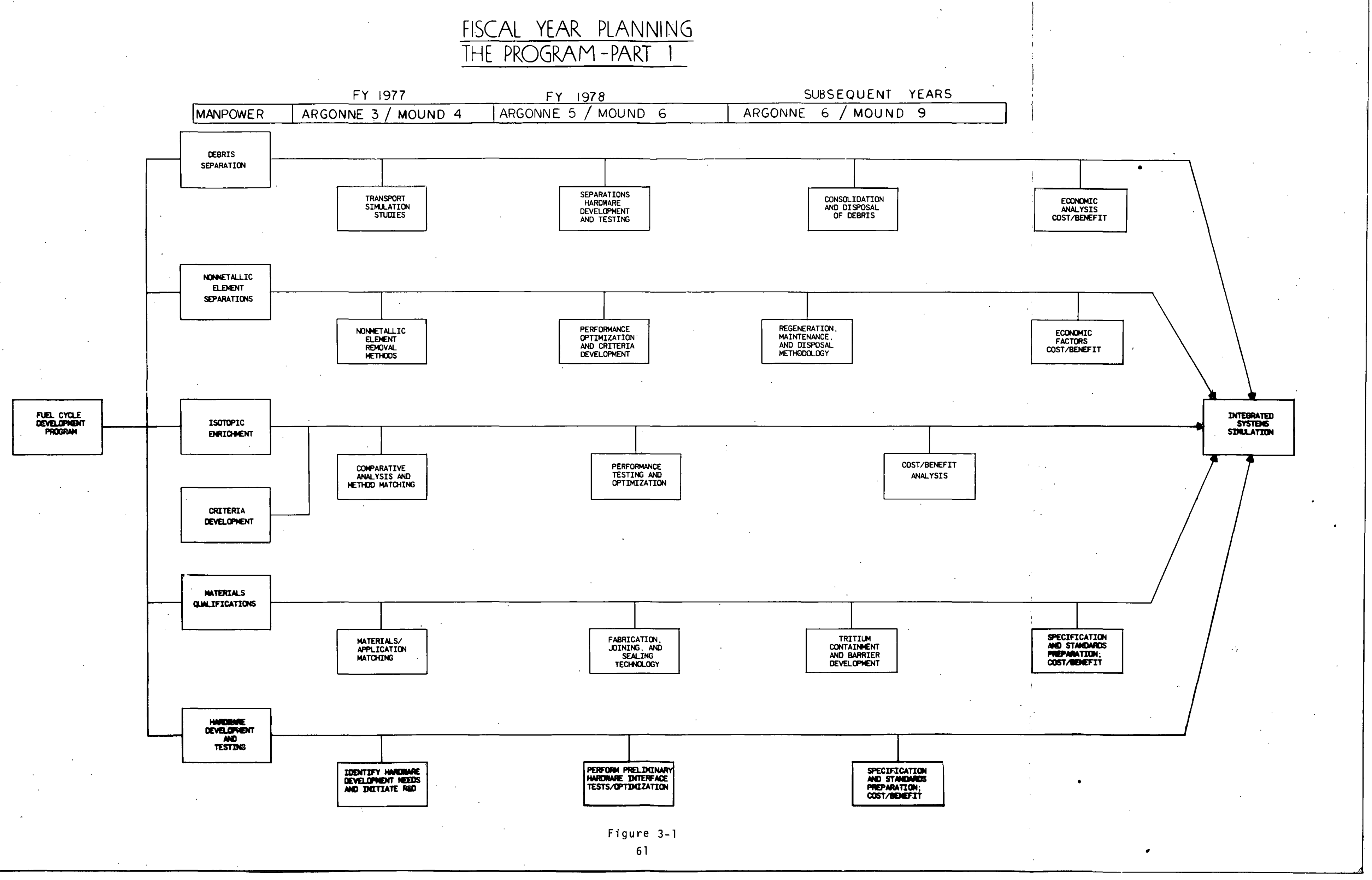


THIS PAGE

\section{WAS INTENTIONALLY LEFT BLANK}


FISCAL YEAR PLANNING

THE PROGRAM PART 2

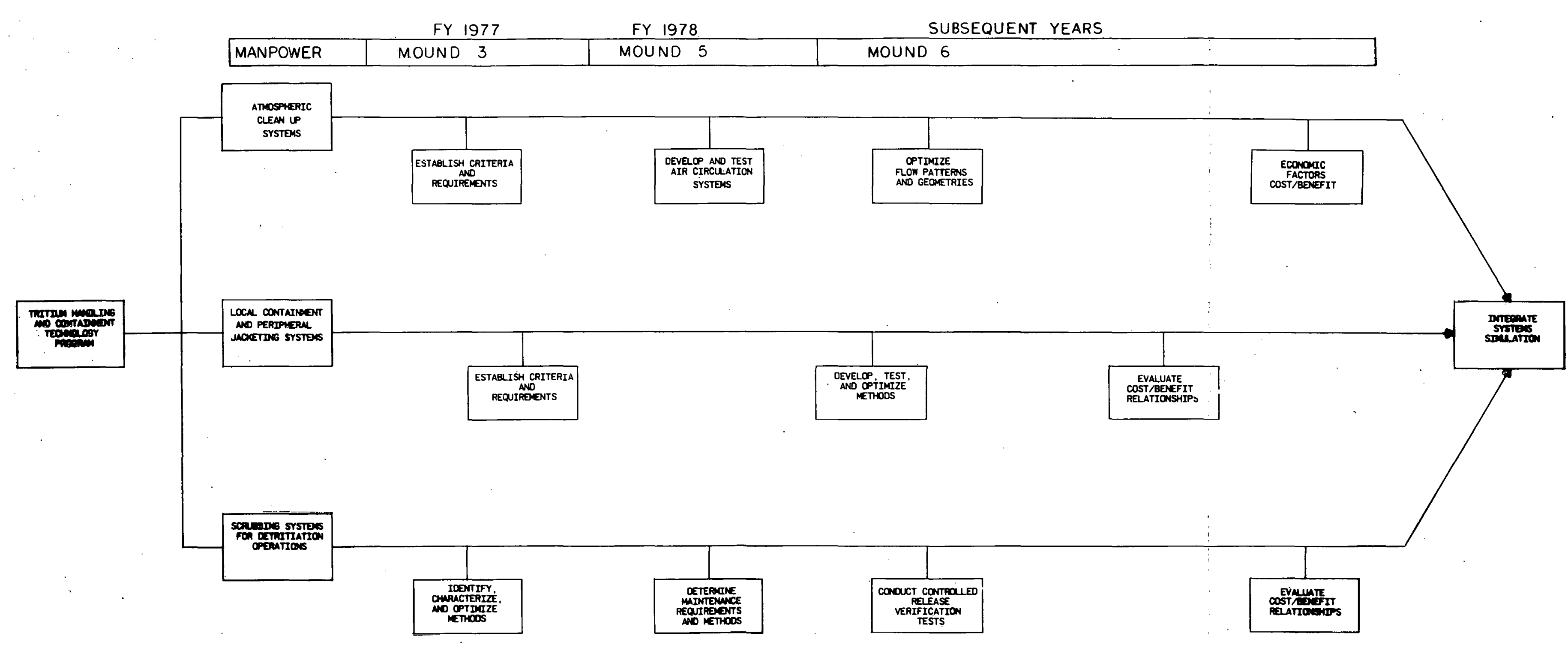


THIS PAGE

\section{WAS INTENTIONALLY \\ LEFT BLANK}


FISCAL YEAR PLANNING

THE PROGRAM PART 3

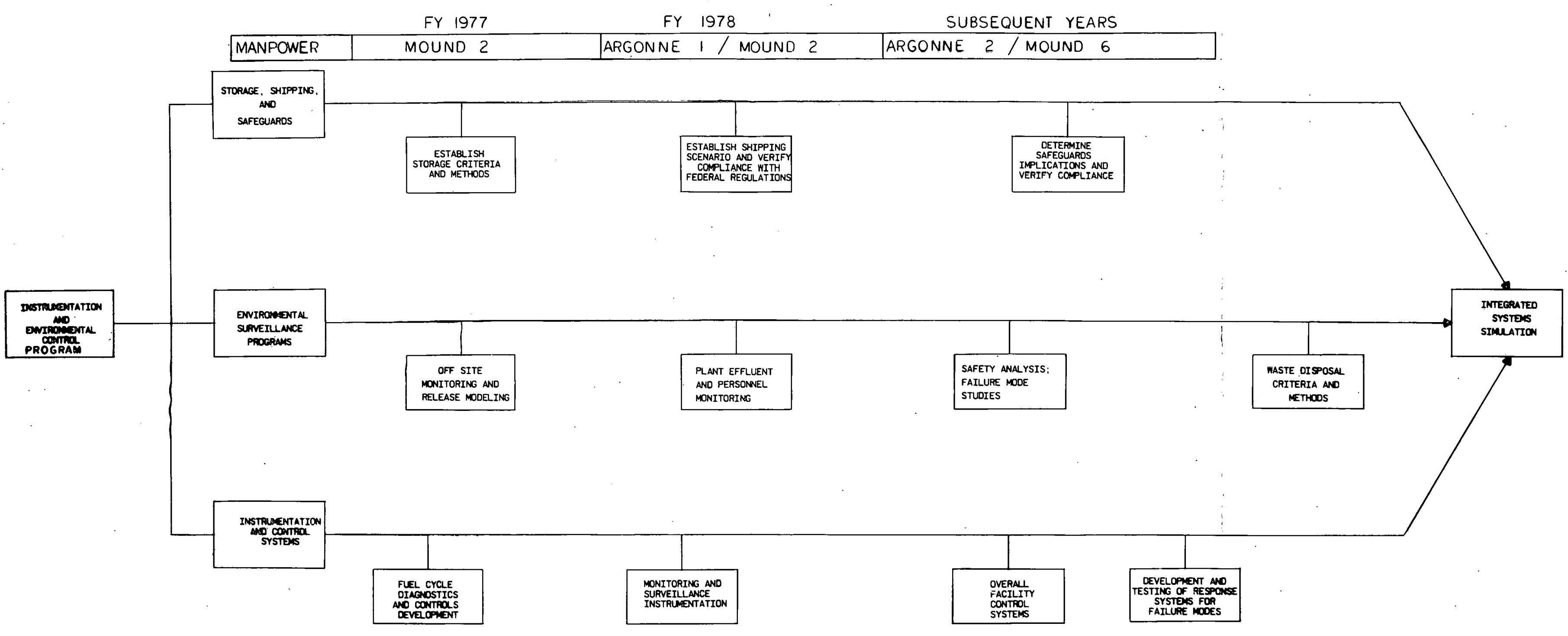


THIS PAGE

\section{WAS INTENTIONALLY \\ LEFT BLANK}


FISCAL YEAR PLANNING

THE PROGRAM PART 4

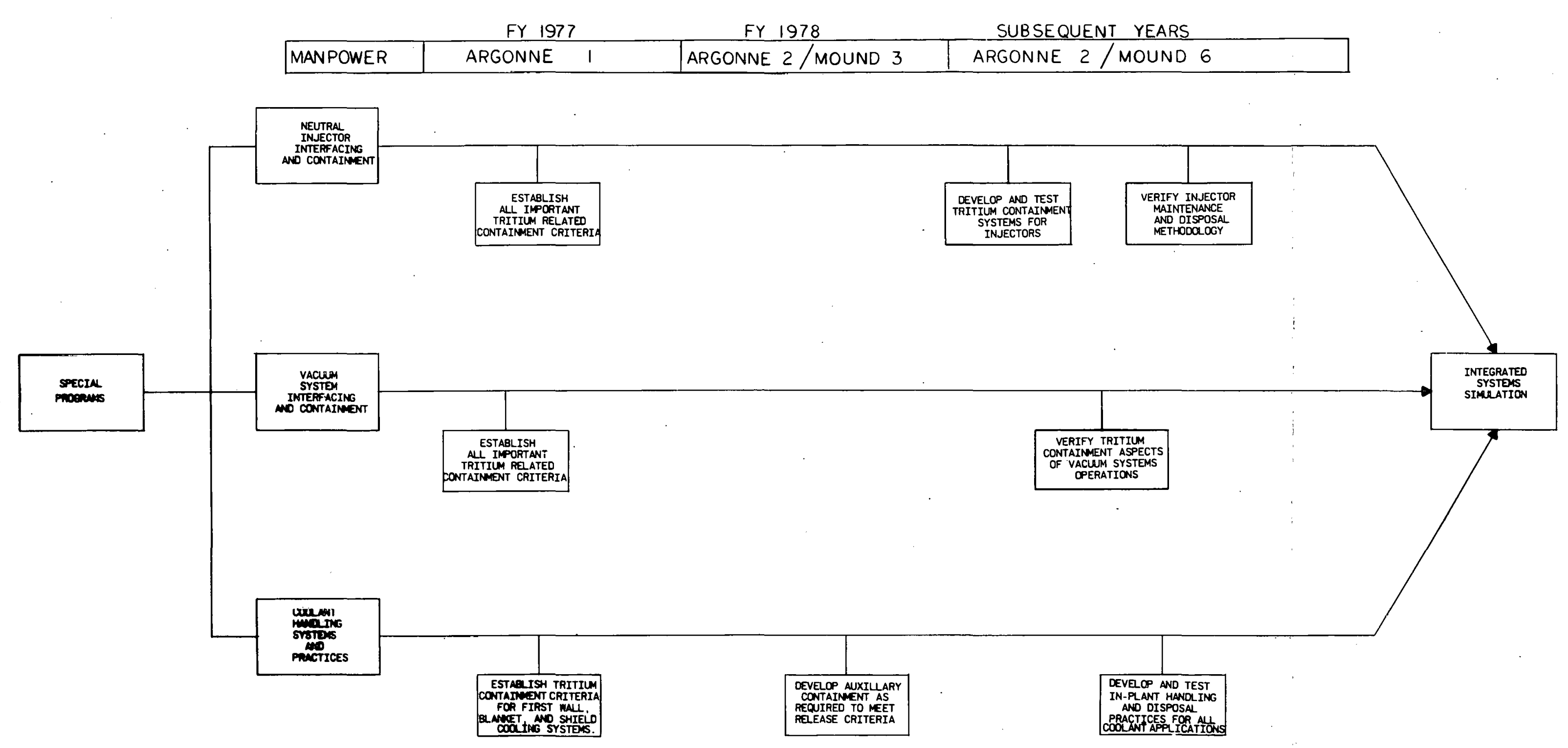


THIS PAGE

\section{WAS INTENTIONALLY \\ LEFT BLANK}




\section{FISCAL YEAR PLANNING}

THE PROGRAM PART 5

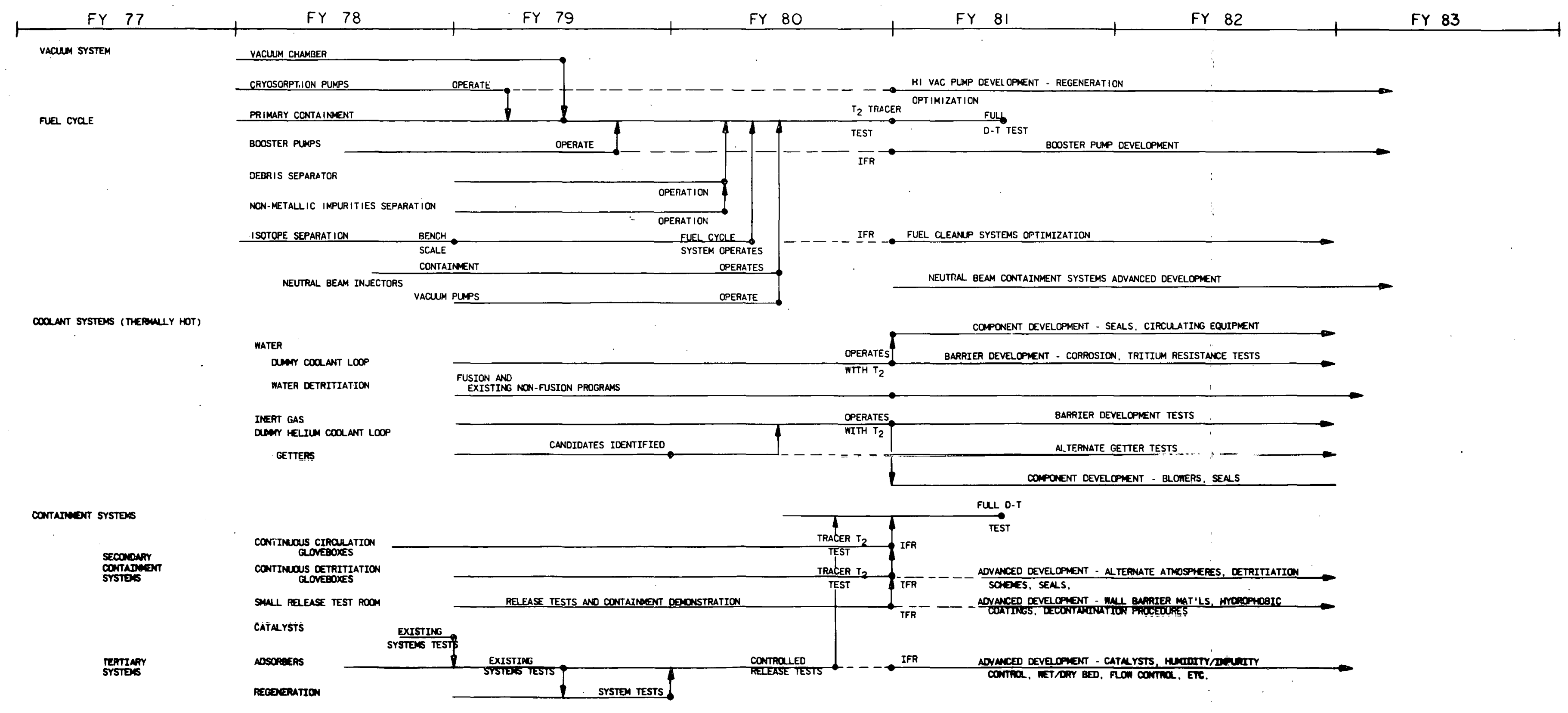

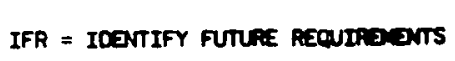


THIS PAGE

\section{WAS INTENTIONALLY LEFT BLANK}




$\frac{\text { FISCAL YEAR PLANNING }}{\text { THE PROGRAM PART } 6}$

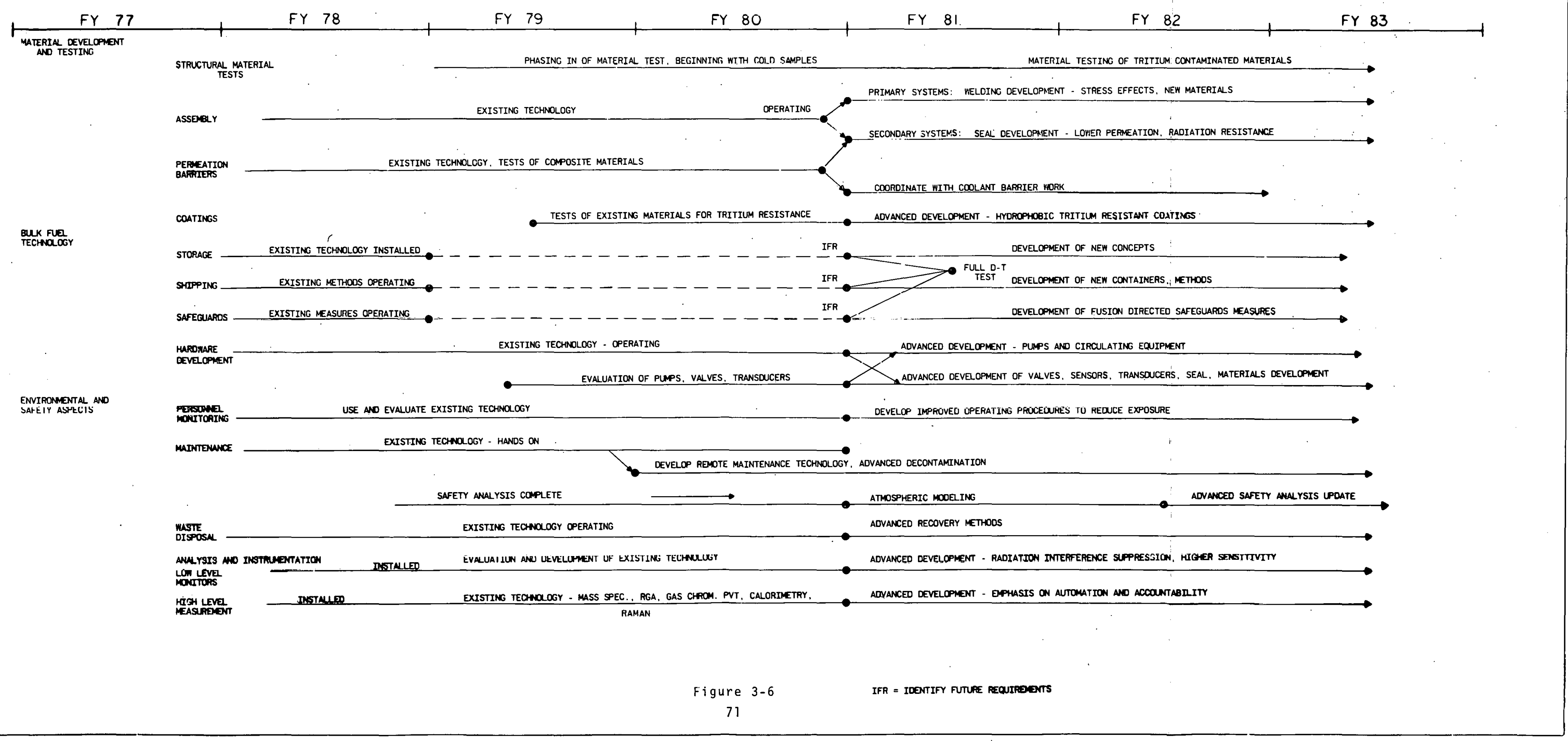


THIS PAGE

\section{WAS INTENTIONALLY \\ LEFT BLANK}




\title{
4. Program Management and Resources
}

\author{
4.1 Organization \\ The joint Mound Laboratory/Argonne National Laboratory Tritium System Test Facility \\ program will be administered through the organization shown in Figure 4-1. A brief \\ description of the management, coordination, planning, advisory, programmatic, and \\ facility functions shown on the chart is given below.
}

\subsubsection{Management}

Responsibility for the direction of the Mound Laboratory and Argonne National Laboratory parts of the TSTF program will reside in the Mound Nuclear Operations Director and the Argonne CTR director, respectively. The Mound and Argonne Program Managers will report to their respective directors. Each program manager will have prime responsibility for the execution of those parts of the experimental program and/or planning function under him.

The scientific program responsibilities of Mound and Argonne Laboratories have been defined and described in detail in Section 3. Briefly, four functions have been identified - two for each laboratory. Mound will have lead responsibility for the operation of the TSTF and for specific research and development projects that fall within its province of expertise (see Section 3). Argonne will contribute to and participate in these two Mound Laboratory-based functions. Argonne National Laboratory will have lead responsibility for program planning and for specific research and development projects that fall within its province of expertise (see Section 3). Mound Laboratury will participate in the program planning function and will contribute to the Argonne-based research and development projects. The program plans generated by the Program Planning function will be subject to review and approval by the Mound Laboratory Program Manager and the Argonne Program Manager before implementation.

\subsubsection{Coordination of the Mound Laboratory and Argonne National Laboratory}

Program Functions

Coordination of the Mound Laboratory and Argonne National Laboratory functions will be the responsibility of both the Mound and Argonne Program Managers and will be reinforced by the joint action of the directors. While this will be accomplished through many mechanisms, it will start with the coordination (with regard to program and budget) of the 189a submission of each laboratory to ERDA/DMFE. Also planned are monthly visits of Mound and Argonne liaison persons to each other's laboratories, quarterly information exchange and coordination meetings (at either Mound or Argonne) of the two program managers and of key technical people on their staff, visits by key staff of Mound Laboratory to Argonne and vice-versa, exchange of staff for short periods to complete a specific work task, and use of the telephone. 
4.1.3 Interaction with ERDA/DMFE

Mound Laboratory and Argonne National Laboratory will submit separate but coordinated 189a requests to ERDA/DMFE for support of their respective portions of the TSTF program. The Mound Laboratory Program Manager will act as the principal ERDA/DMFE interface.

4.1.4 Advisory Committee

To coordinate the program planning function with DMFE program goals, an advisory committee will be organized by the ANL Program Manager. This committee will consist of representatives from 1 ) organizations involved with the design of magnetically confined fusion reactors; 2) university, industrial, and national laboratories involved in relevant tritium-involved research; and 3) Mound and Argonne Laboratories. This committee will meet on a schedule established by the ANL Program Manager and will submit its recommendations to him.

\subsubsection{Facility Design and Construction}

For the design and construction phases, an engineering project manager will be appointed and will report to the Mound Program Manager. The engineering project manager will be responsible for the Mound engineering and drafting personnel and for coordinating design efforts involving Argonne personnel or the architectengineering firm selected for the project. 
Organization Chart for the Tritium System Test Facility and Associated Program

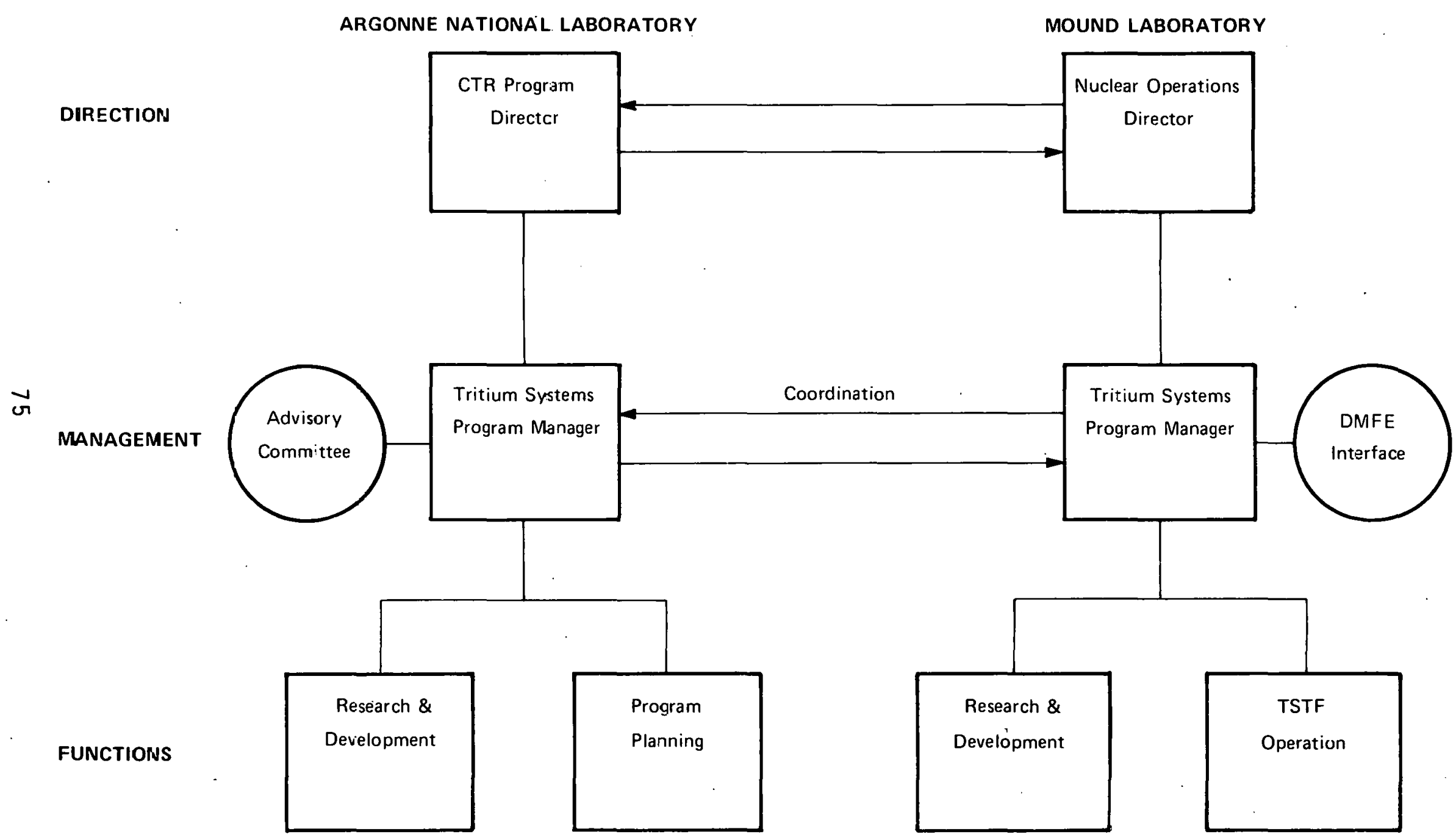

Figure 4-1 
4.2 Technical Resources and Experience

This joint effort of Mound Laboratory and Argonne National Laboratory will bring together over 25 years of experience in nuclear science and engineering with over. 20 years of experience in tritium handling and processing. The TSTF, which will be built at Mound Laboratory, will be an addition to existing tritium facilities which, in terms of plant investment and equipment, are valued at $\$ 23,000,000$.

During the past two years multidisciplinary studies have been conducted of near-term fusion reactor concepts with emphasis on the conceptual design of an experimental Tokamak reactor that could be operational in the mid-to-late-1980's. These efforts have served as a principal focal point for the identification and analys is of fuel recycle and tritium handling criteria in DT burning fusion devices. From these studies have come many of the fuel cycle considerations and development objectives outlined in this proposal.

Other directly applicable expertise that can be brought to bear in the TSTF exists in the areas of neutral beam injector technology, intermediate and high vacuum pumping applications, instrumentation and control systems, tritium recovery and enrichment technology, advanced effluent and environmental control technology, and tritium waste treatment systems. Additional, related areas of expertise include metal hydride research, gas dynamics, cryogenics, radiation damage analysis, remote maintenance technology, and nuclear materials safeguards.

Although laboratory work in these areas is currently funded from other ERDA divisions, this expertise is already being cultivated in support of and is in fact an integral part of the DMFE programs at Mound Laboratory and Argonne National Laboratory.

Many of the analytical and diagnostic facilities needed for the TSTF are already available. These include conventional hot-cell examination facilities, complete with state-of-the-art metallurgical and metallographic equipment. An ion microprobe with tritium ion beam capabilities and tritiated sample handling compartments is already in existence and is available for use. A scanning electron microscope with an ion-mass analyzer attachment for semiquantitative determination of hydrogen isotopes, oxygen, nitrogen, and other light elements in the specimen is enclosed in a separate tritium glovebox system. Also available are electron microprobe and Auger analyzers as well as extensive x-ray analysis equipment. An all-metal, high vacuum, hydrogen isotope permeation apparatus capable of handling tritium is currently. undergoing modification to permit studies at driving pressures as low as $10^{-6}$ torr.

Processes have been developed for purifying tritium and preparing tritium compounds. Experience extends from the realm of laboratory-scale investigations to large-scale development activities. Annual inventories in the past have been in excess of $2 \mathrm{~kg}$. In order to accomplish these processes, numerous components and laboratory techniques have been developed to handle tritium safely.

Tritium is routinely enriched to a purity of $99.9 \%$ at one end of the spectrum and stripped from other materials to below $10-1 i \%$ at the other. High precision analytical techniques have been developed in order to measure the purity of the tritium-bearing mixtures. By very careful design of equipment and knowledge of the physical properties of gaseous tritium, we are able to determine amounts of tritium by PVT measurements with an accuracy at the limit of the present state-of-the-art, $0.2 \%$. In addition, sophisticated mass spectrometry, gas chromatography, and calorimetry systems have been developed for routine laboratory use with tritium. 
As a result of improved containment efforts (which were initiated in 1969), gaseous tritium effluents from Mound Laboratory have been reduced over 96\% (Figure 4-2). At the same time, the average exposure to personnel working in tritium areas has been reduced by a comparable amount (Figure 4-3). While these improvements are substantial, even more rigorous tritium containment will be required in a fusion reactor. This represents the most advanced starting position in the ERDA complex with respect to tritium containment. Additionally, the work being pursued in the Tritium Effluent Control Laboratory (TECL), funded by ERDA/ALO0 and DNFC\&P, will be integrated into the TSTF program plan.

Mound Laboratory has proposed a facility to serve ERDA which would recover and recycle the tritium from moderately concentrated tritiated water. This facility, which could be operational by approximately 1981, would receive the tritiated water evolved during the regeneration of desiccants utilized in tritium effluent control systems. Better fixation methods for disposal of tritium are also being developed. One system being studied in conjunction with BNL fixes the tritiated water in a polymer-concrete disposal package; another utilizes a metal hydride as a permanent fixation matrix.

Extensive experience and facilities for design, evaluation, testing, and inspection of shipping containers for high-level tritiated waste are available for use in the TSTF. A shipping container test facility, valued at $\$ 100,000$ and designed specificaliy for performance of postulated accident condition tests, is available. Considerable experience exists with implementation of quality assurance programs for radioactive materials packaging and with the preparation of Safety Analys is Report for Packaging (SARP) documents.

In addition, members of Mound and Argonne staffs have been involved in and have been on the forefront of the tritium technology program in support of fusion reactor development since the late 1960's. These members have participated in most of the major reactor design efforts of the last five years, including the Princeton Reference Tokamak Reactor Study, the Reference Theta-Pinch Reactor Design Study, the ANL/EPR Studies, and in critical reviews of the tritium handling facilities in the conceptual design studies of the Fusion Test Reactor (both from Princeton and ORNL), the Intense Neutron Source (LASL), and the Fusion Engineering Research Facility (FERF) at LLL.

In a joint project with General Atomics, Argonne National Laboratory is now undertaking the conceptual design of a PEPR/Ignition Test Reactor (PEPR/ITR).

Close cooperation has been cstablished between Mound and the University of Wisconsin Fusion Feasibility Study Group in regard to conceptual breeder blanket designs, and work is in progress on the design of the fuel processing system for a Tokamak Engineering Test Reactor.

The combined expertise at Mound Laboratory and Argonne National Laboratory when organized and integrated, as will be done on this program, will allow all aspects and needs of the tritium fuel cycle and tritium environmental control programs to be developed aptly, efficiently, and smoothly. 


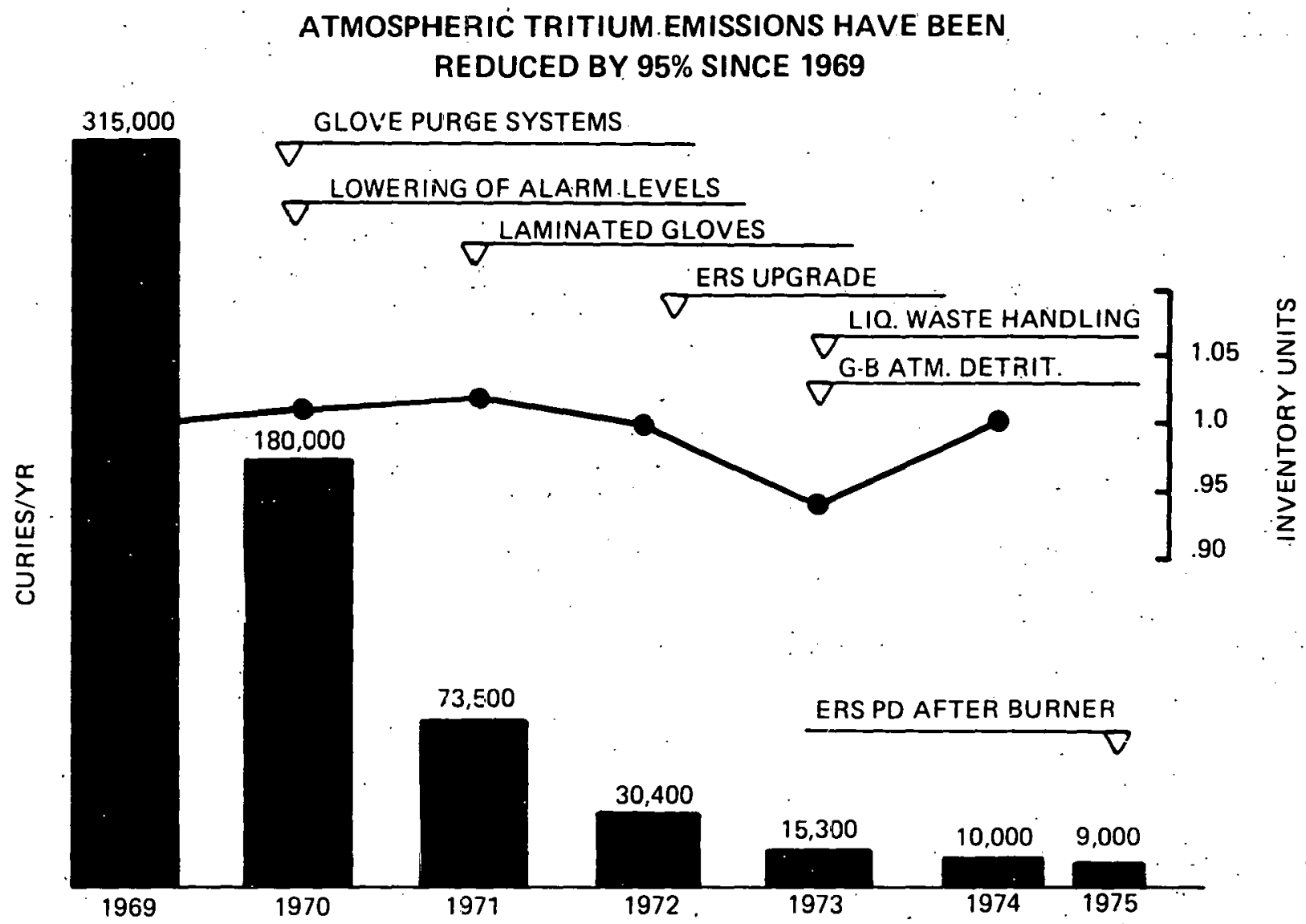

Figure 4-2 
EFFECTIVE TRITIUM MANAGEMENT HAS REDUCED

PERSONNEL EXPOSURES BY A FACTOR OF $\mathbf{3 0 0}$

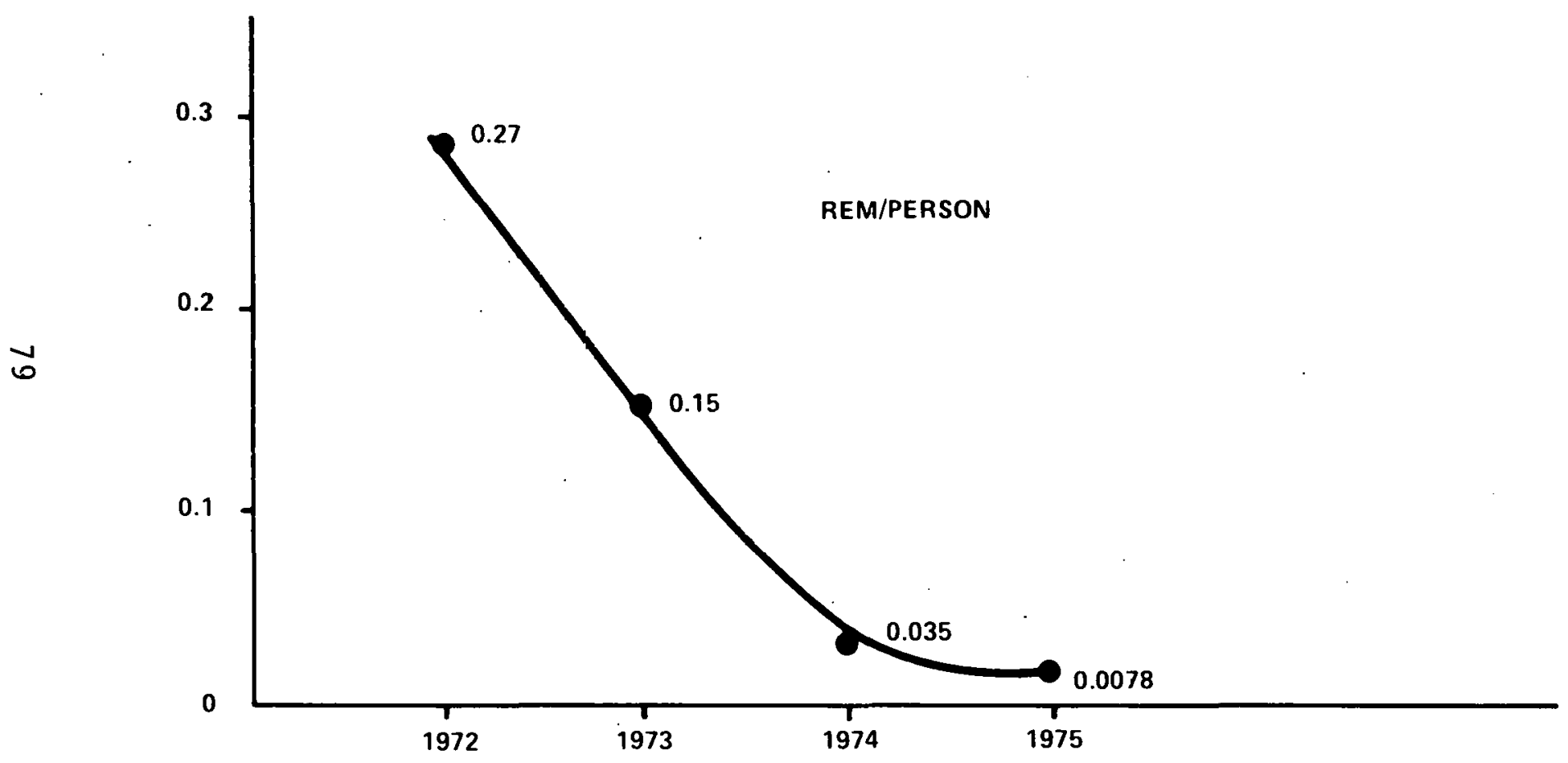

Figure 4-3 
THIS PAGE

\section{WAS INTENTIONALLY LEFT BLANK}


5. Cost Summary

\begin{tabular}{lccccc} 
& \multicolumn{5}{c}{ Costs $(\$ K)$} \\
& $\frac{\text { FY1977 }}{}$ & & FY1978 & FY1979 & FY1980 \\
Facility & 800 & & 10770 & - & - \\
Capital. & 55 & 65 & 100 & 140
\end{tabular}




\section{THIS PAGE}

\section{WAS INTENTIONALLY LEFT BLANK}




\section{Appendix}


THIS PAGE

\section{WAS INTENTIONALLY \\ LEFT BLANK}


HAZARD EVALUATION

\section{Introduction}

The purpose of this section is to identify and evaluate the major safeguards and controls that are provided in the conceptual process and facility designs for the proposed operations. These safeguards and controls are based upon nearly 20 years of experience with tritium and its compounds. Technology developed over the years ensures the protection of the health and safety of employes and the surrounding community.

Additional safety reviews of all aspects of the proposed facilities and operations will be made should Mound Laboratory be selected as the site for the TSTF. These reviews would be conducted in accordance with existing procedures set forth in the Mound Laboratory Loss Prevention and Environmental Control Review System. More detailed accident analysis of the operations would also be presented as part of the Preliminary Safety Analysis Report (PSAR) for the proposed work.

\section{Site Description}

\subsection{Location}

Mound Laboratory occupies 182 acres on the southern edge of the City of Miamisburg, Ohio. The Laboratory is located within Montgomery County in the southwest part of Ohio and is approximately 10 miles south-southwest of Dayton, Ohio, and 40 miles north of Cincinnati, Ohio.

\subsection{Population}

The population within a 20-mile radius of Mound Laboratory is approximately 750,000 . The area within the 20-mile radius includes essentially all Montgomery County and approximately 30 to $60 \%$ of the adjoining counties of Butler, Green, Preble, and warren. The 1970 census showed a total population of $1,062,270$ for the five-county region.

\subsection{Land Use}

The predominant geographical feature in the five-county region is the Great Miami River which flows through Midnisbur'y from the northeast to the southwest. This river valley area contains the largest urban and suburban communities in the five-county region.

The areas to the northwest, west, south, southeast, and east of Miamisburg are predominantly agricultural and contain a number of residential communities with some light industry. 


\subsection{Topography}

The topography in the vicinity of Mound Laboratory varies from gently rolling to hilly terrain. The Administration (A) Building and main building complex of the Laboratory are located on a knoll at an average elevation of $880 \mathrm{ft}$ above sea level. The valley to the south of the main building complex descends to an elevation of $710 \mathrm{ft}$, providing good drainage for storm sewers, treated sanitary wastes, and surface runoff.

\subsection{Geology}

Test borings vary considerably depending on the specific location on the site. In the vicinity of the Administration Building and the general area of the main complex of buildings, which includes the $T B 1 d g .$, the following range of soil conditions prevails:

0-10 ft: clay, broken limestone, or rock

10-80 ft: clay, limestone, and shale

\subsection{Seismology}

Historical data indicate that the State of Ohio is not a major seismic area. The seismological observation sites that are closest to Mound Laboratory are those located at Xavier University, Cincinnati, Ohio, and at Bowling Green State University, Bowling Green, Ohio.

Mound Laboratory is located in a Zone 2 seismic area (reference: Uniform Building Code, 1970 Edition, Volume 2, Figure 2, page 122.) By definition, Zone 2 is as "moderate damage" and corresponds to intensity VII on the "Modified Mercalli Intensity Scale" of 1931. The few earth tremors have been very slight. Any damage has normally been slight. Building designs are based on Zone 2 locations.

\section{Facility Description}

The Technical, T, Bldg. is a two-story, reinforced, concrete building which is completely underground. This building is located under the DS Bldg., and the two entry towers are immediately north of the east and west ends of the DS Bldg.

Fire protection for the T Bldg. consists of $100 \%$ automatic sprinkler coverage.

The T Bldg. also serves as an Office of Civil Defense designated shelter and is stocked with tools and survival supplies as well as emergency medical facilities. Radio communication equipment for the ERDA/Emergency Radio System as well as Civil Defense, state patrol, and local systems is located in the building. Two 300-kW diesel generators and two oill fired steam generators are located in the building for use in emergency. 


\section{Safety and Environmental Control Features}

\subsection{Containment}

Positive containment is paramount to all other considerations in providing effective safety and environmental control. The conceptual design of TSTF provides for positive, multiple containment of tritium.

\subsection{Effluent Control}

ERDA objectives of maintaining radioactive effluent levels below RCG levels at the point of emissions have been adopted by Mound Laboratory and are reflected in. recent achievements in reducing effluent levels. The actual amount of radioactive materials released to the total environment is the major concern as opposed to the concentration at some distance downstream or at a facility boundary. It cannot be expected that the attention focused on the total release of radioactive pollutants from any source, and at any location, will lessen in the foreseeable future.

Mound Laboratory is presently under contract to develop advanced tritium effluent control systems. Technology currently exists to provide systems which will remove tritium and tritiated water from room air at high flows. Such systems will be utilized under emergency conditions should releases of tritium to the room air occur.

The emergency containment system, the process design, and the facilities described in Section 2 will enable Mound Laboratory to maintain tritium effluent levels at the lowest practicable level at the actual point of emission (stack).

\section{Projected Environmental Release}

Estimates have been made of the total environmental releases that would be expected from routine operations and maintenance of the TSTF. These estimates are based on actual experience with similar operations and the impact of current and planned efforts to reduce tritium effluents. It is significant that Mound Laboratory has reduced its tritium airborne releases by $96 \%$ since 1969 . It is estimated that the operation of the TSTF would result in an annual environmental release of approximately 100 to $300 \mathrm{Ci}$. The TSTF will not release any tritium to the aquifer.

\section{Fire Protection}

Fire protection for the proposed operations can be divided into two major areas. One area includes the buildings and the laboratory areas and the other area is the gloveboxes.

The major fire protection concern in the majority of the laboratories is that of ordinary combustibles for which protection will be provided by automatic sprinkler systems.

Fire protection for the processes includes considerations for the use of flammable gas (hydrogen) as well as ordinary combustibles present in laboratory operations.

The primary fire prevention feature of glovebox operations will be positive containment of tritium gas. The secondary fire prevention features will be provided by the inert atmosphere of the glovebox. The oxygen content of this atmosphere will be maintained at levels well below the amount required for combustion of hydrogen. The hydrogen gas content will also be reduced by oxygen combination (water formation). Thus, even a large-scale leakage of room air into the glovebox or of glovebox atmosphere into the room air would not result in an explosive or combustible mixture of hydrogen and air. 
Mound Laboratory has a 14-man professional fire-fighting force. Four-man crews work on a 24-hour-on, 48-hour-off schedule. Fire response vehicles include an ambulance, a $750 \mathrm{gal} / \mathrm{min}$ high pressure/volume class $A$ pumper, a foam truck, and a smaller auxiliary pumper. Additional protection is afforded by emergency brigades trained in initial fire-fighting techniques. Contact is also maintained with the City of Miamisburg Fire Department, which will respond upon request to a fire at Mound Laboratory with an estimated response time of 5 min.

The fire-protection water distribution system consists mostly of 8-inch pipe with flows of $1500 \mathrm{gpm}$ available. Fire water reserve is currently 575,000 gal minimum. Municipal water from the City of Miamisburg is available for fire protection. This water supply functions as a backup supply in event of emergency.

\section{Personnel Safety}

The potential personnel hazards associated with the proposed processes will be countered by facility design, operating procedures, and administrative controls. The risk of personnel injury by fire or explosion will be minimized by the fire protection features described earlier.

As a result of secondary containment and secondary atmospheric purification, it is estimated that room levels can be maintained below $5 \mu \mathrm{Ci} / \mathrm{m}^{3}$ and that personnel radiation exposures will be maintained below those specified in ERDAM-0524.

\section{Design Basis Accident Analyses}

\subsection{Introduction}

This section defines a "design basis accident" and analyzes the vulnerability of the process facilities to various postulated accident conditions. To provide as much meaningful information as possible, the accident conditions were selected to include the effects of forces external to the process facility as well as potential. accident conditions which could be considered "process related".

The analyses are based on the conceptual design information presented elsewhere in. this report as well as on previous reviews and analyses made of existing and proposed tritium operations and programs. More detailed documentation of the fire/safety aspects of the selected option will be provided in the form of a PSAR for this program.

\subsection{Definition of Design Basis Accident}

A design basis accident is the postulated accident which represents the greatest risk potential associated with a proposed facility. The design basis accident forms the basis for engineering design by establishing those safeguards and controls which are necessary to prevent the accident or mitigate its consequences.

A major release of tritium into the operating laboratory was selected as the design basis accident. This accident was selected because it represents the greatest potential risk to the operating personnel, the environment, and members of the general public. 
After identification of the design basis accident, all process, equipment, and facility design efforts have been, and continue to be, directed toward the goal of positively preventing its occurrence under all foreseeable accident conditions and mitigating the consequences of such an accident.

The two most important equipment design features specific to the prevention of the design basis accident are the integrity of containers and the use of multiple containment throughout the process. With a few minor exceptions, it is not possible for the design basis accident to occur without postulating the defeat of at least two independent containment barriers - at least one of these containment barriers is a sealed metal container designed for temperatures and pressures far exceeding process requirements. Facility design features of special importance are the extremely low fuel loading, the fixed fire protection, and the structural integrity of the buildings involved.

It will be shown later in this section that a major release of tritium into the operating laboratories (under any realistic accident condition) is positively prevented by the process, equipment, and facility design features. However, the possible consequences of the design basis accident make it imperative that some type of emergency containment system be provided as a backup to all other engineering features. This emergency containment system will be provided as described earlier in this document. Its function under emergency conditions is analogous to the use of HEPA filtration for plutonium facilities; i.e., if the worst occurs and a serious breach of containment releases tritium into the operating areas, the emergency system will prevent any serious release to the environment.

\subsection{Analyses of Accident Conditions}

Five classes of accident conditions were analyzed and are discussed in the following paragraphs. The five classes are: 1) Fires/Explosions, 2) Acts of Nature, 3) External Operations, 4) Equipment Failure, and 5) Human Error. As explained earlier, the discussions of these accident conditions are kept as general as possible; however, where different options required, specific facility differences are highlighted. Detailed analyses involving the evaluation of probabilities are beyond the scope of this report but will be provided, as part of any future PSAR.

\subsubsection{Fires/Explosions}

The vulnerability of the proposed facilities to fires/explosions is presented in terms of facility construction, processes, and exposures to external sources of fires/explosions.

The $T B 1 \mathrm{dg}$. is buried undergound with approximately $16-\mathrm{ft}$ thick heavily reinforced concrete "exterior" walls which far exceed 4-hr fire ratings. Class "B" doors are installed in the 30-in thick isolation walls on the operating and service floors of the building to permit a 2-hr fire rating for these walls. Accordingly, the intensity and propogation rate of any credible fire will be severely limited. These limitations increase the probability that a fire will be detected and extinguished automatically or manually before any serious damage results.

The underground location and the massive construction of the $T B 1 d g$. make any process in the $T$ B $7 d g$. safe from jossible external fire/explosion exposures. 


\subsubsection{Acts of Nature}

The vulnerability of the proposed facility to severe acts of nature, including high winds, earthquakes, and floods, is presented below and is based on the original design criteria of the T BIdg. An independent, in-depth structural analysis of all the major facilities at Mound under tornado and earthquake stresses has been completed. Such information will be supplied as part of the FSARs requested by the ERDA for all major facilities at Mound.

The $T$ Bldg. is not considered vulnerable to structural damage from high winds, including the classic ERDA defined tornado. The T Bldg. can be expected to survive earthquake shock exceeding that expected in the seismic zone for this area. The T B $1 \mathrm{dg}$. is not considered vulnerable to flooding, as it is approximately $100 \mathrm{ft}$ above the highest water level on record in the past 50 years. In addition, the Miami Conservancy District has juilt a series of dams for adequate flood control along the Miami River Valley.

\subsubsection{External Operations}

The vulnerability of the proposed facility to external operations such as nearby airports, private industry, or major shipping arteries such as highways and railways was considered.

There are two small airports within 5 miles of the Laboratory. These airports handle primarily private, light aircraft. Larger airports in the general vicinity (within 25 miles) include a commercial airport at Vandalia and the military airport at Wright Patterson Air Force Base. Mound Laboratory's stacks and water towers are painted and lighted in accordance with FAA regulations. No attempt was made to evaluate the effect of a direct impact by a falling aircraft on the T Bldg.; however, its construction suggests that even this highly improbable accident condition would have little or no effect on the integrity of the structure.

There are no industrial sites near Mound Laboratory which could be considered a possible threat to the safety of the Laboratory's operation. The nearest highway and railway are in Miamisburg and a spur track enters the Mound site. A serious truck or train wreck involving the spillage of toxic chemicals would be a matter of some concern, but it is doubtful if they could interrupt operations in the $T$ Bldg.

In summary, the $T B l d g$. is not considerable vulnerable to damage from external operations.

\subsubsection{Equipment Failure}

The vulnerability of the proposed processes to equipment failure is a function of design, quality control, installation, and process operation. Although the possibility of equipment failure will always exist, it was concluded that the vulnerability of tritium to release is extremely low.

As stated previously, multiple degrees of containment are provided for the tritium. Failure of a primary container would not result in the design basis accident because of the secondary, and in most cases, additional, containment barriers. All process equipment will be designed to be passively safe under power outage conditions. Special attention will be given to the computer control system to ensure the safety of operations during any electrical fluctuation or failure.

Mound Laboratory actively applies a systems safety approach to the design of process equipment in general and to the review of such designs for possible failure modes.

There appears to be no significant difference in the vulnerability of the proposed process facilities to equipment failure under any option. The vulnerability to equipment failure will be quite low in all cases. 


\subsubsection{Human Error}

Any operation must be considered vulnerable to human error. Of all conceivable accident conditions, human error stands as the most unpredictable and, realistically, the most probable.

The proposed process operations and equipment will incorporate extensive checks and balances, monitoring, interlocks and, in some cases, computer supervision to minimize the possibility and the consequences of human error. Detailed operating procedures and emergency procedures will be prepared and all personnel will be trained in the procedures applicable to their work. Strict administrative controls are exercised over all operations at Mound Laboratory. The future operation of the tritium facilities will continue to be conducted in accordance with existing management emphasis on safety and environmental control.

In conclusion, there will always be some risk of human error; however, every effort will be made to prevent and minimize the consequences of human error. Mound Laboratory's proven record of accomplishment in reducing tritium emissions is evidence that administrative controls and employe attitudes will minimize the vulnerability of the proposed facility to human error.

\section{Analysis of the Design Basis Accident}

The design basis accident for the proposed facility was defined earlier as a major release of tritium into an operating laboratory. The preceding analyses confirm that such a release is positively prevented by the process, equipment, and facility design features. Mound Laboratory will provide an emergency containment system designed to prevent any serious release of tritium to the environs of Mound Laboratory.

To evaluate the possible effects of the design basis accident, it is necessary to assume its occurrence. The major process steps were reviewed to obtain some estimate of the quantity of tritium that could be released into the operating laboratories.

It is postulated that a major breach of the main chamber occurs and simultaneously the valves on the cryogenic pumps fail to close. For the purpose of this analysis, a total inventory of $10 \mathrm{~g}$ of tritium is assumed to be released into the operating area. The postulated method of release is nearly incredible; however, as $10 \mathrm{~g}$ could be present. it was assumed to be relcased. A more definitive analysis will be made for the PSAR. The resulting room concentrations would activate the ECS. Because of the tritium monitoring systems to alert personnel of a release and the slow assimilation rate of elemental tritium, operating personnel would escape without receiving a major uptake of tritium. The estimated dose an individual could receive under these circumstances is 0.5 rem or $10 \%$ of the annual allowable dose.

The ECS is assumed to have an efficiency of $99.99 \%$ for the single-pass removal of tritium from air. Since negative air differentials essentially permit only inflow, the room wall permeation and leakage is assumed to be less than $1 \%$ of the air processed. It is also assumer that $50 \%$ of the contamination is removed from the contained volume bccause of complete dir mixing during each air change. 
These assumptions lead to the conclusion that most of the tritium released to the environment would result from room leakage and not as a result of inefficiency of the ECS. It is estimated that approximately $1600 \mathrm{Ci}$ of tritium would be released to the environment. Most would be released in the first $2 \mathrm{hr}$. The average 2-hr maximum ground level concentration would be $1.4 \times 10^{-6} \mu \mathrm{Ci} / \mathrm{m}^{3}$. The resultant whole body dose to a member of the general public would be less than $1 \times 10^{-3}$. rem. There would be no restrictions or contamination of public property as a result of the design basis accident.

This analysis indicates that the safeguards incorporated into the design of the TSTF ensure the protection of the employes and members of the general public under postulated accident conditions.

10. Safety, Effluent Control Record

Mound Laboratory's current record of achievement in personnel safety and in tritium effluent reduction is indicative of the emphasis placed on safety and environmental control in all phases of the Laboratory's operations.

The Laboratory recently passed 37,000,000 manhours without a disabling injury. This record has been compiled over 10 years and is currently the best safety record among the ERDA/ALO contractors.

Mound Laboratory has been engaged in a concentrated effort to reduce tritium effluents to both air and water since early 1970. This effort has been highly successful. Mound Laboratory has reduced its tritium airborne effluents by $96 \%$ since 1969. These indicators support a high level of confidence in the technical and managerial capability to control effluents to achieve increasingly stringent goals. 


\section{Distribution}

\section{EXTERNAL}

TID-4500 UC-2 of (189)

N. Amherd, Electric Power Research Institute

J. A. Chacon, DOE/DAO

R. K. Flitcraft, MRC, Dayton

J. M. Mintz, SLL

C. Pierce, Princeton Plasma Physics Laboratory

R. Sager, General Atomic Co.

L. Yemin, Ebasco Services, Inc.

Technical Report Library, Monsanto, St. Louis

INTERNAL

H. F. Anderson

B. E. Baughn

R. P. Bowser

J. D. Braun

W. T. Cave

T. M. Flanagan

S. S. Freeman

J. F. Griffin

M. F. Hauenstein

C. W. Huntington

L. V. Jones

B. R. Kokenge

P. H. Lamberger
M. I. Rogers

C. S. Sebastian

W. A. Slusher

W. H. Smith (5)

R. E. Vallee

C. B. Voth

R. A. Watkins

W. R. Wilkes (5)

L. J. Wittenberg (5)

Records Center

Library (15)

Publications 